\title{
Recent Results from Studies of Electric Discharges in the Mesosphere
}

\author{
T. Neubert - M. Rycroft - T. Farges - E. Blanc $\cdot$ O. Chanrion - E. Arnone \\ A. Odzimek $\cdot$ N. Arnold $\cdot$ C.-F. Enell $\cdot$ E. Turunen $\cdot$ T. Bösinger $\cdot$ Á. Mika \\ C. Haldoupis $\cdot$ R. J. Steiner $\cdot$ O. van der Velde $\cdot$ S. Soula $\cdot$ P. Berg $\cdot$ \\ F. Boberg · P. Thejll · B. Christiansen · M. Ignaccolo $\cdot$ M. Füllekrug • \\ P. T. Verronen $\cdot$ J. Montanya $\cdot$ N. Crosby
}

Received: 28 March 2008/Accepted: 27 August 2008/Published online: 18 September 2008

(C) The Author(s) 2008. This article is published with open access at Springerlink.com

\begin{abstract}
The paper reviews recent advances in studies of electric discharges in the stratosphere and mesosphere above thunderstorms, and their effects on the atmosphere. The primary focus is on the sprite discharge occurring in the mesosphere, which is the most commonly observed high altitude discharge by imaging cameras from the ground, but effects on the upper atmosphere by electromagnetic radiation from lightning are also considered. During the past few years, co-ordinated observations over Southern Europe have been made of a wide range of parameters related to sprites and their causative thunderstorms. Observations have been complemented by the modelling of processes ranging from the electric discharge to perturbations of trace gas concentrations in the upper atmosphere. Observations point to significant energy deposition by sprites in the neutral atmosphere as observed by infrasound waves detected at up to $1000 \mathrm{~km}$ distance, whereas elves and lightning have been shown significantly to affect ionization and heating of the lower ionosphere/mesosphere. Studies of the thunderstorm systems powering high altitude discharges show the important role of intracloud (IC) lightning in sprite generation as seen by the first simultaneous observations of IC activity, sprite activity and broadband, electromagnetic radiation in the VLF range. Simulations of sprite ignition suggest that, under certain conditions, energetic electrons in the runaway regime are generated in streamer discharges. Such electrons may be the source of X-and Gamma-rays observed in lightning, thunderstorms and the so-called Terrestrial Gamma-ray Flashes (TGFs) observed from space over thunderstorm regions. Model estimates of sprite perturbations to the global atmospheric electric circuit, trace gas concentrations and atmospheric dynamics suggest significant local perturbations, and possibly significant meso-scale effects, but negligible global effects.
\end{abstract}

T. Neubert $(\bowtie) \cdot$ O. Chanrion

National Space Institute, Technical University of Denmark, Juliane Maries Vej 30,

2100 Copenhagen O, Denmark

e-mail: neubert@space.dtu.dk

M. Rycroft

CAESAR Consultancy, 35 Millington Road, Cambridge CB3 9HW, UK

T. Farges $\cdot$ E. Blanc

Commissariat à l'Energie Atomique, DASE, Bruyères le Châtel, 91297 Arpajon Cedex, France 
Keywords Lightning $\cdot$ Mesosphere $\cdot$ Sprites $\cdot$ Thunderstorms $\cdot$ Electric discharges

\section{Introduction}

It is less than 20 years since scientists first documented spectacular optical flashes in the stratosphere and mesosphere above large thunderstorm systems (Franz et al. 1990). The flashes were discovered over the US plains, where summer thunderstorms are powered by hot humid air masses sweeping up from the Caribbean and the Pacific. The discovery was a confirmation of predictions made by the Nobel prize winner C.T.R. Wilson in the 1920s (Wilson 1925), and led researchers to examine the literature of the past, discovering anecdotal evidence dating as far back as the 19th century. A careful re-examination of such data sources as video recordings made by the space shuttle payload bay cameras further identified previously unnoticed emissions over Africa and Australia (Vaughan and Vonnegut 1989; Boeck et al. 1995; Boeck et al. 1998). In the years following, ground and aircraft campaigns were conducted, mostly in the US, but also in Australia, Japan, Taiwan, South America, and Europe. In all regions the occurrence of optical emissions in the stratosphere and mesosphere associated with thunderstorms was documented.

E. Arnone $\cdot$ A. Odzimek $\cdot$ N. Arnold

Department of Physics and Astronomy, University of Leicester, Leicester LE 1 7RH, UK

C.-F.Enell · E. Turunen

Sodankylä Geophysical Observatory, University of Oulu, Tähteläntie 62,

99600 Sodankyla, Finland

\section{T. Bösinger}

Department of Physical Sciences, University of Oulu, P.O. Box 3000, Oulu 90014, Finland

Á. Mika · C. Haldoupis · R. J. Steiner

Department of Physics, University of Crete, Vassilika Vouton, 71003 Heraklion, Greece

O. van der Velde $\cdot$ S. Soula

Laboratoire d'Aérologie, UMR 5560, Université de Toulouse/CNRS, Toulouse, France

P. Berg · F. Boberg · P. Thejll · B. Christiansen

Danish Meteorological Institute, Danish Climate Center, Lyngbyvej 100,

2100 Copenhagen O, Denmark

M. Ignaccolo · M. Füllekrug

Department of Electronic and Electrical Engineering, Centre for Space, Atmospheric and Oceanic

Science, University of Bath, Claverton Down, Bath BA2 7AY, UK

P. T. Verronen

Finnish Meteorological Institute, Earth Observation, P.O. Box 503,

Erik Palménin aukio 1, 00101 Helsinki, Finland

J. Montanya

Departament d'Enginyeria Electrica, Universitat Politecnica de Catalonia,

Colon, 1, 08222 Terrassa, Barcelona, Spain

N. Crosby

Belgian Institute for Space Aeronomy, Ringlaan 3 - Avenue Circulaire,

1180 Brussels, Belgium 
Research in the past decade has identified a surprising variety of emissions (Neubert 2003). The most commonly observed emission from ground, the so-called "sprite", is a manifestation of electrical breakdown of the mesosphere at 40-80 km altitude (Sentman et al. 1995). Sprites are almost always associated with positive cloud-to-ground $(+\mathrm{CG})$ lightning discharges which lower positive charge from clouds to the ground (Boccippio et al. 1995). A CG lightning discharge, or flash, is composed of several strokes, each involving a downward leader and an upward return stroke (Rakov and Uman 2003). The "blue jet" is a discharge propagating upwards into the stratosphere from cloud tops. It is the discharge that most resembles classical lightning except that it propagates upwards into the stratosphere, to about $40 \mathrm{~km}$ altitude. It may or may not be associated with cloud-toground (CG) lightning activity (Wescott et al. 1995). Then there is the "elve", which is a concentric ring of optical emissions propagating horizontally outwards at the bottom edge of ionosphere at $\sim 90 \mathrm{~km}$ altitude (Fukunishi et al. 1996). Elves are associated with CG lightning of either polarity and are caused by the electromagnetic pulse radiated by the CG discharge current (Inan et al. 1996; Cho and Rycroft 1998; Füllekrug et al. 2006a). Observations have further documented the "gigantic jet", a discharge where a blue jet triggers a sprite, creating electrical breakdown of the atmosphere from the thunderstorm clouds directly up to the bottom of the ionosphere (Pasko et al. 2002; Su et al. 2003). The panoply of the most commonly observed emissions of the upper atmosphere, also referred to as "Transient Luminous Events" (TLEs), is shown in Fig. 1.

Within the past decade, a different, but possibly related, type of flash has been discovered. It is the Terrestrial Gamma-ray Flash (TGF) from the atmosphere above

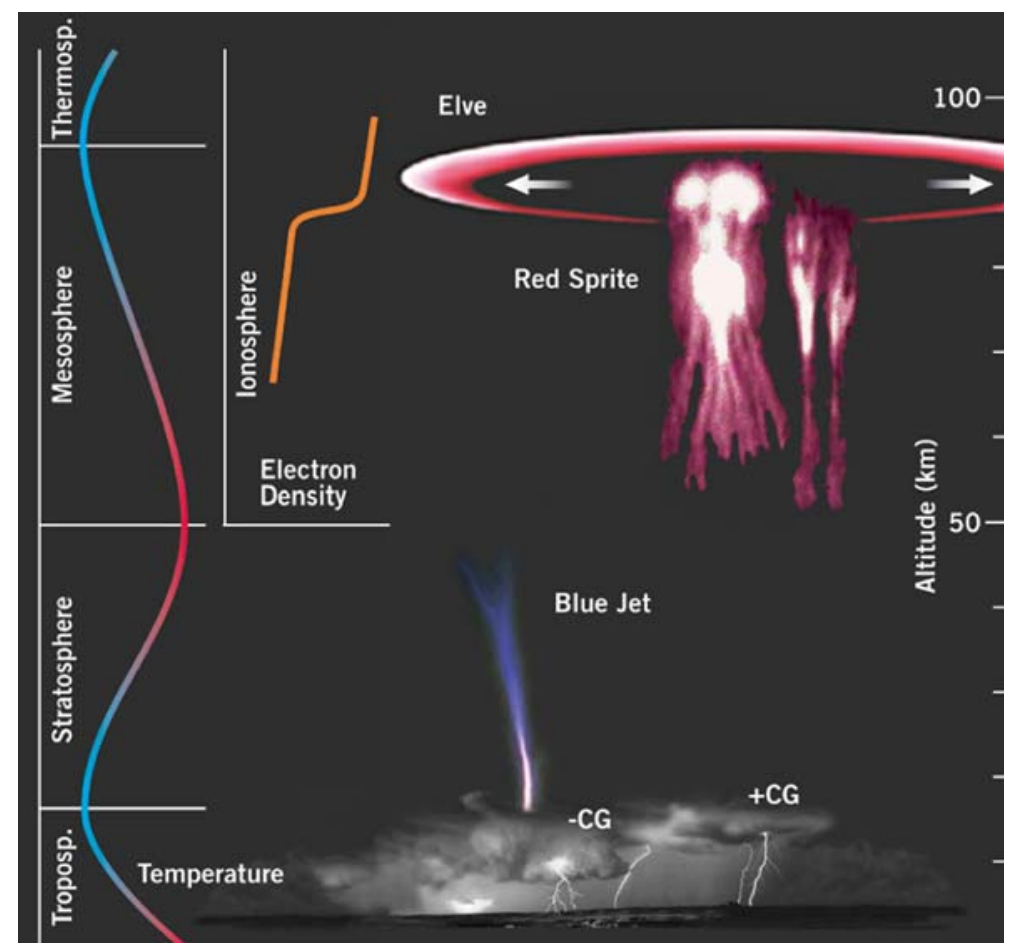

Fig. 1 Diagram illustrating the variety of upper atmospheric flashes and the altitudes at which they occur (Neubert 2003) 
thunderstorms, first recorded by the Compton Gamma Ray Observatory (CGRO) satellite (Fishman et al. 1994; Nemiroff et al. 1997; Østgaaard et al. 2008). More recent observations come from the Reuven Ramaty High Energy Solar Spectroscopic Imager (RHESSI), detecting 10-20 TGFs per month with energies up to $20 \mathrm{MeV}$ (Smith et al. 2005). It has been suggested that TGFs are bremsstrahlung radiation from upward propagating, relativistic $(\mathrm{MeV})$ electron beams generated in a runaway discharge process powered by the transient electric field in the stratosphere and mesosphere following a lightning event. The runaway discharge process has further been suggested for the initiation of lightning and sprites (Roussel-Dupré and Gurevich 1996), but there is no evidence yet for a direct connection between sprites and TGFs.

In this paper we discuss the most recent results of European research into electric discharges in the mesosphere. The research was conducted within the Research Training Network (RTN) "Coupling of Atmospheric Layers" (2002-2006) of 11 participating research institutions and 9 young doctoral students and post-doctoral fellows. The network fielded annual observational campaigns to Southern Europe, the EuroSprite 2003-2006 campaigns, and developed computational tools to model sprite discharges and their various effects on the mesosphere. Emphasis in this paper is placed on sprites, which are the most commonly observed high-altitude discharges in the campaigns.

\subsection{The Electric Earth}

Up to $\sim 2000$ thunderstorms are active over the surface of the Earth at any given time, with an average of 40-50 lightning discharges occurring every second (Christian et al. 2003). The most active regions of lightning are over the Americas, Africa, and South-East Asia, with the major proportion of lightning being over land. Lightning discharges radiate intense electromagnetic (EM) pulses, from a few $\mathrm{Hz}$ to hundreds of $\mathrm{MHz}$, of $\sim 20 \mathrm{GW}$ peak power for $\sim 1 \mathrm{~ms}$ to $\sim 1 \mathrm{~s}$ duration, as measured by electric and magnetic field sensors. The EM radiation heats the partly ionized layers of the upper atmosphere called the D- and E-regions (60-120 km) of the ionosphere. Lightning also produces quasi-static electric fields up to $1 \mathrm{kV} / \mathrm{m}$ at mesospheric altitudes, which are capable of accelerating electrons to relativistic energies.

In general, thunderclouds charge to positive potentials at their tops and negative potentials at their bottoms. The global distribution of thunderstorms generates an electric current from the top of the clouds to the ionosphere, charging the ionosphere to $\sim 250 \mathrm{kV}$ relative to the Earth's surface. In fair weather regions, the electric field of the atmosphere at ground level is $120-130 \mathrm{~V} / \mathrm{m}$ pointing downwards, and the electric current density in the air from the ionosphere to ground is $\sim 2 \mathrm{pAm}^{-2}$ (Williams 2002). This simplistic picture does not describe the heterogeneous character of the charge distributions found in thunderclouds, with many charge-carrying regions of varying polarity. While in situ measurements of electric fields within thunderclouds and above have been made from rockets and balloons (Stolzenburg et al. 2007), they are rare because of the difficulty of such measurements. The fields at mesospheric altitudes where sprites occur are primarily estimated from simple assumptions on the charge distributions in the thunderclouds and from observations of the AC components of the electromagnetic field radiated by lightning discharges.

Sparked by the discovery of TLEs and TGFs, our understanding of fundamental processes related to atmospheric electricity is under re-evaluation (Arnold and Neubert 2002). It is now appreciated that thunderstorms of the troposphere couple in important ways to the stratosphere, mesosphere and near-Earth space. It has been proposed that electric currents in the atmosphere affect cloud formation through the electro-scavenging process, where 
electric charges on ice particles and electric double layers in clouds enhance the growth of ice crystals (Tinsley et al. 2000, 2001). Lightning also generates Very Low Frequency (VLF) electromagnetic radiation that propagates through the magnetosphere in the whistler mode. These waves scatter energetic electrons from the radiation belts to precipitate into the atmosphere (Rycroft 1973) where they can ionize the atmosphere above $\sim 60 \mathrm{~km}$ altitude (Inan et al. 2007). Finally, the strong convection of thunderstorms powers the transport of water into the upper troposphere and through the tropopause to the stratosphere, where this important greenhouse gas is distributed over wider regions (Chaboureau et al. 2007), as well as gravity waves that propagate to the mesosphere where they break and deposit their energy (Dewan et al. 1998).

Processes in space also couple to the atmosphere, perturbing the electric environment. Solar X-ray and UV radiation ionize the upper atmosphere creating the ionosphere with high electrical conductivity, and energetic charged particles from the Sun and the magnetosphere generate bursts of enhanced ionization in the mesosphere and ionosphere. Electric fields and currents generated by solar wind-magnetosphere interactions affect the ionosphere and thermosphere. Cosmic rays control the electrical conductivity in most regions below the mesosphere, and may create the seed charges for the runaway electron discharge mechanism mentioned earlier. It is also suggested that galactic cosmic rays influence the production of ion-mediated cloud condensation nuclei, and thus cloud formation (Svensmark et al. 2007). Research efforts in atmospheric electrical processes further support the view, also put forward in other areas of atmospheric research, that global models of atmospheric circulation, properly representing the dynamics, must include all atmospheric layers from the surface to the thermosphere and ionosphere.

While TLEs are understood in general terms, many aspects of their behaviour are not known, including their chemical effects, which are virtually unexplored. Modification of trace gas concentrations such as the oxides of nitrogen $\left(\mathrm{NO}_{\mathrm{X}}\right)$ and ozone could be important as they affect the Earth's radiative balance. While the lifetime of these gases is relatively short in the troposphere (weeks), the gases may reside for years in the mesosphere. In addition, while processes in the middle and upper atmosphere, such as stratospheric cooling associated with global warming and solar-terrestrial events, are well known, the coupling to the troposphere and the overall dynamic response of the atmosphere are not understood.

The mesosphere and lower thermosphere are the regions of the atmosphere about which the least is known. They are difficult to access as they are too low for in situ spacecraft observations, too high for balloon observations, and remote sensing is hampered by the low densities of important trace species and the high degree of variability over a broad range of temporal and spatial scales. As a consequence, these regions have received less attention than more readily accessible regions, both above and below. In many respects, the mesosphere and lower thermosphere represent an uncharted "frontier" for upper atmospheric science. TLEs and TGFs represent a new coupling path between the troposphere, stratosphere, mesosphere, and the near-Earth space environment. An in-depth understanding of TLEs and TGFs holds the additional promise of improving our knowledge of the regions in which they occur.

\subsection{Red Sprites: Observations}

Red sprites are large but brief luminous flashes that appear directly above an active thunderstorm system-usually coincident with a positive cloud-to-ground stroke (Boccippio et al. 1995). They may occur in clusters reaching horizontal distances of 
50-100 km, or as single luminous columns (c-sprites) (Wescott et al. 1998). The brightest region is in the altitude range $65-85 \mathrm{~km}$ with most of the intensity in the red, and with blue tendril-like filamentary structures extending downward at times to as low as the cloud top. The optical intensity of sprite clusters when observed with TV-frame rate cameras is comparable with that of a moderately bright auroral arc, reaching $50 \mathrm{MR}$ for the most intense events (Sentman et al. 1995).

The structure of sprites is fascinating and is now being studied from the ground with increasingly sophisticated instrumentation. Early observations showed that the spatial structure could range from small single or multiple vertically oriented filaments of $\sim 1 \mathrm{~km}$ thickness, the c-sprites, to bright clusters of two, three, or more "carrot-shaped" emissions. Later telescopic imaging of sprites has revealed an amazing richness, with intertwined discharge channels and beads to scales down to $80 \mathrm{~m}$ diameter and smaller (Gerken et al. 2000; Mende et al. 2002).

High-speed photometry shows that the duration of sprites is from a few ms to $\sim 200 \mathrm{~ms}$ (Winckler et al. 1996; Armstrong et al. 1998), and high-speed imaging at $1 \mathrm{kHz}$ reveals discharges, initiated at $\sim 65 \mathrm{~km}$ altitude, propagating downwards and, shortly after, upwards (Stanley et al. 1999; Stenbaek-Nielsen et al. 2000; Moudry et al. 2003). Even a frame rate of $1 \mathrm{kHz}$ is not sufficient to capture fully the dynamics of sprites. Recent imaging at $10 \mathrm{kHz}$ provides fascinating insights into the formation and propagation of streamers and resolves, for the first time, the streamer heads (McHarg et al. 2007). On the shortest time scales, sprite emission rates can reach 1-500 GR (Stenbaek-Nielsen et al. 2007).

Sprite morphology and temporal characteristics are certain to depend on the underlying thunderstorm source field; however, studies of this relationship are still in their infancy. Assumptions on the source field include the quasi-electrostatic field from a $+\mathrm{CG}$ discharge (Pasko et al. 1996, 1997), the field from the horizontal component of the discharge within the cloud feeding the +CG (Valdivia et al. 1998), and the very rapidly varying field composed of the directly emitted electromagnetic field from the intracloud (IC) flash current and the components reflected from the ground and the ionosphere (Cho and Rycroft 2001). One of the reasons that the source field is still debated is, of course, the difficulty of making in situ observations of the fields in the mesosphere.

It is also thought that local perturbations of the mesosphere may affect the sprite morphology and that understanding the sprite process will increase our understanding of the mesosphere itself. For instance, perturbations in the neutral gas density caused by gravity waves generated in the underlying thunderstorm, typically at scales of 10-50 km, could modulate the local threshold electric field for the sprite discharge, with low densities having lower thresholds (Sentman et al. 2003). An example of a sprite cluster that could have been formed in such a process is shown in Fig. 2. It is structured in individual sprite elements at horizontal distances of $\sim 10 \mathrm{~km}$ within an overall envelope of dimension $\sim 100 \mathrm{~km}$ that maps the region of the largest "reduced" field (namely, the electric field divided by the pressure) expected from a quasi-electrostatic field following a positive cloud-to-ground discharge (Neubert et al. 2005). However, it is not known whether the medium-scale structure $(10 \mathrm{~km})$ is caused by the local properties of the mesosphere or by interference patterns in the radiated and reflected source electric field as mentioned earlier.

It has also been proposed that perturbations of the electric conductivity induced by meteor trails at scales below $1 \mathrm{~km}$ are instrumental in the sprite ignition process (Suszcynsky et al. 1999; Symbalisty et al. 2000). Thus, the discussion of the medium and small scale structure of sprites and of the conditions that lead to ignition is relevant not only for 


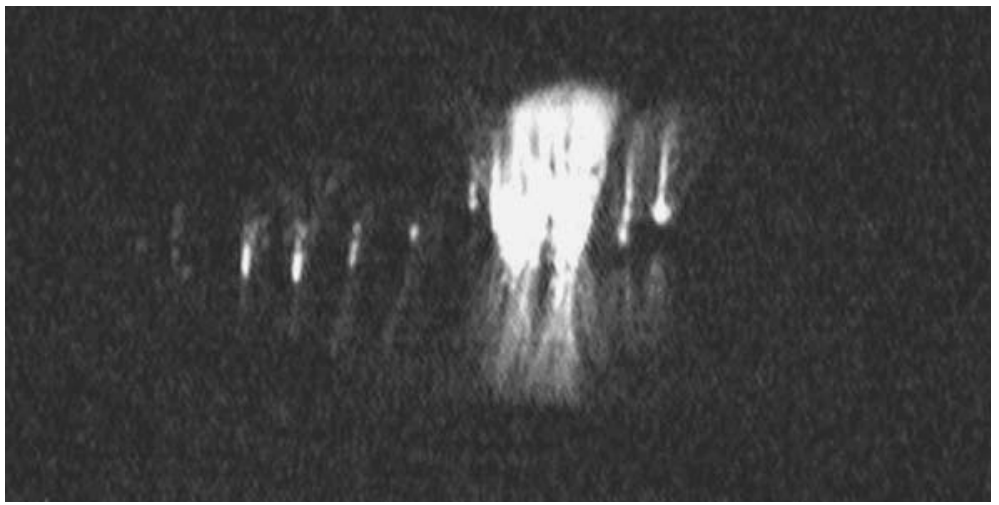

Fig. 2 Medium-scale structure of sprites observed over Southern France from Observatoire Midi-Pyrénées on 28 August 2003 at 23:16:55.809 UT. The horizontal dimension of the luminous region is $\sim 100 \mathrm{~km}$ and the separation between sprite elements is $\sim 10 \mathrm{~km}$ (Neubert et al. 2005)

understanding the sprite discharge itself but also for advancing our understanding of the medium and small scale structure of the mesosphere.

\subsection{Red Sprites: Discharge Mechanisms}

Several theories have been put forward to explain the sprite phenomenon. They all rely on free electrons accelerated to energies sufficient to excite atmospheric constituents by collisions. However, they differ on the processes involved. They can be categorized according to the energy $\mathrm{E}$ of the free electrons driving the process observed as optical emissions:

(1) $\mathrm{E}<\sim 15 \mathrm{eV}$ : optical emissions are really not signatures of a discharge but only of excitation of atmospheric constituents by collisions with free electrons created by detachment from negative ions.

(2) $\sim 15 \mathrm{eV}<\mathrm{E}<\sim 100 \mathrm{eV}$ : free electrons are created by ionization of the neutral atmospheric constituents in a classical neutral air breakdown cascade.

(3) $\sim 5 \mathrm{keV}<\mathrm{E}<\sim 5 \mathrm{MeV}$ : energetic seed electrons are created by cosmic ray ionization of the atmosphere. The gas breakdown is carried by electrons in this highenergy range.

The spectrum of sprites contains the information needed for studying the energetics of TLEs. Early observations suggested a strong signature of $\mathrm{N}_{2}(1 \mathrm{P})$ emissions and an absence of the $\mathrm{N}_{2}{ }^{+}$Meinel emissions, consistent with average energies of free electrons of the order of $1 \mathrm{eV}$ and insignificant amounts of air ionization. A theory has been proposed that invokes the release of electrons from pre-existing negative ions naturally present in the atmosphere (Swenson and Rairden 1998). The collisional energy needed for the release is 0.5-1.5 eV. This model belongs to category (1). It has been noted, however, that emissions in the Meinel bands, which reflect ionization processes, are strongly quenched by the atmosphere. Thus one has to be careful when comparing emission ratios estimated from ground measurements with theoretical predictions (Armstrong et al. 1998).

Models have been suggested where classical air breakdown is generated by the polarization electric field over the cloud tops following a positive cloud-to-ground stroke. The 
cloud top charges to positive potentials, with time-scales of the order of hundreds of seconds, and the more tenuous atmosphere above has time to supply polarization currents to a shielding space charge above the cloud. When the positive cloud top layer discharges directly to the ground, a downward-directed, transient electric field is generated in the atmosphere above with a time constant that depends on the continuing current of the order of a few ms to a few tens of ms. Theory for conventional air breakdown requires 200$500 \mathrm{C}$ to be discharged to ground in order for the field to be above the breakdown limit (Pasko et al. 1995, 1996, 1997). Breakdown occurs when streamers are formed with high space-charge density in the streamer tips. The downward-directed streamer propagating in the direction of the electric field is called a positive streamer. Positive streamers are thought to occur in the sprite discharge. The energy of electrons is generally higher in the streamer tip than in the streamer body (a sprite filament), and the tail of the electron distribution at energies exceeding the ionization threshold thus drives the avalanche. To explore the validity of the model, a characteristic energy of the electrons has been estimated and compared to estimates based on optical spectral measurements. Model and observations compare well with energies of $\sim 2 \mathrm{eV}$ in the sprite proper (Morrill et al. 2002) and $\sim 5-25 \mathrm{eV}$ in the halo surrounding the sprite (Miyasato et al. 2003). The model is one of category (2) and is the one mostly accepted. It is worth commenting that the model also allows for discharges by electric fields of opposite polarity, i.e. directed upwards and generated by -CGs, although they would be less efficient than +CGs. However, negative -CGs have been observed to cause sprites on rare occasions (Taylor et al. 2008).

The runaway electron discharge process belongs to category (3). When the electron energy increases beyond $\sim 500 \mathrm{eV}$, the combined effects of the atmospheric collisional cross sections decrease and reach a minimum around $\sim 1 \mathrm{MeV}$. At higher energies the cross sections increase again because of the increase in the mass of a relativistic electron. The discharge process is driven by energetic electrons $(\sim 1 \mathrm{MeV})$ where collision cross-sections minimize for atmospheric constituents (Gurevich et al. 1992, 1999; Roussel-Dupré et al. 1994). In this energy range, the air breakdown field is a factor of 10 below the conventional air breakdown field. Because the threshold field is lower, this mechanism should be triggered before the conventional one described above, and should supply neutralizing currents keeping the field just at the relativistic breakdown limit. The runaway discharge process thus seems to preclude classical air breakdown (Roussel-Dupré and Gurevich 1996; Taranenko and Roussel-Dupré 1996). However, this scenario has now been revised. Simulations suggest two categories dictated by the duration of the parent lightning. For fast $(<\mathrm{a}$ few $\mathrm{ms}$ ), high current $(>100 \mathrm{kA}$ ) positive CG lightning, the high altitude discharge is dominated by a diffuse airglow driven by conventional breakdown at high altitudes $(>60-70 \mathrm{~km})$, followed by runaway breakdown that initiates at the top of the cloud $(\sim 15 \mathrm{~km})$ and develops upward to altitudes exceeding $90 \mathrm{~km}$. For longer duration continuing currents $(>\mathrm{a}$ few $\mathrm{ms})$, streamers driven by conventional breakdown develop at high altitudes $(\sim 75 \mathrm{~km})$ and evolve downward to lower altitudes (terminating at $\sim 50 \mathrm{~km}$ ). The streamers are then followed by a runaway discharge that is initiated at the top of the cloud and propagates to high altitudes (Roussel-Dupré 2005).

Observations indicate that several of the processes outlined above operate in sprite discharges, but their relative roles and importance remain unclear. One of the key parameters to be observed in order to evaluate the significance of the processes is the degree of ionization. Models belonging to category (2) are in fairly good agreement with spectral observations of $\mathrm{N}_{2}^{+}$ionization transitions. However, such observations are 
marginal from the ground or from aircraft because of atmospheric absorption at the blue end of the spectrum. Spectral observations are best performed from space. That has been done since 2004 by the Instrument for Sprite and Upper Atmospheric Light (ISUAL) instrument on the FORMOSAT-2 satellite (Mende et al. 2005; Frey et al. 2005), which clearly show the existence of significant impact ionization of $\mathrm{N}_{2}$. Ionization has also been inferred from ELF observations of currents associated with sprites (Cummer and Inan 1997; Cummer 2003), from radar echoes from ionization enhancements thought to be generated by sprites (Roussel-Dupré 1997), and from perturbations of VLF transmitter signals propagating in the Earth-ionosphere waveguide (Rodger 1999; Haldoupis et al. 2004). However, while classical electric breakdown of the atmosphere has been demonstrated beyond doubt, the role of the release of low energy electrons from negative ions in the sprite process is not known.

It is difficult to make progress on the question of the importance of the runaway process of category (3) without observations from space of bremsstrahlung radiation in the upper atmosphere, as the radiation is absorbed in the lower atmosphere and is not observable from the ground. The observations must be taken simultaneously with observations of optical emissions to identify the connection of TGFs to lightning and TLE activity. Such observations have so far not been performed, but are planned with the French microsatellite TARANIS (Tool for the Analysis of RAdiations from lightNIngs and Sprites) and the ASIM (Atmosphere-Space Interactions Monitor) payload on the International Space Station, both scheduled for launch in 2012. In the mean time, experimental evidence for this process operating in relation to lightning is mounting, with observations of $\mathrm{X}$ - and $\gamma$-rays associated with thunderstorm electrification and lightning discharges from balloons, from mountain tops, and in connection with rocket-induced lightning (Brunetti et al. 2000; Moore et al. 2001; Dwyer et al. 2004a, b, 2005).

The runaway process requires the presence of seed electrons at energies within the runaway regime and with their momentum vector within a certain angle of the downwarddirected electric field. Such electrons are abundant from cosmic ray bombardment of the atmosphere. Computer simulations of sprites indicate that $10^{6}-10^{7}$ electrons $/ \mathrm{cm}^{2}$, accelerated in the $\sim 100 \mathrm{MV}$ potential between cloud tops and the ionosphere following a lightning discharge, are injected into the magnetosphere (Lehtinen et al. 1996, 1997). One of the questions raised by the RHESSI observations is the lack of TGF observations over North America, where powerful thunderstorms develop in the summer time and sprites are observed routinely. This is particularly puzzling when one considers the effect of the Earth's magnetic field, which is horizontal at the magnetic equator, and has increasing inclination towards higher latitudes. For relativistic electrons with energies around $\sim 1 \mathrm{MeV}$, the geomagnetic field in the equatorial region begins to play a role at altitudes of $\sim 30 \mathrm{~km}$. Above this altitude the almost horizontal geomagnetic field hinders a runaway electron discharge driven by a vertical electric field. Thus, the runaway mechanism favours regions of high inclination of the geomagnetic field because it allows electrons to be accelerated upwards. To resolve this issue an alternative acceleration process to the quasistatic electric field has been proposed. It invokes the field associated with the return stroke of the lightning process. This field has a horizontal component, and thus a component parallel to the geomagnetic field at low geomagnetic latitudes (Inan and Lehtinen 2005). However, it is still not certain at what altitudes TGFs are generated. Some observations suggest altitudes below $30 \mathrm{~km}$ within, or just above, the clouds although most of the radiation then is absorbed in the atmosphere before reaching satellite instrumentation (Østgaaard et al. 2008). In this case the Earth's magnetic field would play no significant role in the discharge process. 


\subsection{The Eurosprite Campaigns}

While observations of sprites made in the 1990s concentrated on the very powerful thunderstorms over the plains of the USA, it was not known whether smaller storm systems like those in Europe would generate Transient Luminous Emissions (TLEs). To address this question, the first ground campaign in Europe was conducted during the summer of 2000. The campaign documented sprites over Southern France and Northern Italy and the observations suggested that sprites were more common than previously thought (Neubert et al. 2001).

Since then, annual observational campaigns have been conducted over Southern Europe every summer. The backbone instrument is a camera system mounted at the Observatoire Midi-Pyrénées, in France. It has been upgraded every year with varying combinations of cameras and photometers. The cameras operate at $40 \mathrm{frames} / \mathrm{s}$ with light-sensitive CCDs at up to $1000 \times 1000$ pixels. The system is connected to the Internet and commanded from anywhere with access to the Internet. Real time information on lightning activity is available from the French Météorage company, allowing the system managers to point the cameras in the direction of lightning activity. Compressed event images are available in real time, with uncompressed data and extended footage downloaded during the daytime.

With the European Framework 5 Research Training Network "Coupling of Atmospheric Layers" (CAL) (2002-2006), the campaigns gained considerable momentum. It brought together teams from different scientific disciplines with expertise in a wide range of experimental techniques. The guiding principle for the network campaigns was that new science comes from new observations or from new combinations of observations. Following this approach, the EuroSprite campaigns included infrasound measurements from several locations in France, documenting the infrasound signatures of sprites at up $1000 \mathrm{~km}$ distance, and measurements of ground-based VLF (3-30 kHz) transmitter signals by a receiver on Crete, showing impulsive perturbations in the amplitude when the signals propagate in the Earth-ionosphere waveguide over thunderstorms. In addition, measurements of electromagnetic waves from a number of locations ranging from ULF $(<3 \mathrm{~Hz})$ to VHF (30-300 MHz) have given information on lightning activity, such as charge moment changes, intracloud lightning activity, and perturbations to the ionospheric conductivity. The collaboration also enabled more optical stations to be set up, which increased the coverage and in some cases permitted the triangulation of sprites when observed from two stations. Finally, meteorological measurements made from satellites or by ground-based radars of cloud cover, cloud top temperatures, and precipitation have also been available.

Sprite observations and associated lightning activity during the summers of 2003-2006 form the basis of the experimental observations presented in this paper. The data are summarized in Appendices 1-3. The first results of the EuroSprite2003 campaign were published by Neubert et al. (2005). In the following sections we report on the advances made since then, both as a result of campaign activities and modelling efforts by participants in the network.

\section{The Thunderstorm Source of Sprites}

Operational lightning detection systems usually measure the properties of cloud-to-ground (CG) lightning, whereas intracloud (IC) lightning activity remains undetected. For this reason, studies in the past of the relationship between lightning discharges and sprites have focussed primarily on the role of CGs, showing that, in almost all cases, a $+\mathrm{CG}$ can be 
identified as a trigger of sprites (Boccippio et al. 1995). Broad-band recording of radiation at frequencies below $\sim 100 \mathrm{~Hz}$ in the ELF range, which can be observed at very considerable distances from the source, have further enabled estimation of the associated charge moment change (CM), which is the amount of charge lowered to the ground multiplied by the distance between the charge reservoir and the ground. It has been shown that the CM change needed to generate sprites is of the order of 300-600 C km for short delayed sprites (ms) and larger for larger delays (Cummer 2003) (Note that some authors consider the charge moment change to be twice this, accounting for the image charge in the ground-see also Sect. 7.2).

It was recognized early (Lyons 1994; Sentman et al. 1995) that sprites are associated with the stratiform regions of mesoscale convective systems adjacent to the stronger convective cores and that they tend to occur during the mature to decaying stages of thunderstorm development. These regions contain extensive layers of charge that can be tapped by IC lightning. Rare observations from IC lightning mapping systems have shown that a significant IC component may be feeding the $+\mathrm{CG}$ flashes that trigger sprites and thus sustaining strong continuing currents (Stanley et al. 2000; Lyons et al. 2003).

During the EuroSprite campaigns thunderstorms were monitored with a more complete set of instrumentation, thereby allowing a better characterization of cloud and lightning properties of the sprite-producing regions of the storms. The storms were sometimes located over the short-range lightning detection system SAFIR that also detected IC discharges. The SAFIR systems were located in northern Spain and in the Provence region of Southern France. The systems were based on three VHF $(\sim 100 \mathrm{MHz})$ receivers in a triangle with $\sim 100 \mathrm{~km}$ distance between the receivers that measure activity in clouds, giving information on the location (in the horizontal plane) and time of IC and CG activity (Drüe et al. 2007). Additional information came from a broad-band, VLF $(\sim 10 \mathrm{kHz})$ receiver located at Nançay in central France. CG activity was also available from conventional lightning detection networks provided by the French Météorage system of 17 sensors covering the whole country. Each sensor uses two techniques for CG location, a direction finder (DF) and time of arrival (TOA) information. The characteristics of the $\mathrm{CG}$ flashes determined include the location (horizontal), the time of occurrence, the polarity, the multiplicity and the peak currents of each stroke (Cummins et al. 1998).

Other characteristics of thunderstorms are derived from meteorological radars. France is covered by a network of weather radars, ARAMIS, run by MétéoFrance. Seventeen radars with $250-\mathrm{km}$ range provide complete horizontal scans every 5 minutes. The elevations of the beams are kept almost constant so that altitude information is not available. The parameter provided by the radars is the reflectivity factor which is directly related to the precipitation rate (or rainfall rate). Sprites can then be related to the cloud system properties, to determine the type of thundercloud structure that favours their production and in what evolutionary phase of the convective system they are generated. Near-infrared images from the geostationary Meteosat satellite are also used, from which the altitudes of the cloud tops are estimated.

In the following sections we give results from our studies of the characteristics of spriteproducing thunderstorm regions observed in Europe and the importance of the IC activity for sprite generation and morphology. Some of the results are published in van der Velde et al. (2006) and Soula et al. 2008 whereas others are published here for the first time. Earlier studies, including those made by (Lyons 1996) and Lyons et al. 2003, analyzed storms over the US Plains in depth. 


\subsection{Characteristics of Sprite-Producing Storms}

Optical imaging, which is the most reliable method of sprite detection, can only be done during night time when the sky is clear and there is an unobstructed view of the region observed. One usually cannot be certain that the full period of sprite production by a storm is recorded, as sprites could be undetected because they were outside the field of view of the cameras. While the complete thunderstorm phase of sprite production from start to end usually cannot be characterized with certainty, it is possible to determine the thunderstorm conditions present during the period when sprites are observed. Cases were selected for studies based on the number of sprites observed in a given period and the availability of simultaneous radar, satellite and lightning data. The last requirement excludes most of the cases over the Mediterranean Sea. In all, seven of the storm systems observed during 2003, 2005 and 2006 were analysed with regards to cloud properties and their relation to sprite generation (Soula et al. 2008).

Satellite images suggest that sprites tend to occur over the stratiform region near the coldest (highest) cloud tops. For the storm systems observed during the EuroSprite campaigns, sprites tended to occur when the cloud canopy reached its largest extent. The size of the storm with cloud top temperatures lower than $-50^{\circ} \mathrm{C}$ (near the tropopause level) peaks during the sprite period. The significant growth of this region may be attributed to the development of a front-to-rear mesoscale updraft. Figure 3 shows the development of cloud top regions at various temperatures during a sprite-active phase of the thunderstorm of 21 July 2003. The maximum size of the $-50^{\circ} \mathrm{C}$ region lags that of the coldest cloud tops (over the strongest cells, usually $-60^{\circ} \mathrm{C}$, or colder) by an hour or more. A similar study of a mesoscale convective system over Kansas found the maximum sprite production rate when the overlying cloud top temperatures were minimum, $-69^{\circ}$ to $-72^{\circ} \mathrm{C}$ (São Sabbas

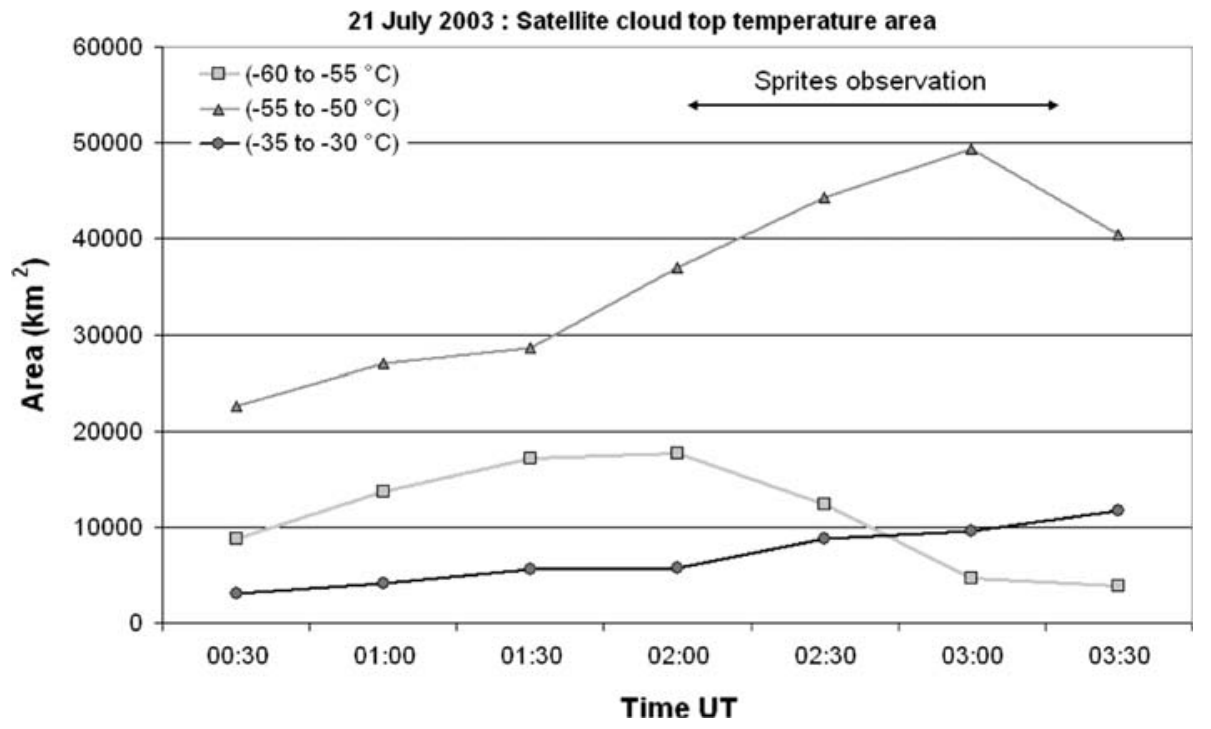

Fig. 3 Time series of the area of cloud regions with different cloud top temperatures derived from observations made by Meteosat for the storm on 21 July 2003. Sprites are generated in the period from $\sim 2: 00-3: 30$ UT when the area of the coldest cloud tops decreases and the area of medium-cold cloud tops reaches its maximum 


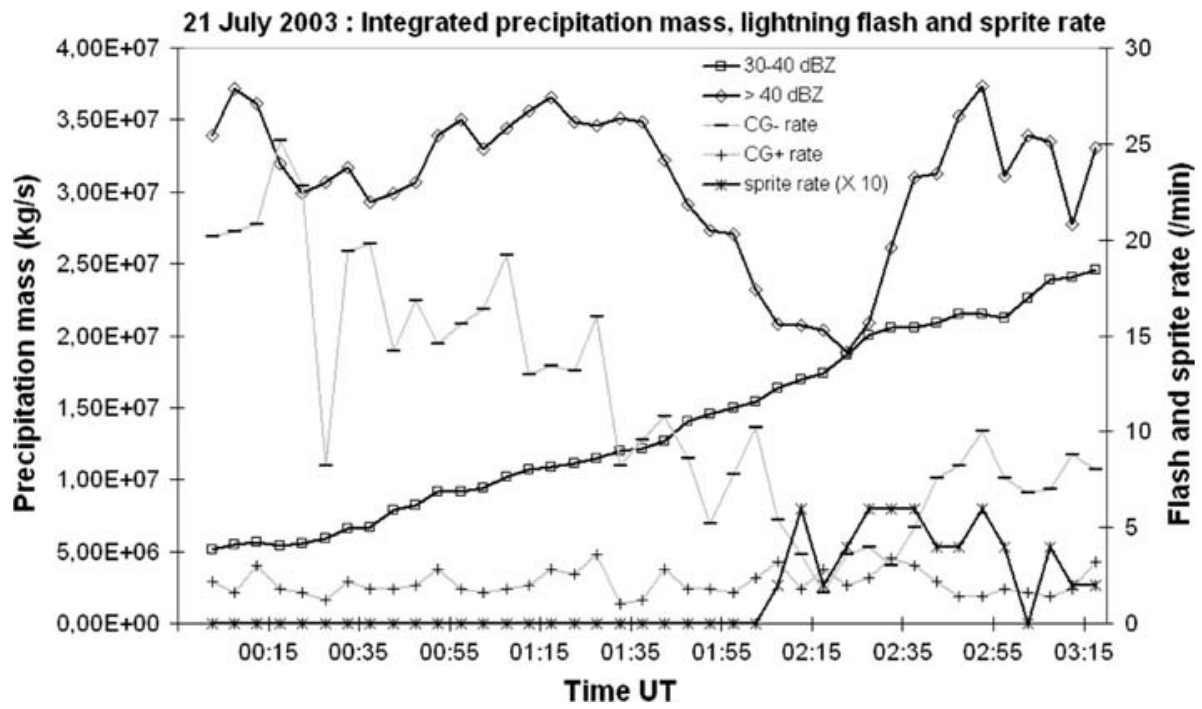

Fig. 4 Time series of the integrated precipitation mass from regions of the cloud with different radar reflectivity values, of the positive and negative cloud-to-ground lightning flash rates, and of the sprite rate for the storm on 21 July 2003

and Sentman 2003). The difference is possibly caused by a difference of tropopause height for the two regions or by differences in storm size.

Radar reflectivity $Z$ (expressed in dBZ) gives a view of the internal structure of thunderstorms. Reflectivity $Z_{O}$ can be conveniently converted to the rainfall rate $R$ by the commonly used empirical $Z-R$ relationship stemming from the Marshall and Palmer 1948 drop size distribution: $Z_{O}=200 R^{1.6}\left(Z_{O}\right.$ in $\mathrm{mm}^{6} \mathrm{~m}^{-3}$ and $R$ in $\mathrm{mm} / \mathrm{hr}$ ). The rainfall rate can be summed over an area and be expressed in $\mathrm{kgs}^{-1}$. This was done for different intervals of $Z$ values in order to separate convective and stratiform rainfalls. The result for the storm of 21 July 2003 is shown in Fig. 4. All storms begin small with predominantly intense convective precipitation $(>50 \mathrm{dBZ}$ ). Sprites were observed during periods where the area of the stratiform precipitation region with reflectivities from 30-45 dBZ was growing, and usually lasted until the size of this region began to decrease. This result is consistent with the observed range of reflectivity values for sprite-triggering $+\mathrm{CG}$ flashes over the US Plains reported by Lyons et al. 2006. A decrease of the area suggests that the regeneration of precipitation in the stratiform region, and hence of fresh charge, has ceased. Areas of reflectivity weaker than $30 \mathrm{dBZ}$ were not found to correlate with sprite production in any of the observed systems.

The precise reflectivity range that correlates with sprites in the manner described above differs among the storms. The storms of 21 July 2003, 29 July 2005 and 11 September 2006 featured the strongest growth in the 30-40 dBZ range, during which time sprites were observed. The area of the 40-45 dBZ region was growing, especially in the late stages of the storm, but not correlating with the sprite period. On the other hand, the storm of 17 November 2006 already had a very extensive area of 30-40 dBZ reflectivity when sprites were first observed, and the 40-50 dBZ-range expanded its area significantly during the sprite period; sprites stopped when this area started to decrease. This relatively strong stratiform precipitation was enhanced by orographic lifting of moist Mediterranean air over 
the Massif Central plateau. However, the +CGs that triggered sprites in this system occurred in the usual 30-40 dBZ range, bordering the higher reflectivities.

For the storm of 21 July 2003, the start of the sprite period could unambiguously be identified from optical observations. It began not long after a part of the convective region weakened, as made evident by the rapid decrease of $>45 \mathrm{dBZ}$ integrated precipitation. The lightning flash activity of the storm is shown in Fig. 4. Weakening of the convective region is accompanied by decreasing - CG flash rates, to very low levels, when sprite-triggering + CGs started. During the sprite period, low flash rates of predominantly positive flashes are observed. This is a trend also observed in other storms. This observation is different from the large MCS studied by São Sabbas and Sentman (2003) where sprites were found to peak during the period with the largest -CG flash rates. However, in such a large MCS there can be several convective core areas in different stages of their life cycle. In the 21 July storm convective cells were regenerating themselves in an area far from where the sprites occurred, so the rising -CG rate shown on the figure is not relevant to the sprite producing region.

A statistical analysis of all CG lightning flashes in a thunderstorm has been undertaken for seven sprite-producing storm systems. Within circles of 5 and $10 \mathrm{~km}$ radii, radar reflectivity and cloud top temperatures were determined for every CG flash. An average precipitation rate over the circle was determined using a Marshall-Palmer relation for the raw reflectivity average $(Z)$. Radar pixels with a reflectivity lower than $9 \mathrm{dBZ}$ ('dry') in the circle have been excluded. Next, flashes were grouped into three basic classes: flashes not related to sprites $(+,-)$, flashes occurring within $250 \mathrm{~ms}$ before a sprite assumed to be the triggering flash $(\mathrm{ST}+)$, and extra flashes that appeared close to the sprite in time and space $(\mathrm{S}+, \mathrm{S}-)$. This latter category occurred usually within 1 second before or after the sprite and in areas with sparse lightning activity, giving the appearance that they were part of the same horizontal lightning flash sequence. The results show that ST+ and S+ occur in the most uniform precipitation region of moderate intensity, whereas $(+)$ occur in a wider variety of conditions but overlapping with those associated to sprites. One-third of $+\mathrm{CG}$ flash sequences were found to produce two-thirds of all sprites. Of the sequences, first +CGs occurred in less stratiform precipitation regions than later +CGs in the sequence, suggesting that extensive horizontal lightning was associated with the +CGs, propagating away from precipitation cores. This interpretation is supported by earlier observations of the evolution of CG and IC lightning channels (Carey et al. 2005) and IC and +CG activity in association with sprites (Lyons et al. 2003).

\subsection{Cloud Discharges and Sprites}

The relationship between sprites and their causative discharges has been studied using the entire data set of more than several hundred sprites. The distribution of the time delays between sprites and their causative +CGs was found to have a well defined tail showing that at least one third of the sprites were lagging the causative $+\mathrm{CG}$ discharges by more than $25 \mathrm{~ms}$, reaching values up to $\sim 250 \mathrm{~ms}$ (Mika et al. 2005). Based on observations of ELF/VLF observations it has been suggested that IC activity plays a role in sprite generation (Ohkubo et al. 2005). This was examined for 15 sprites within range of the SAFIR VHF lightning detection system which directly could monitor IC activity. Column sprites were generally characterized by a short time delay relative to the causative $+\mathrm{CG}$ discharge ( $<25 \mathrm{~ms}$ ), high +CG peak current, little IC activity and short, intense bursts of broad-band VLF radio wave activity. Carrot sprites seem to be associated with longer time delays, large IC activity and weaker, but longer-lasting, bursts of lightning discharges (termed 
atmospherics, or sferics for short) at times preceding the +CG (van der Velde et al. 2006). The association of lightning activity, sferic activity and sprites is illustrated for two cases in Fig. 5. The above characteristics suggest that IC discharges and long-lasting continuing currents play an important role in the generation of carrot sprites but are relatively unimportant for the more impulsive column sprites. These characteristics are summarized in Table 1.

The IC flash and sferic activity is caused by breakdown processes inside the clouds feeding the continuing current of the $+\mathrm{CG}$. As the sferic radiation is broad-band, this may not seem to favour the mechanism proposed by Cho and Rycroft (2001), where ionization enhancements in the lower ionosphere are caused by structured interference patterns of fields from horizontal lightning bouncing in the Earth-ionosphere cavity. However, a timevarying interference pattern will be created by the radiated waveform, whatever its
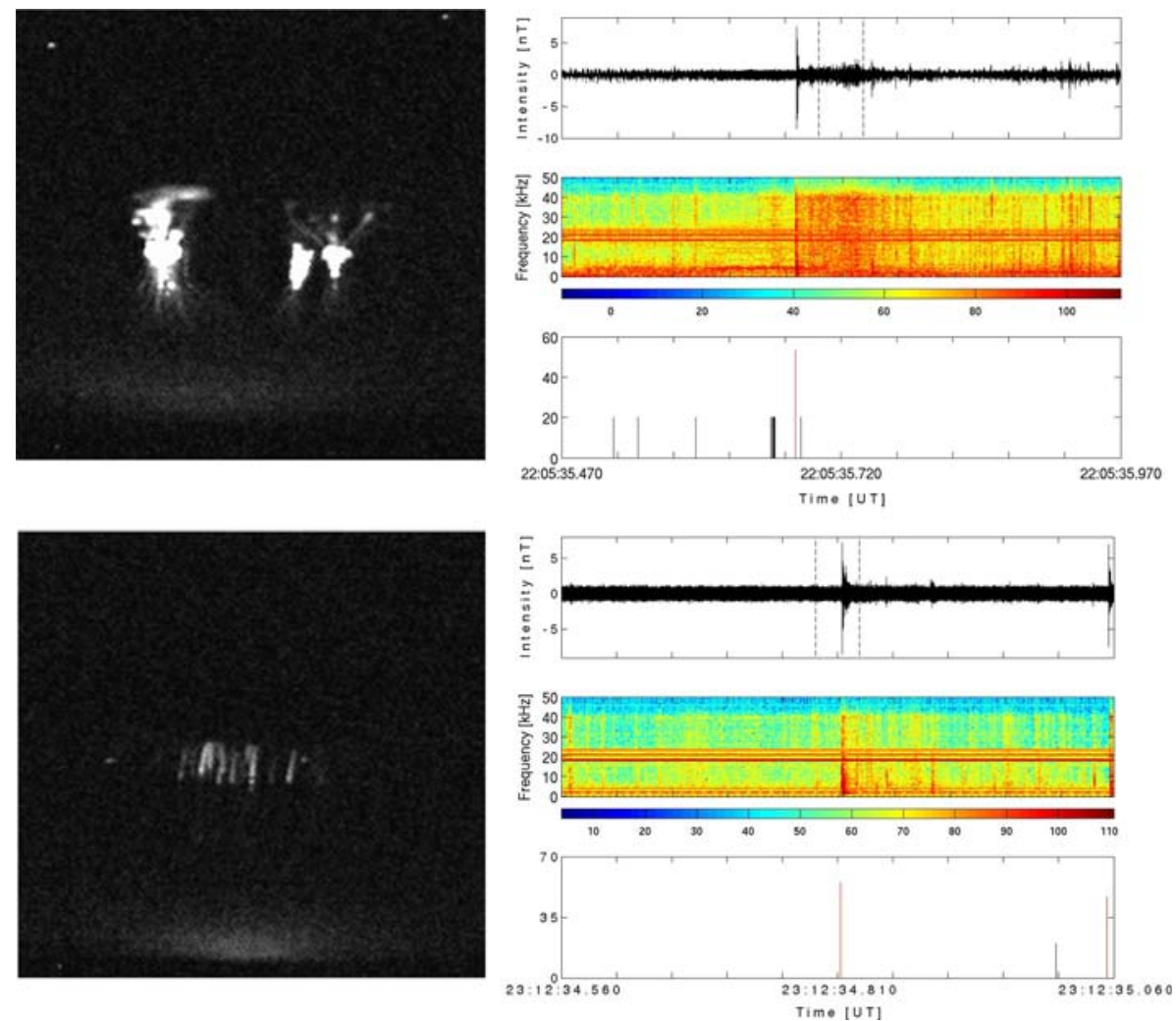

Fig. 5 Observations made on 23 July 2003 (van der Velde et al. 2006). Magnetic East-West component of ELF/VLF waveforms (top panel, right), corresponding wave spectra (middle panel, colour) and lightning activity (bottom, right) for $500 \mathrm{~ms}$ time period around observations of carrot sprites (top, left) and column sprites (bottom, left). The two vertical dashed lines on the waveform panels mark the time of sprite detection by the optical cameras. The ELF/VLF data were observed at Nançay, France, about $300 \mathrm{~km}$ from the events. The lightning data of $+\mathrm{CG}$ strokes from Météorage are shown in red and the SAFIR VHF intracloud lightning sources in black. The vertical scale indicates the $+\mathrm{CG}$ peak current $(\mathrm{kA})$; the lengths of the black lines representing the SAFIR data are scaled arbitrarily. For the carrot sprite significant broad-band ELF/ VLF activity is following the causative $+\mathrm{CG}$ and some SAFIR activity is preceding it. For the column sprites the broad-band activity is weaker and SAFIR sources are absent 
Table 1 Characteristics of the lightning source of column and carrot sprites

\begin{tabular}{|c|c|c|c|c|c|}
\hline Type & Time delay & $\begin{array}{l}\text { VHF Sources } \\
\text { SAFIR }\end{array}$ & VLF sources Nancay & $\begin{array}{l}\text { Peak } \\
\text { current }\end{array}$ & $\begin{array}{l}\text { Triggering } \\
\text { lightning }\end{array}$ \\
\hline Column & $\begin{array}{l}\text { Small } \\
\qquad(<25 \mathrm{~ms})\end{array}$ & Low activity & $\begin{array}{l}\text { Short }(<25 \mathrm{~ms}) \\
\text { high intensity }\end{array}$ & High & Impulsive $+\mathrm{CG}$ \\
\hline Carrot & Larger & $\begin{array}{l}\text { High activity } \\
\text { preceding }+\mathrm{CG}\end{array}$ & $\begin{array}{l}\text { Long duration lower } \\
\text { amplitude }\end{array}$ & Moderate & $+\mathrm{CG}$ and $\mathrm{IC}$ \\
\hline
\end{tabular}

bandwidth, so that this mechanism should, nonetheless, operate. One observed sprite event could not be associated with a +CG flash, but was instead preceded by an unusually large cluster of SAFIR IC sources and an unusually strong VLF sferic cluster, suggesting that IC lightning activity can also be important for the triggering of sprites.

An alternative interpretation is that a $+\mathrm{CG}$ flash was indeed generated, but went undetected, which opens the question of the reliability of lightning detection networks. The VHF sources observed by the SAFIR system were usually found to precede the +CGs, but were never observed after the $+\mathrm{CG}$ stroke. In contrast, the VLF broad-band sferic activity usually began at the onset of the $+\mathrm{CG}$ flash. This suggests that the interferometry system cannot locate sources when the fields become too complex, with high currents established by the $+\mathrm{CG}$ and new IC discharges being formed simultaneously at widely different locations in the storm. This conclusion is in accordance with (Mazur et al. 1997, 1998).

The relationship between IC lightning and the horizontal displacements of a sprite from its parent +CG stroke was studied for a sprite displaced by $20 \mathrm{~km}$ which was observed over northeastern Spain on 16 August 2005. This was within range of one of the SAFIR systems and the relevant information is shown in Fig. 6. First the VHF sources propagated from the location of the (later) +CG towards the region over which the sprite would occur, with a speed that is typical of a horizontal stepped leader $\left(2 \times 10^{5} \mathrm{~m} / \mathrm{s}\right)$. The $+\mathrm{CG}$ flash was then triggered and was followed by broadband VLF activity and the sprite. The sequence suggests that IC lightning propagated into the stratiform precipitation region as a negative stepped leader, which connected to the ground by the +CG discharge near the location where the negative leader started. A similar observation was reported by Mazur et al. (1998). The return stroke process discharges the IC channels, bringing their potential closer to that of the ground, and triggering additional breakdown that supplies charge to the $+\mathrm{CG}$ channel over a time interval as long as the sferic cluster $(60 \mathrm{~ms})$. This event shows the well known fact that a +CG may transfer charge from a remote region of the storm to the Earth. It also shows that the process may favour sprite generation which is laterally displaced from the $+\mathrm{CG}$. Our data suggest that this is a very common occurrence. The above interpretation is consistent with the conclusions of Marshall et al. 2007 that VLF sferic clusters are produced by horizontally propagating lightning, although their data do not show a one-to-one match between all lightning data detected by the Lightning Mapping Array and the VLF sferic clusters.

\section{Ionization and Heating of the Mesosphere by Sprites, Elves and Lightning}

Studies of conductivity changes above thunderstorms in the mesosphere and lower ionosphere were undertaken by measuring changes in the amplitudes of signals from narrowband radio transmitters passing over thunderstorm regions. The measuring principle 

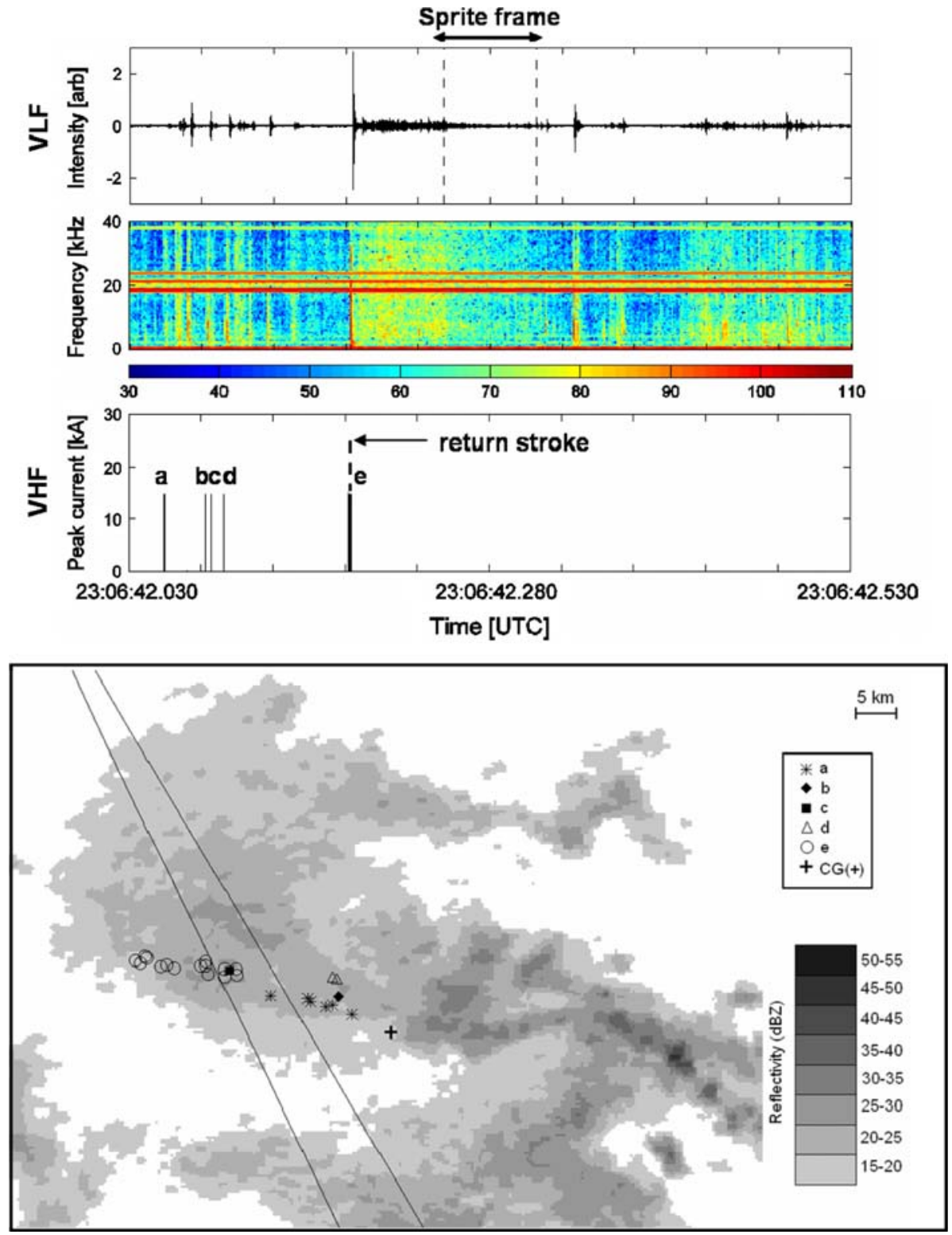

Fig. 6 Observations on 16 August 2006: Upper panel top and middle: Broadband VLF waves (East-West component) $250 \mathrm{~ms}$ before and after the sprite event at 23:06:42.260 UTC. The two vertical dashed lines indicate the sprite observation time, accounting for the video frame integration time of $40 \mathrm{~ms}$ plus the timing uncertainty of $12 \mathrm{~ms}$. Upper panel bottom: Cloud-to-ground strokes detected by Météorage (red) and intracloud lightning sources detected by SAFIR (black). The vertical scale indicates the + CG peak current (kA). The black lines representing the SAFIR data are scaled arbitrarily; a, b, c, d and e mark the different sequences of the activity in VHF range. Lower panel: Lightning activity and composite radar reflectivity distribution. The small symbols indicate the VHF sources gathered in five sequences $(a, b, c, d$ and e of upper panel) and the arrows indicate the direction of displacement. The cross indicates the location of the $+\mathrm{CG}$ stroke. The two lines show the directions of the sprite edges as seen from the Pic du Midi 


\section{LOWER IONOSPHERE ( 70-90 km)}

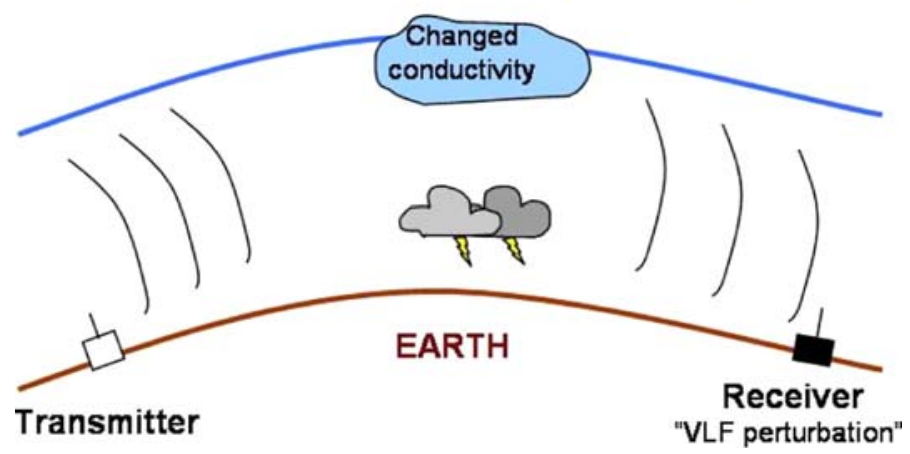

Fig. 7 Diagram showing how the bottom side ionosphere and the mesosphere above a thunderstorm are probed by the signals from a ground based radio transmitter propagating in the Earth-ionosphere waveguide

is shown in Fig. 7. The transmitters were either powerful VLF (3-30 kHz) transmitters used for navigational purposes or MF (0.3-3 MHz) radio station transmitters. At these frequencies electromagnetic waves propagate in the Earth-ionosphere waveguide, the upper boundary of which is affected by perturbations of the electrical conductivity in the mesosphere where TLEs (i.e. sprites and elves) are generated. State-of-the art VLF receivers in Crete and France recorded simultaneously with the TLE detection system at the Observatoire Midi Pyrénées, and with lightning detection systems; broad-band MF radio signals were recorded at several locations in France.

\subsection{Perturbations by Sprites}

The electromagnetic energy from a lightning discharge can cause additional ionization and heating of the electron population in the collisional plasma of the lower ionosphere. Consequently, the resulting change in electrical conductivity may cause changes in the amplitude and/or phase of VLF ground transmitter signals passing through the region and can be detected experimentally provided that the perturbation is of sufficient magnitude (Rodger 1999). The most common perturbation observed follows within a few ms of the causative lightning discharge and has a short onset duration of less than $\sim 50 \mathrm{~ms}$. Such perturbations are referred to as "early/fast" (Inan et al. 1995). During the nights of 21-24 July 2003, 42 sprites were observed over three thunderstorms in central France. They were located such that VLF ground transmitter signal paths, received in Crete, passed over the thunderstorms. All these sprites were triggered by + CGs and the receiver on Crete detected "early" VLF amplitude perturbations for $\sim 90 \%$ of them (Haldoupis et al. 2004; Mika et al. 2005). On the other hand, among the much more numerous $+\mathrm{CG}$ and $-\mathrm{CG}$ discharges which were not associated with sprites, only a few were associated with amplitude perturbations. Video frames, available for one of these events, were played back; this led to the discovery of an additional sprite which had previously been missed. These observations suggested that sprites are nearly always accompanied by "early" VLF perturbations.

Most of the sprite related VLF events had long recovery times ( 30-300 s), which suggests spatially extended, diffuse regions of electron density increases at altitudes higher than $75 \mathrm{~km}$. This agrees with previous studies and supports theoretical predictions of air 
breakdown in the upper D-region ionosphere during sprite occurrences, triggered by strong quasi-electrostatic (QE) fields. For more details see Mika et al. (2005) and Sect. 7.2.

A new category of VLF perturbations with a long onset duration of up to $2.5 \mathrm{~s}$ was observed in relation to $\sim 55 \%$ of the sprite events. These "early/slow" events are indicative of a new physical process at work which, following a causative $+\mathrm{CG}$ discharge, leads to a slow change in the conductivity of the lower ionosphere. Analysis of simultaneous broadband VLF recordings from the receiver in Nançay located within a few hundred $\mathrm{km}$ of the storms shows that the growth phases of "early/slow" events coincide with the occurrence of continued lightning activity during the growth phase. An "early/slow" event seen by the Crete receiver is shown in Fig. 8 together with Nançay broadband time series and Météorage lightning data. The event is associated with a few sequential CG lightning strokes (lower panel), and clusters (bursts) of VLF sferics which are due to intracloud (IC) lightning (upper panel). The observations suggest that the long onset duration is a result of secondary ionization build-up in and/or heating of the upper D region below the nighttime VLF reflection height, caused by sequential electromagnetic pulses (EMP) radiated upwards from horizontal IC discharges. The radiation fields accelerate sprite-produced electrons which then impact to produce secondary electrons in an avalanche process which
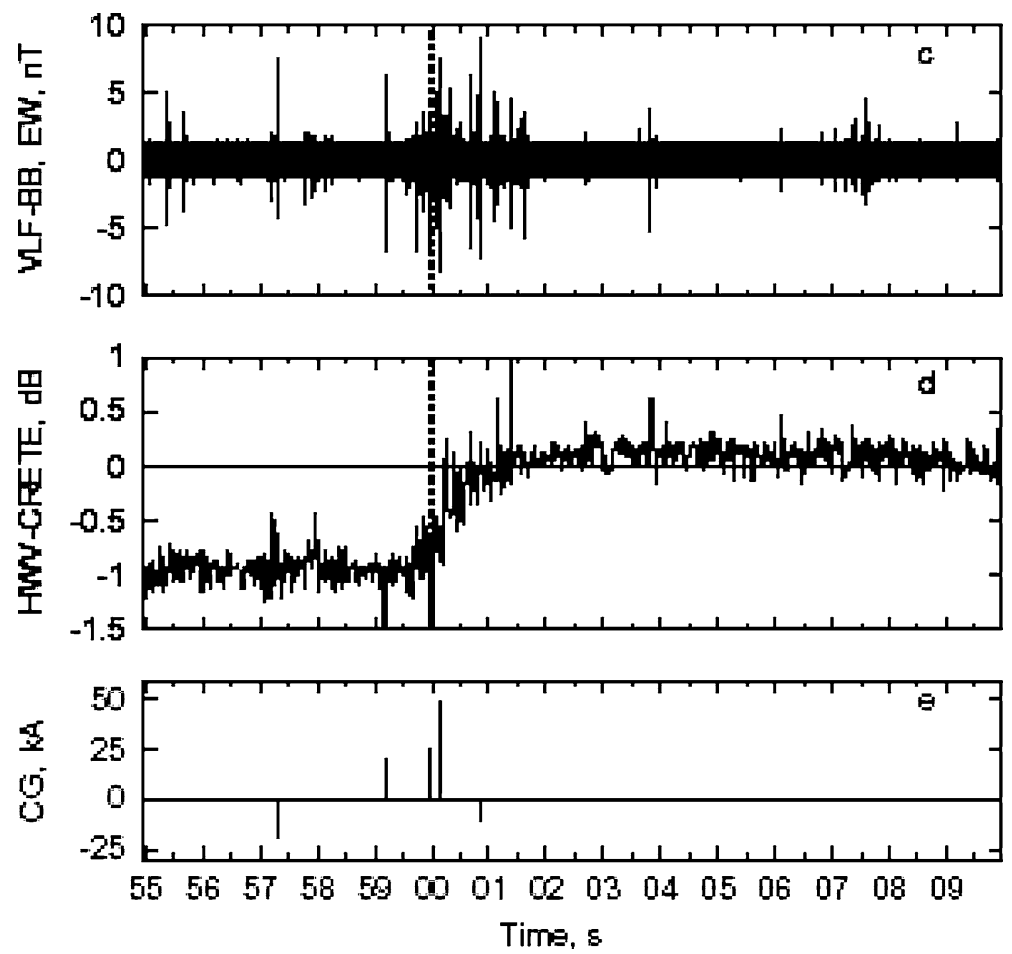

Fig. 8 An "early/slow" VLF event observed in Crete (middle panel) at $\sim 2000 \mathrm{~km}$ from the thunderstorm. A sprite is observed at the time marked by the vertical dashed line; currents flowing in the causative $+\mathrm{CG}$ discharge and other CGs are shown in the bottom panel. This "early/slow" event is characterized by an onset of $\sim 2 \mathrm{~s}$, during which sferics (top panel) are detected by a broadband VLF receiver in France $\sim 200 \mathrm{~km}$ North East of the thunderstorm. The sferics are attributed to intracloud lightning discharges which heat and ionize the lower ionosphere, causing the observed onset in the signal from the HWV transmitter at Le Blanc (Rosnay), France, to Crete 
leads to the observed ionization build-up (Haldoupis et al. 2006). However, any associated optical emissions are below the sensitivity of the cameras (magnitude 6).

VLF transmitter signals recorded by the Nançay broadband VLF receiver, located 200 to $300 \mathrm{~km}$ West of the sprite-producing storms of 21 to 24 July 2003, were analyzed to study VLF backscatter from sprite-induced ionisation structures, as suggested by Dowden et al. 1996. Our study has shown that only $\sim 5 \%$ of the sprites were accompanied by weak backscatter, indicating that backscatter from sprite plasma structures is possible but not as frequent as recorded by Dowden et al. (1996).

An existing D-region model, suitable for simulating electron density variations, was applied in order to compute the relaxation of extra ionization associated with sprites. The recoveries of observed "early" VLF perturbations were compared to the model results and the magnitude and altitude of enhanced ionisation was inferred. Reactions between four types of charged particles (electrons, negative and positive ions and positive cluster ions) were accounted for, along with various electron loss mechanisms. Direct heating effects were not included since "early" VLF perturbations are known to be caused by electron density changes (electron cooling times at the altitudes of interest $(\sim 75-90 \mathrm{~km})$ are between $\sim 5 \mathrm{~ms}$ and $0.2 \mathrm{~s}$ (Rodger et al. 2004), much shorter than the "early" VLF event recovery times). The continuity equations describing the time variation of the number densities of each of the species were solved numerically to compute the decay with time of the electron density enhancements produced by the action of lightning-induced QE fields which can lead to the appearance of sprites. The model results, obtained using different parameters corresponding to various altitudes, were then compared with the recovery times of "early" VLF events observed in relation to sprites. Good agreement with the observed recovery times of 20 to $250 \mathrm{~s}$ was obtained assuming electron density increases at altitudes of 75 to $85 \mathrm{~km}$ by factors from $10^{2}$ to $10^{4}$ times the unperturbed densities. This, in addition to the strong forward scattering pattern observed in relation to the VLF events recorded on Crete, leads to the conclusion that the incident VLF transmitter signals underwent scattering from horizontally extended diffuse regions of electron density enhancements, most likely associated with halos or the diffuse region of the upper part of carrot sprites, rather than small-scale streamers observed at lower altitudes (Mika 2007).

\subsection{Perturbations by Elves}

Elves are generated by the electromagnetic pulse (EMP) radiated by an intense CG stroke (e.g., Rowland 1998). It has been suggested that the EMP also creates ionisation (Tararenko et al. 1993; Rowland 1998), but this has not been verified experimentally. The largest database, so far, of elves observed over thunderstorms also probed by VLF transmitter signals, was secured during the EuroSprite campaigns. The optical data came from the cameras at the Observatoire Midi-Pyrénées (five elves) and from the ISUAL instrument on the FORMOSAT-2 satellite (Chern et al. 2003). VLF perturbation studies were conducted to search for evidence of ionization produced simultaneously with the optical emissions of the elves (Mika et al. 2006). During the EuroSprite 2003 campaign all five elves captured were found to be accompanied by "early" VLF perturbations on transmitter signals recorded by the Crete receiver. An example is shown in Fig. 9. Many elves observed from space, about 20 over Europe and 280 over North- and MiddleAmerica, were examined. Eight elves detected above Europe and 42 seen over America were located at distances less than $500 \mathrm{~km}$ from the transmitter-receiver great circle paths, but only a few (all seen above Europe) were associated with early VLF perturbation events. 

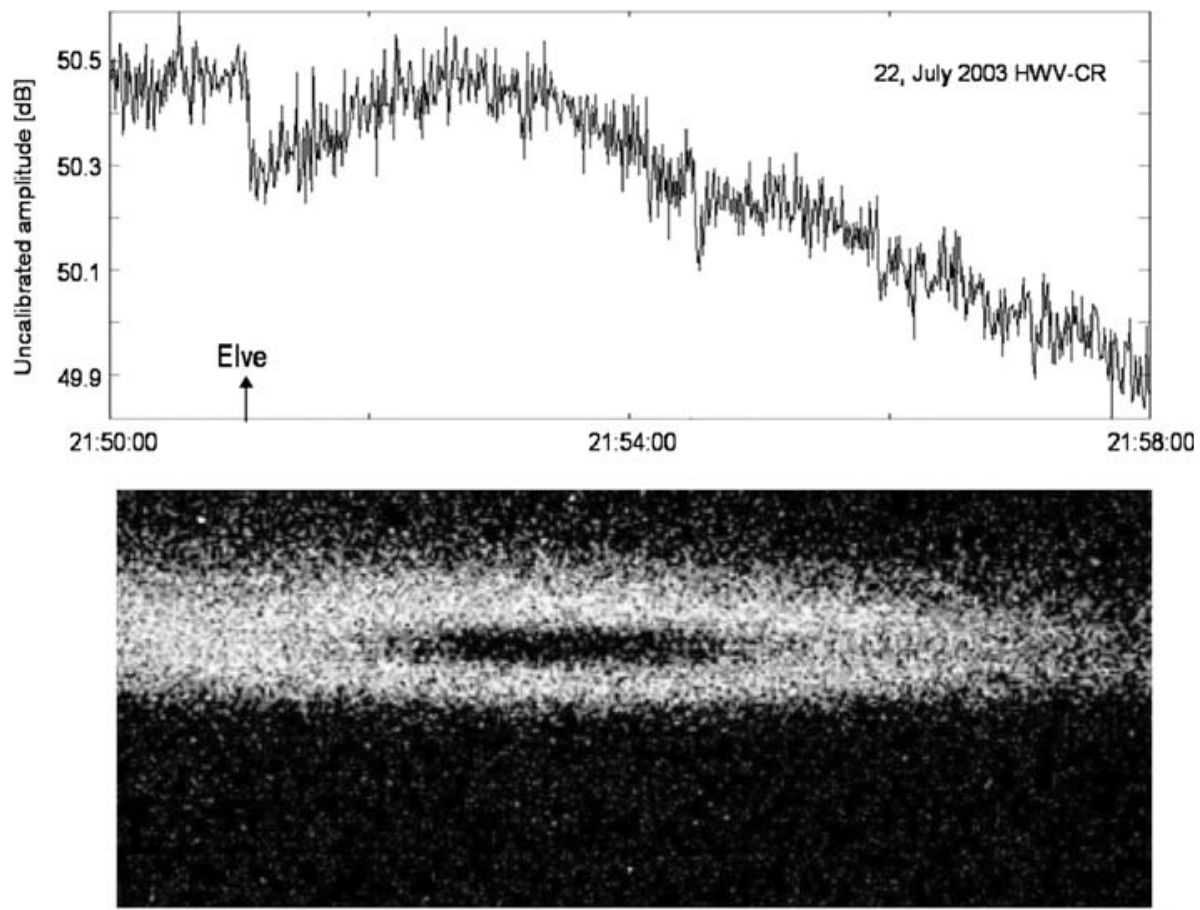

Elve at 22 July 2003, 21:51:05.038 UT

Fig. 9 An "early/fast" VLF perturbation event (upper panel) detected by the Crete receiver $\sim 2000 \mathrm{~km}$ from the thunderstorm, and an associated elve observed from the Observatoire Midi-Pyrénées shown in the lower panel. This provides evidence for the creation of a diffuse region of heating/ionization in the upper D region which produces strong forward scattering of the incident VLF wave

The observations suggest that the lightning EMPs at times create regions of diffuse electron density enhancements in the uppermost D region of the ionosphere and that subionospheric electron density changes associated with elves can intrude to lower altitudes (say below $85 \mathrm{~km}$ ) and perturb VLF transmitter signals. VLF detection, however, is sensitive to several factors such as the distance of the elve to the receiver, the altitude of the perturbed ionospheric region and the EMP intensity. The EMP may be sufficient to cause optical emissions (elves) and ionization, but not ionization at lower altitudes which affects VLF propagation.

\subsection{Perturbations by Lightning}

Broad-band Medium Frequency (MF) measurements can also be used to study the perturbations of the lower ionosphere related with lightning activity. The Avril sur Loire (AVF) station measures simultaneously the vertical electric field in the VLF and MF band $(500 \mathrm{kHz}-1500 \mathrm{kHz})$ using an active rod antenna mounted on a 3-m-high mast. It was set up in the centre of France $\left(3^{\circ} 21.075 \mathrm{E}, 46^{\circ} 47.352 \mathrm{~N}\right)$ in 2004 . During the summer, no sprites were recorded; however, the effect of lightning from several storms was analysed.

It was very frequently found that, just after a return stroke, strong attenuation of narrowband, MF radio signals was observed, as shown in Fig. 10. This perturbation effect has 

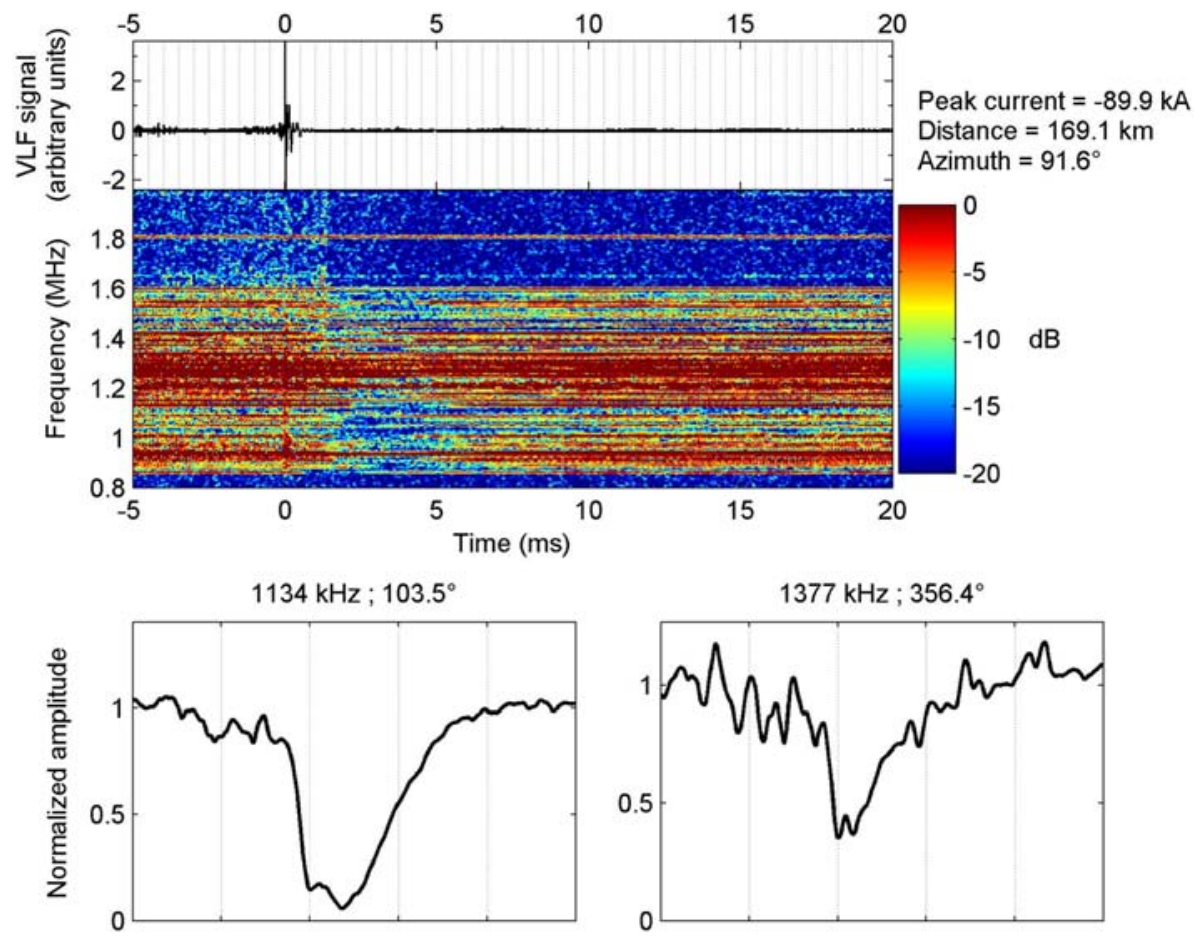

$1377 \mathrm{kHz} ; 356.4^{\circ}$

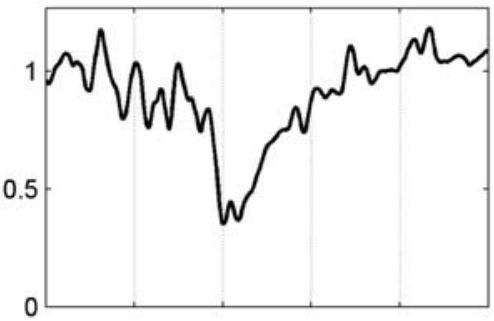

$945 \mathrm{kHz} ; 203.3^{\circ}$
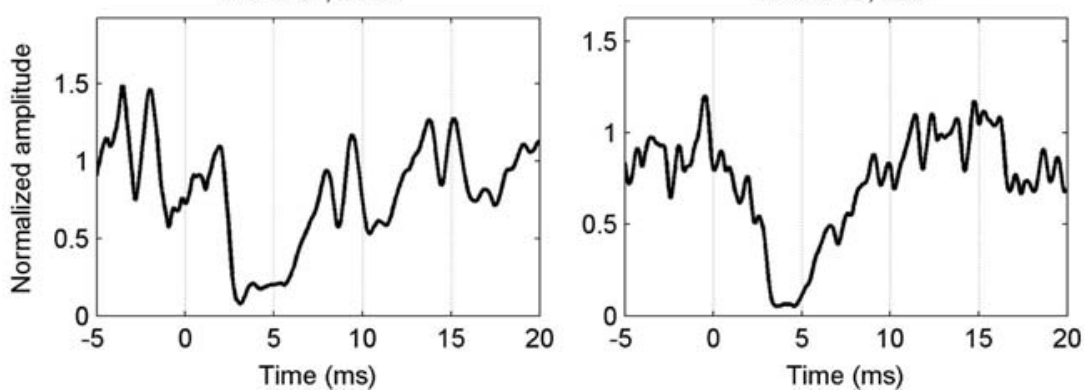

Fig. 10 The top of the plot is the VLF signal recorded after a +CG on 16 July 2004 at 23:07:03.848 UT and the respective MF signal spectrogram. The horizontal lines in the spectrogram are due to medium wave radio transmissions and the vertical line at the triggering time $(t=0)$ is the return stroke MF signal. The lightning characteristics are shown at the right of the VLF plot (distance and azimuth relative to AVF). The 4 panels at the bottom of the figure are the normalized filtered radio signals (normalization with the value of the signal in the milliseconds preceding the return stroke). The radio frequency and the azimuth of the transmitter, with respect to the location of AVF, are given in the respective panels. Strong absorption of the MF radio waves is observed about $1 \mathrm{~ms}$ after the lightning electromagnetic signal at time 0 in the top figure. This absorption affects radio propagation at different azimuths and distances from the lightning, indicating a very large disturbed area ( $\sim 200 \mathrm{~km}$ radius) (Farges et al. 2007)

been studied by Farges et al. (2007) based on the effects of about 4000 return strokes on nine chosen radio transmission signals. The main characteristics of the perturbation are a mean peak attenuation of $12 \mathrm{~dB}$, an onset time of less than $1 \mathrm{~ms}$, and duration from 3 to $10 \mathrm{~ms}$. Peak attenuations and durations are roughly proportional to the lightning-induced 
peak current. The perturbations have a circular structure centred over the return stroke and reach distances as large as $\sim 250 \mathrm{~km}$. Almost all return strokes having a peak current higher than $60 \mathrm{kA}$ perturb radio signals passing through the ionospheric D region at less than $250 \mathrm{~km}$ from the lightning.

The fading of the MF signals is consistent with impulsive heating of the electrons at $\sim 90 \mathrm{~km}$ altitude to $4-14 \mathrm{eV}$ by the EMP from the discharges, followed by cooling of the electrons with a time constant (from 0.1 to $100 \mathrm{~ms}$ ) that matches the recovery time of the signals. The absorption perturbation at MF reflection heights from EMP ionization must be relatively weak compared to that produced by EMP heating (20 dB below) because the recovery time for electron density enhancements is long (from 1 to $100 \mathrm{~s}$, typically $10 \mathrm{~s}$ ) in comparison with the MF signal recovery time. These perturbations are the MF radio signature of the EMP effect on the lower ionosphere, just as elves are their optical signature. This study shows the capability of this technique to monitor heating changes in the lower ionosphere, even for weaker EMPs that do not lead to enhanced ionization; it complements the VLF technique described above.

\section{Infrasound from Lightning and Sprites}

Infrasound is an acoustic pressure wave with frequencies below the human hearing threshold at $\sim 20 \mathrm{~Hz}$. The infrasound stations used during the campaigns are composed of four microbarometers (MB2000) that measure the relative pressure with a sensitivity of $10^{-3} \mathrm{~Pa}$, a band pass of $0.01-27 \mathrm{~Hz}$, and a sampling frequency of $20 \mathrm{~Hz}$. The measurements are used to identify natural infrasound sources and develop discrimination methods as part of the Comprehensive Test Ban Treaty verification procedures. A permanent station is located at Flers in the North West of France and a temporary station was set up in 2005, in the South West of France at St Just, some $400 \mathrm{~km}$ South of Flers to deduce the attenuation of infrasound with distance from the lightning source. Several natural and also anthropogenic signals have been measured by infrasound stations, including volcanic eruptions, aurorae, ocean swell, thunderstorms and meteoritic explosions (Blanc 1985), or shock waves from supersonic aircraft (Le Pichon et al. 2002).

\subsection{Infrasound from Lightning}

The thunderstorm of 9 September 2005 provided typical infrasound signals. The storm moved North East from the Bay of Biscay, passing just over the St Just station at around 23:00 UT. The observations are shown in Fig. 11. The right hand part of the figure shows the pressure signals recorded at both stations from 18:00 to 03:00 UT. At St Just, the pressure reaches $20 \mathrm{~Pa}$ peak-to-peak when the storm was just over the sensors, whereas it never exceeds $1 \mathrm{~Pa}$ peak-to-peak at Flers. The amplitude of the infrasound produced by lightning is higher than the mean signal level when lightning is close to the station. The lightning-induced infrasound amplitude is lower than the noise when it is located $50 \mathrm{~km}$ or more from the sensor. When the storm is just over the St Just station, the amplitude at $1 \mathrm{~Hz}$ is $40 \mathrm{~dB}$ higher than the noise level. The spectrum of the lightning-induced infrasound is very flat from 0.1 to $10 \mathrm{~Hz}$. These measurements show that infrasound produced by lightning and measured at St Just is not detected at Flers, $400 \mathrm{~km}$ away. Other signals, recorded during a thunderstorm close to the station and having very large and continuous azimuth dispersion (more than $100^{\circ}$ ), are presumably associated with intracloud (IC) lightning over an extended area, termed spider lightning. 

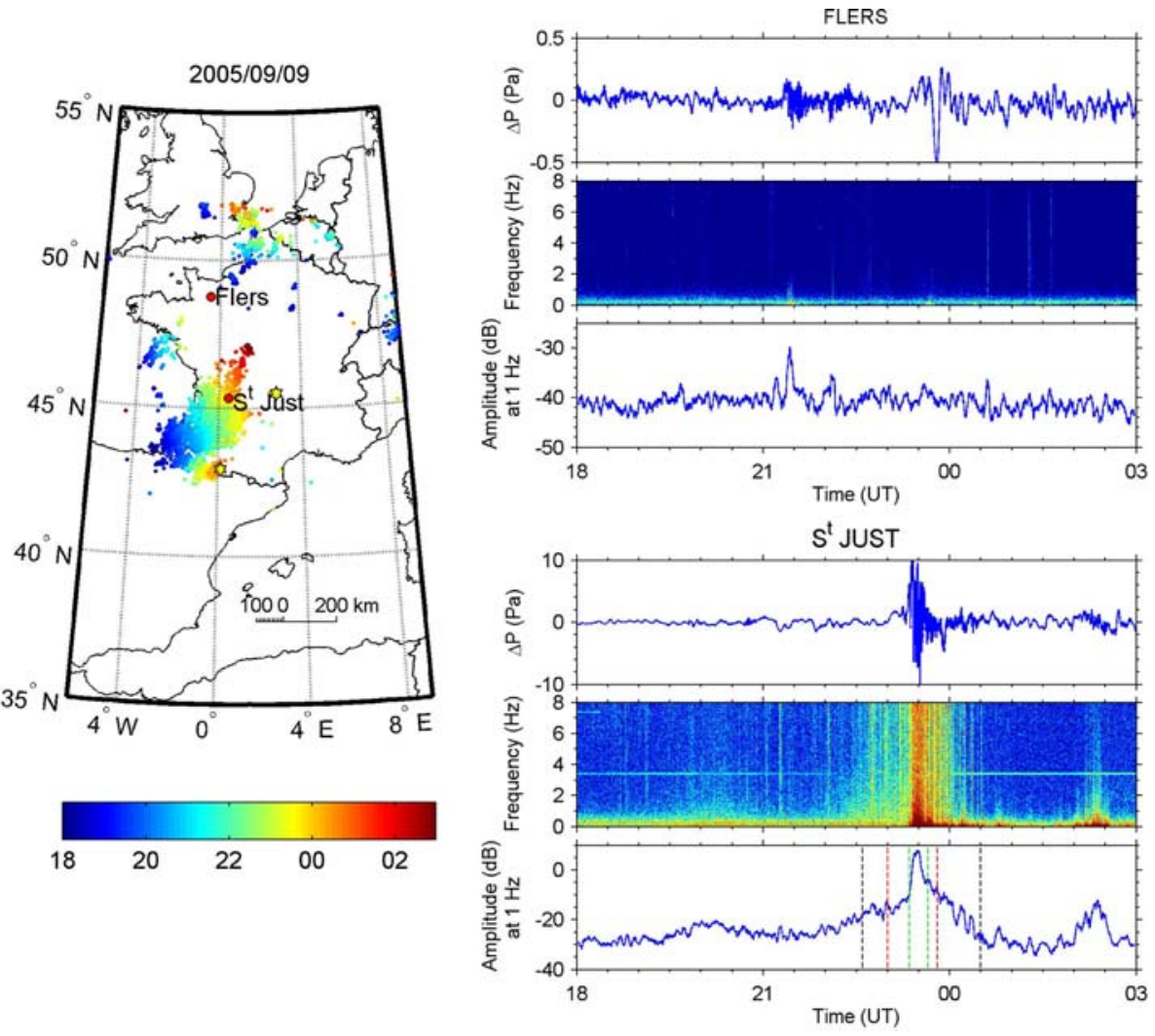

Fig. 11 (Left) Map of lightning recorded on 9 and 10 September 2005, from 18 to 03 UT, with the locations of the Flers and St Just infrasound stations (red circles) and of camera sites (yellow stars) shown. (Right) Overpressure signal, its spectrogram and the amplitude at $1 \mathrm{~Hz}$ recorded at Flers (top) and St Just (bottom). On the St Just amplitude at $1 \mathrm{~Hz}$ plot, the vertical dashed lines indicate the mean distance of the storm: less than $50 \mathrm{~km}$ (black), $20 \mathrm{~km}$ (red) and $10 \mathrm{~km}$ (green)

\subsection{Infrasound from Sprites}

Infrasound waves from sprites were suggested by Liszka 2004), who had noticed a chirp signature in the spectrograms of infrasound detected by a network of sensors in Sweden already in 1995 (Liszka and Hobara 2006). Unfortunately, no simultaneous sprite images were recorded to confirm or refute this hypothesis. These came for the first time during the EuroSprite 2003 campaign where both types of measurements were made (Farges et al. 2005). Examples of the data obtained are shown in Fig. 12. Considering the propagation time of infrasound waves from the source using a ray-tracing model, a clear correlation was found between infrasound signatures and optically identified sprites by cameras at Observatoire Midi-Pyrénées, and over Corsica, to distances up to $1000 \mathrm{~km}$ from the Flers infrasound station. A model study shows that a vertically extended cylindrical volume with a radial dimension of the order of several tens of meters placed in the mesosphere and heated by $5^{\circ} \mathrm{K}$, consistent with previous analyses ( Pasko et al. 1998), is sufficient to explain the amplitude of infrasound from a sprite (Pasko and Snively 2007). The result supports the ideas advanced by Farges et al. (2005) that the chirp-shape can be explained 


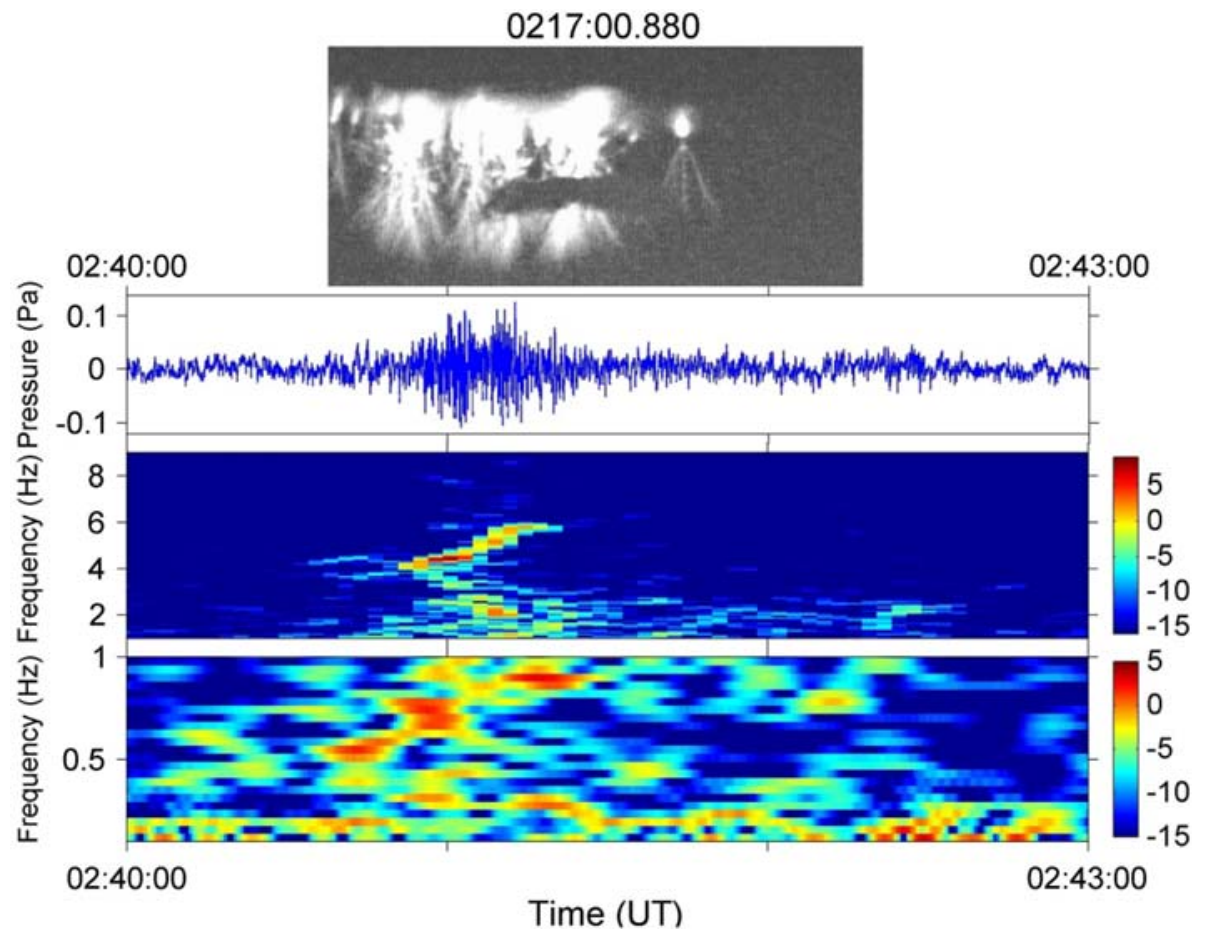

Fig. 12 Image of sprites observed from Observatoire Midi-Pyrénées at 02.17:00 UT on 21 July 2003, and the characteristics of the associated infrasound signals. The infrasound spectrograms are given for two ranges, $1-9 \mathrm{~Hz}$ (upper) and $0.1-1 \mathrm{~Hz}$ (lower), with the colour scales being in $\mathrm{dB}$. The infrasound signal was observed at the Flers station at 02.40:50 UT. The propagation delay of $23 \mathrm{~min}$ is consistent with a source to receiver distance of about $400 \mathrm{~km}$, computed using a ray tracing model (Farges et al. 2005)

by the horizontal size of the sprite. The sprite-correlated infrasound signatures are characterized by durations of several tens of seconds, which are well correlated with the physical (horizontal) dimensions of sprites observed optically.

During the night of 21 July 2003, infrasound chirp signals were detected after the cameras were shut down because of the approaching dawn (Farges et al. 2005). Several chirp-shaped infrasound waves were measured from 3:50 to 6:00 UT. For the cameras, dawn starts when the Sun is $12^{\circ}$ below the horizon, i.e. at 3:50 UT on this date. However, D-region ionization starts to increase from 04.45 UT. The conductivity of the middle atmosphere is thus expected to remain the same up to this time. The infrasound station observed 3 sprites up to about one hour after illumination of the D-region (from 4:45 to 6:00 UT). After 6:00 UT, the conductivity had reached such a level that the electric field produced by lightning is below the threshold for breakdown. The result shown in Fig. 13 is consistent with the conclusions of Stanley et al. (2000) based on ELF signatures of sprites near sunrise.

It is concluded that the detection of sprites by infrasound is an attractive alternative to optical detection, as it is not limited by clear viewing conditions or by the absence of daylight. The infrasound signature is so characteristic that it makes automated detection of sprites possible (Ignaccolo et al. 2008) (see Sect. 6). The automatic detection of sprites in infrasound data opens up the possibility of an interesting scientific use of data obtained by the infrasound stations of the Comprehensive Test Ban Treaty monitoring network. 


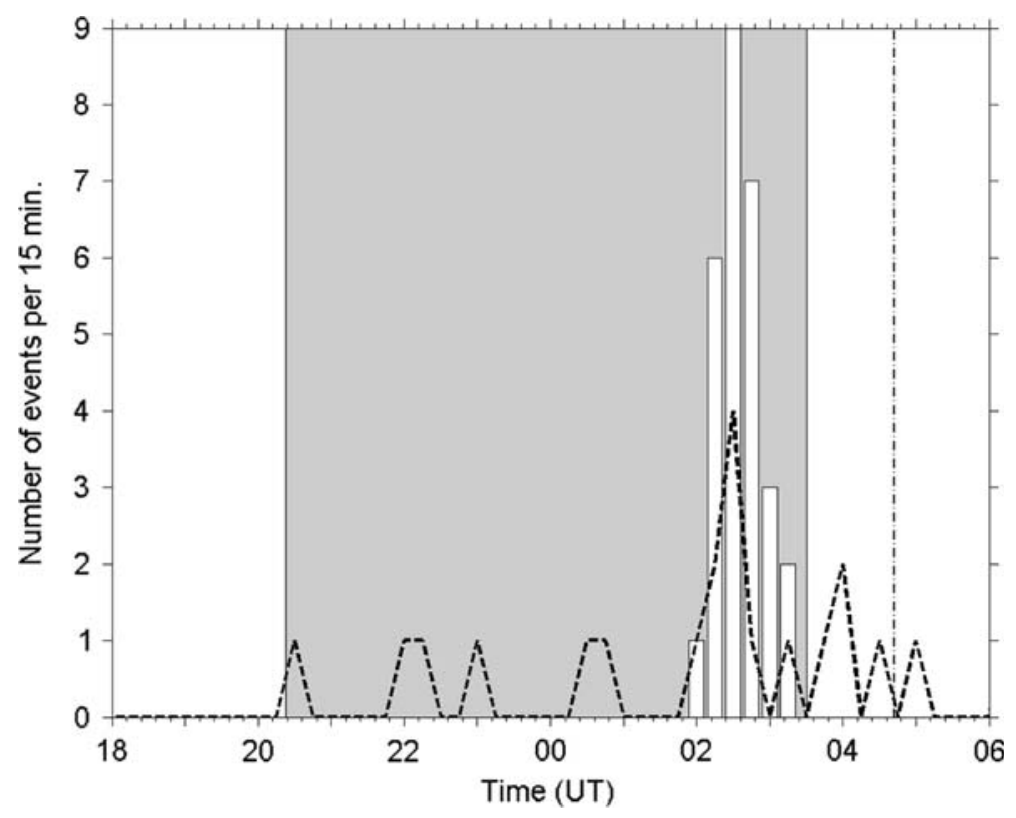

Fig. 13 The number of sprites per quarter of an hour observed from Observatoire Midi-Pyrénées on 20 and 21July 2003 (full line, vertical bars) and the number of infrasound chirps per quarter of an hour measured at Flers (dashed line). The grey zone indicates night-time, using nautical sunset/sunrise times; the vertical dash-dot line marks the time of sunrise in the D-region

\section{Electromagnetic Radiation from Lightning and Sprites}

The electromagnetic (EM) radiation from electric discharges in the atmosphere can be observed to large distances of $\sim 1000 \mathrm{~km}$ or more. The frequency bands of the radiation emitted are determined by the time scales of different processes acting in the discharges, making EM radiation a powerful tool for studying lightning and TLEs. Since a sprite is triggered by a lightning discharge and therefore occurs almost simultaneously with it, it is a challenge to separate the radio signature of a sprite from that of the causative lightning discharge.

\subsection{Radiation at ULF}

The ultra low frequency (ULF) $(\sim 0.1-10 \mathrm{~Hz})$ signals of + CGs that generate sprites and those that do not were investigated in a one-to-one case-study and in a statistical approach which included 240 strong $+\mathrm{CG}$ events. The ULF observations were at the southernmost Finnish station of Nurmijärvi (NUR), whose average great circle distance from the European thunderstorms studied during the EuroSprite campaigns is $\sim 2000 \mathrm{~km}$.

The pulsation magnetometer used here is optimized for the observation of long period geomagnetic pulsations (period range $\sim 200$ to $0.1 \mathrm{~s}$ ); it is almost insensitive to broad-band electromagnetic emissions which originate from processes characterized by time scales from microseconds to some tens of $\mathrm{ms}$, the dominant time scales of lightning discharge and sprite processes (Füllekrug et al. 2006a). In spite of this fact a large proportion of lightning discharges produce a detectable trace in the recordings of pulsation magnetometers around the world (Fukunishi et al. 1997). This is because, in association with the lightning flash, 
there are secondary and/or tertiary processes having much longer time scales which emit electromagnetic waves as well. This is a fundamental point when searching for a unique signature in the ULF-range to sprite-associated lightning flashes.

From the original Météorage data set of cloud-to-ground lightning discharges occurring over France, a subset was created (list 1) of only those +CG and -CG events which stem from the same thunderstorm centres as observed optically by the CAL cameras. The CAL list of sprite-associated +CG events is a subset of list 1 (termed list 2). Using both lists, those $+\mathrm{CG}$ events which are followed by a sprite might be distinguished from those which are not. The general properties of the ULF response to sprite-associated lightning flashes were then collected and analysed, and their properties compared with those of a control group not associated with a sprite.

The comparison did not reveal any unique and identifiable ULF signatures relating to sprites (Bösinger et al. 2006). The analysis resulted, however, in categorizing a collection of ULF responses to +CG (and actually also to $-\mathrm{CG}$ ) discharges, which has not- to our knowledge- been compiled so far in a similar systematic fashion. Some of the properties of ULF responses to +CGs have already provoked subsequent investigations (Shalimov and Bösinger 2006, 2008). One typical result of the superposed epoch analysis is shown in Fig. 14. All responses represent single, isolated, strong events, the so called Q-bursts (Ogawa et al. 1967), which exceed the average natural background noise level (primarily caused by world-wide thunderstorm activity) by at least an order of magnitude.

It is essential to be certain of the selection of non-sprite-associated +CGs forming the control group; this is not trivial since sprites can be missed for various reasons such as

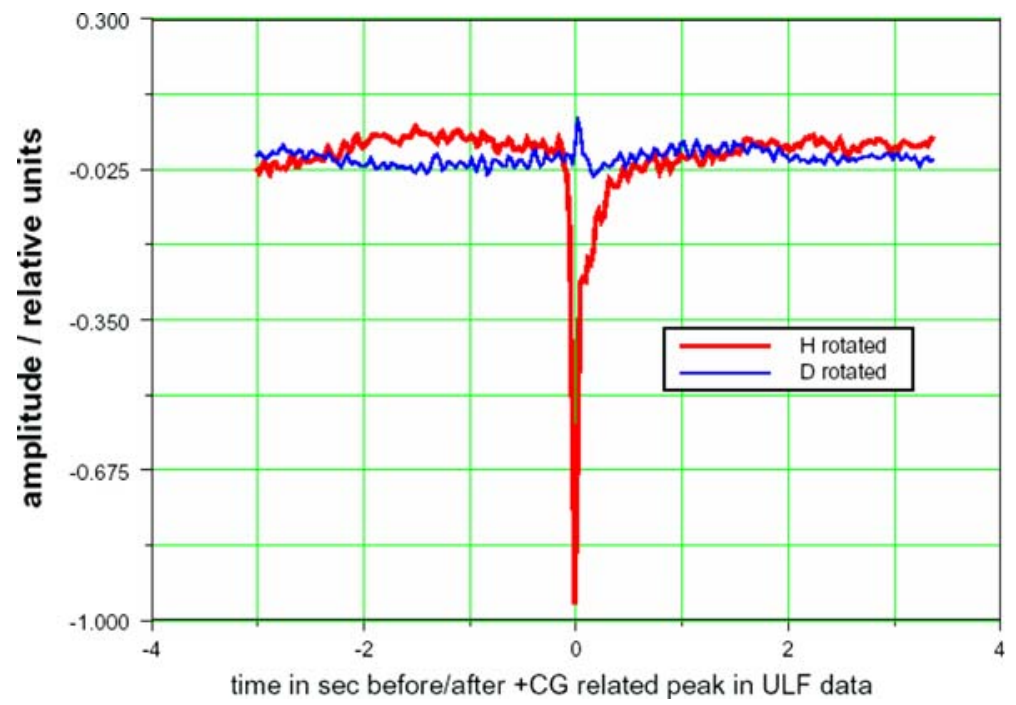

Fig. 14 The result of superposing the ULF response at NUR of 32 clean and isolated +CG events which were all associated with sprites; the plot for the control group looks similar. The data have been corrected for the frequency and phase response of the instruments, and the coordinate system was rotated such that the response maximizes (in absolute terms) in one component (H-component). This was achieved by rotating the horizontal H-D plane of the Cartesian coordinate system $(\mathrm{H}, \mathrm{D}, \mathrm{Z})$ around its vertical Z-axis. The rotation angle is chosen such that the disturbance minimizes for the D-component (East-West orientation). The zero time represents the data point with the minimum (or peak) value in the rotated H-component (North-South orientation). The individual time series in the superposition were normalized to this minimum. The small deflection in this component indicates an almost totally linearly polarized disturbance vector. The amplitudes of these Q-bursts were of the order of 10 pT (Bösinger et al. 2006) 
clouds, light pollution, low emission intensities or simply because the camera's field of view (FOV) does not cover the entire thunderstorm cell with active lightning. This difficulty was overcome by using the same data set as Haldoupis et al. (2004) and Mika et al. (2005); the one-to-one association found by these authors already implied the pinpointing of every +CG within the camera's FOV. Moreover, their various VLF links crossing the thunderstorm regions studied provided additional information on sprite occurrence.

\subsection{Radiation at ELF}

Extremely Low Frequency (ELF) electromagnetic radiation, ranging from $8 \mathrm{~Hz}$ to $3 \mathrm{kHz}$, from particularly intense lightning discharges and sprites can be used for remote sensing of both types of discharge. Since the ELF radiation propagates over long distances within the Earth-ionosphere cavity, the recordings can be used to determine global occurrence rate of sprites (see Sect. 6).

Sprites are produced by + CG discharges (Boccippio et al. 1995), with the lightning having a strong continuing current (Reising et al. 1996), and they cause Earth-ionosphere cavity (or Schumann) resonances (Füllekrug and Reising 1998). The sprite appears $\sim 5 \mathrm{~ms}$ after the causative lightning discharge and radiates ELF electromagnetic waves (Cummer et al. 1998) as a result of mesospheric breakdown (Füllekrug et al. 2001).

To study the influence of the natural atmospheric variability on the generation of sprites, a model of lightning electric fields above thunderstorms was developed (Füllekrug 2006). The model uses typical parameters of particularly intense positive lightning discharges which cause sprites. For this, the charge transfer within intense lightning discharges needs to be determined.

A mean lightning current waveform was inferred from the recordings of 52,510 intense lightning discharges (Füllekrug et al. 2006b) made with a global network of ELF magnetometers (Füllekrug and Constable 2000). It was found that the lightning current initially decays with a time constant of $\sim 2 \mathrm{~ms}$ and that it lowers $\sim 60 \mathrm{C}$ from cloud to ground within the first $\sim 10 \mathrm{~ms}$ of the discharge. The subsequent continuing current exhibits a decay time constant of $\sim 40 \mathrm{~ms}$ and lowers $\sim 170 \mathrm{C}$ from cloud to ground within the next $\sim 100 \mathrm{~ms}$. The current associated with the total charge transfer of $\sim 230 \mathrm{C}$ from cloud to ground deposits electrical energy in the middle atmosphere via quasi-static (Joule) heating. The energy deposition is dominated by the lightning continuing current and is $\sim 10^{-5} \mathrm{Jm}^{-3}$ at $30 \mathrm{~km}$ altitude. The associated peak electric field in the mesosphere is generally not sufficient to produce conventional breakdown, such that the natural variability of other physical parameters seems to be important for sprite production. The least known parameters in the model are the altitude and the horizontal extent of the lightning discharge which causes a sprite, and also the atmospheric conductivity which can vary by an order of magnitude, e.g., between day and night. The atmospheric conductivity above thunderstorms may be strongly influenced by the electrical activity within the thunderstorms themselves through quasi-static heating.

\subsection{Radiation at Higher Frequencies}

In 2003 and 2004, four stations were deployed in France to observe electromagnetic radiation from lightning and sprites. The objective was to measure the vertical electric field across the frequency ranges from VLF (3-30 kHz) to LF (30-300 kHz), MF (0.3-3 MHz) and HF (3-30 MHz), and to detect the possible burst of radiation associated with the runaway breakdown process (Roussel Dupré et al. 2002; Gurevich and Zybin 2004). In 2003, possible 
radio emissions were correlated with observations of CG discharges made by Météorage with optical observations of sprites made from the Observatoire Midi-Pyrénées.

Weak HF emissions, i.e. enhancements of the signal from 0.5 to $3 \mathrm{MHz}$, were measured during the time interval when sprites were observed. The system recorded HF signals for 58 of 133 sprites observed in 2003 (Appendix 1). To prevent any confusion between radiation from lightning and from sprites, we select only events for which no CG discharge is observed during the time interval where a sprite is observed with the camera $(20 \mathrm{~ms}$ exposure time). 8 events were kept after this selection, with HF bursts being associated with sprites in 5 cases, or $\sim 60 \%$.

In several cases, HF emissions were recorded simultaneously with VLF emissions which are presumably either from the sprite or from intracloud (IC) lightning, which has been associated with carrot sprites (van der Velde et al. 2006). With at least three receiver stations, it is possible to localize the source of the VLF signals. Figure 15 shows the image of a sprite
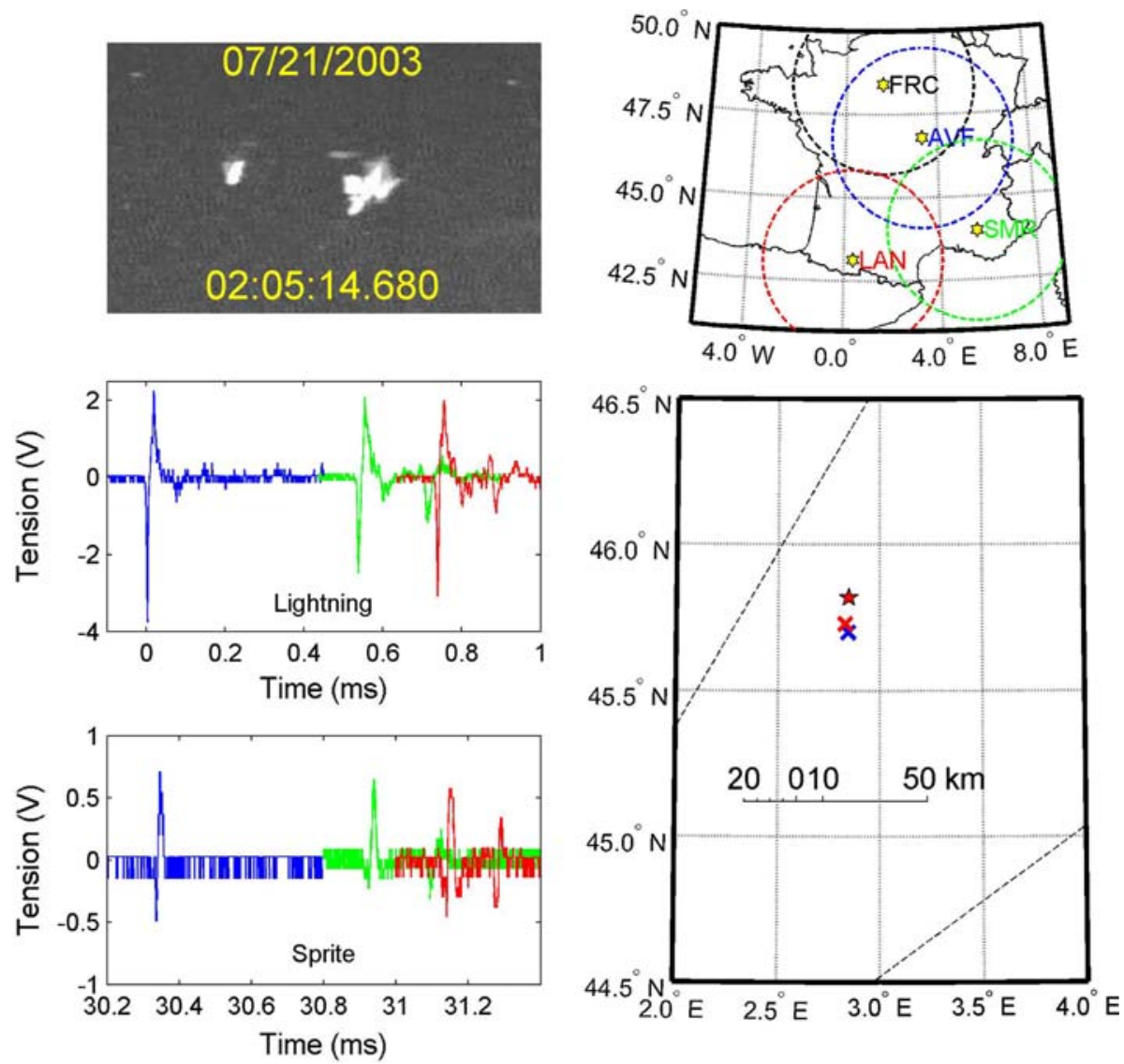

Fig. 15 VLF radiation from lightning and/or sprite. (Left, top) sprite image at 02.05:14.668 UT 21 July 2003, (left, middle) waveforms of the lightning, observed at the station AVF in blue, at SMR in green and at LAN, (left, bottom) waveforms of the sprite with the same colour presentation, (right, top) location of Commissariat à l'Energie Atomique (CEA) stations, (right, bottom) lightning localisation by Météorage (blue cross), and lightning (red cross) and sprite (red star) localisations using CEA station data. The dashed lines represent the camera field of view (FOV) 
taken on 21 July 2003 at 02:05:14.680 UT, from 12 to $32 \mathrm{~ms}$ after the parent lightning. Also shown is the VLF signal induced by the parent lightning and a second signal $30 \mathrm{~ms}$ after that, within the time interval of the optical observation. The triangulation calculation locates the lightning (red cross) as being only $1 \mathrm{~km}$ away from the location given by Météorage (blue cross), which corresponds to the precision of the Météorage localisation. The location of the second VLF signal is $10 \mathrm{~km}$ away (red star), a separation distance which is often observed. The second VLF signal is due either to a CG with a very weak peak current or to an IC discharge, both undetected by Météorage, or to the sprite itself.

\section{The Global Rate of Sprites}

An assessment of the planetary rate of sprite events is necessary to determine the global impact of sprites on the properties of the atmosphere such as perturbations to the chemical composition, mesospheric conductivity and the global electrical circuit. However, almost 20 years after the first sprite observations, the rate of sprite occurrence over the Earth is yet to be reliably determined. Several estimates of the planetary rate of sprite events have been made. These estimates range from 0.5 to 33 sprites per minute (Sato and Fukunishi 2003; Yair et al. 2004; Blanc et al. 2004).

\subsection{Algorithm to Estimate the Global Sprite Rate}

A new formula to find the planetary rate of sprite events has been developed based on remote sensing strategies, for various detectors of optical, infrasound and radio wave sprite signatures (Ignaccolo et al. 2006). The formula uses the number of detected sprites, the detection efficiency and the false alarm rate of each detector along with spatial and temporal effectiveness functions. The formula estimated an average planetary rate of sprite events of $\sim 2.8$ per min, with an accuracy of a factor $\sim 2-3$. The proposed formula is general, and can be used to calculate the occurrence rate of any physical event detected by remote sensing.

An important element for determining the planetary rate of sprite events is the newly discovered infrasound signature of sprites for which an automated detection algorithm has been developed (Ignaccolo et al. 2008). Three different methods were compared to detect the sprite infrasound signature (chirps) automatically in random background noise: (1) the standard deviation detector uses the signal-to-noise ratio of the measurements, (2) the spectral covariance detector uses the spectrogram to detect the spectral features of chirps in background noise, and (3) the "Complex Analysis of Sequences via Scaling AND Randomness Assessment” (CASSANDRA) detector (Allegrini et al. 2002; Allegrini et al. 2003) uses diffusion entropy analysis to detect periodic patterns such as chirps in noise. All three detectors were applied to the observed infrasound recordings to detect the chirps produced by sprites. It was found that the CASSANDRA detector provided the best trade-off between the false alarm rate and the detection efficiency for automated sprite detection. With optimised parameters, the algorithm achieved a null false alarm rate with a detection efficiency of $\sim 66 \%$.

\section{Perturbations to the Global Atmospheric Electric Circuit}

Thunderstorms around the world are one important generator which powers the Earth's electric circuit. Thunderstorms, generally being primarily positive at the tops of clouds, 
drive an electric current up to the electrically good conducting ionosphere, which distribute the currents and the associated electrical potential globally. Currents flow back to the Earth in the fair weather regions, where these currents are of the order of $10^{-12} \mathrm{~A} / \mathrm{m}^{-2}$ and the electric field at ground level is $\sim 120 \mathrm{~V} / \mathrm{m}$, directed downwards. The Earth's global atmospheric electric circuit is reviewed within the wider field of planetary atmospheric electricity in a comprehensive new book (Leblanc et al. 2008). In this paper, studies of the global electric circuit have been undertaken to estimate the effects of lightning discharges and sprites, as outlined below.

\subsection{The Circuit Model of a Thunderstorm and the Atmospheric Electric Circuit}

Using the commercially available electrical engineering software package PSpice (Personal SPICE-Simulation Program with Integrated Circuit Elements), a novel model for the operation of the global atmospheric electric circuit has been developed. Shown in Fig. 16, this consists of a current generator $I_{O}$ representing the $\sim 1000$ thunderstorms that are active at any one time. A "battery" between the thunderclouds' negative charge at $5 \mathrm{~km}$ altitude and the positive charge at $15 \mathrm{~km}$ drives an upward current which maintains the potential of the ionosphere at $80 \mathrm{~km}$ altitude at up to $\sim 300 \mathrm{kV}$ with respect to the Earth. The values of the resistors $\mathrm{R}_{1}, \mathrm{R}_{2}$ and $\mathrm{R}_{3}$ are derived from a model of the height profile of the electrical conductivity of the atmosphere such that, using Ohm's law, the current flowing in the circuit is $\sim 1000 \mathrm{~A}$.

One particular thunderstorm is represented (see the central part of Fig. 16) by a current generator $I_{T}$, it being assumed that there are $80 \mathrm{R}$ components and $80 \mathrm{C}$ components, each representing a $1 \mathrm{~km}$ thick layer of the atmosphere (so that $i$ goes from 1 to 80). The values of the capacitors $C$ are derived from standard electrostatic theory for plane capacitors. Both the background, with a full literature survey, to this study and complete details of the

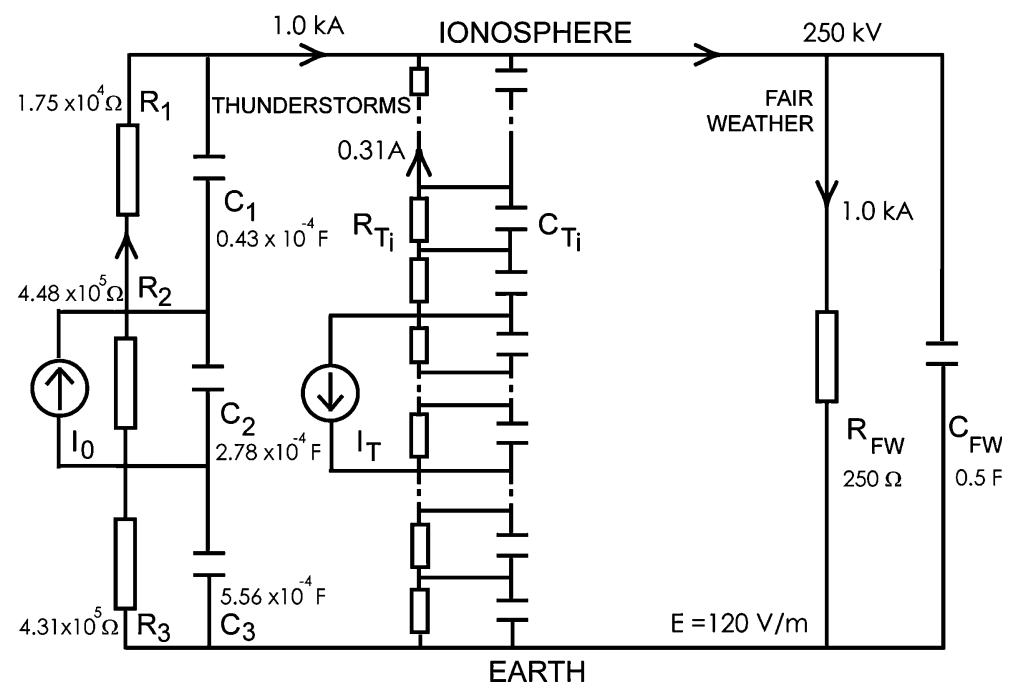

Fig. 16 Model circuit diagram (similar to that presented by Rycroft et al. 2007), representing 1000 thunderstorms worldwide generating $\sim 1 \mathrm{kA}$ flowing in the global atmospheric electric circuit through the fair weather resistance $\sim 250 \mathrm{ohms}$. The model of an isolated thunderstorm generating $+\mathrm{CG}$ discharges is shown in the centre 
model, together with its justification, have recently been presented by Rycroft et al. (2007). This model has, in fact, been extended to include currents generated by electrified shower clouds which are believed to be as important as those generated by thunderstorms.

The good conducting ionosphere is assumed to be an equipotential surface, as is the good conducting Earth. Between the two, in regions remote from thunderstorms and electrified shower clouds, and termed the fair weather region (almost 98\% of the Earth's surface), there is a downward current, with a current density of $\sim 2 \mathrm{pA} / \mathrm{m}^{2}$. Near the Earth's surface there is a downward electric field, or a positive potential gradient (as height increases), of $\sim 120 \mathrm{~V} / \mathrm{m}$.

To simulate lightning discharges occurring in the atmosphere, voltage-controlled switches are included in the circuit in parallel with the thunderstorm $T$. A negative cloudto-ground lightning discharge having the median characteristics of observed lightning has been satisfactorily simulated. By inverting the polarity of the thunderstorm, a positive cloud-to-ground $(+\mathrm{CG})$ stroke has similarly been simulated.

\subsection{Some Results}

Two different $+\mathrm{CG}$ discharges from the region at $140 \mathrm{MV}$ at $5 \mathrm{~km}$ altitude have been modelled, to examine the differences in the effects on the mesosphere which may result in different kinds of upper atmosphere discharges such as sprites. Observations suggest, as mentioned in Sect. 2.2, that "column" sprites occur several ms after a +CG discharge with a large $(\sim 100 \mathrm{kA})$ return stroke current, while "carrot" sprites might be delayed by some tens of ms after a smaller $(\sim 30 \mathrm{kA})$ return stroke current with a strong continuing current caused by the redistribution of charges by preceding inter-cloud (IC) lightning activity. Here, the first modelled $+\mathrm{CG}$ discharge (A) as a return stroke with $110 \mathrm{kA}$ peak current lasting $0.2 \mathrm{~ms}$, while the second (B) is a $+\mathrm{CG} 30 \mathrm{kA}$ return stroke lasting $0.2 \mathrm{~ms}$ and a continuing current of $2 \mathrm{kA}$ for $90 \mathrm{~ms}$. During the first discharge $20 \mathrm{C}$ is transferred to ground, whereas the second transfers $70 \mathrm{C}$ in total. With their image in the conducting Earth, these correspond to a dipole moment, termed the charge moment, of 200 and $700 \mathrm{C} \mathrm{km}$, respectively. The $+\mathrm{CG}$ discharges reduce the ionospheric potential everywhere by $\sim 10 \mathrm{~V}$ and $40 \mathrm{~V}$, respectively, in $\sim 20 \mathrm{~s}$. The ionospheric potential recovers with the $\sim 250 \mathrm{~s}$ RC time constant of the fair weather circuit. If there were to be ten such discharges around the world in $\sim 20 \mathrm{~s}$, as might well occur, the ionospheric potential would be reduced by between 100 and $400 \mathrm{~V}$.

Analysis of the changes of the vertical electric field above the thundercloud caused by the modelled $+\mathrm{CG}$ discharges reveals differences which can explain the occurrence of different types of sprites. Figure 17 shows the extent in altitude and time of regions above the thundercloud where the vertical electric field exceeds a certain threshold field, namely the breakdown threshold $\mathrm{E}_{\mathrm{b}}$ which has to be exceeded for the creation of streamers (see Sect. 8), and the thresholds required for sustaining the propagation of positive and negative streamers, $E_{p}$ and $E_{n}$, respectively (Pasko 2006). For the return stroke with the larger current, the region where the breakdown threshold field was exceeded occurs at altitudes from $\sim 80$ to $65 \mathrm{~km}$ within 0.01 to $1 \mathrm{~ms}$ after the current starts. A similar effect, but of much shorter duration (only $0.04 \mathrm{~ms}$ ) and lesser altitude extent ( $\sim 80$ to $75 \mathrm{~km}$ ) appears after the $30 \mathrm{kA}$ return stroke, but breakdown occurs again later at lower altitudes of $\sim 75$ to $65 \mathrm{~km}$. These modelled changes of electric field agree with the scenario that columniform sprites are created at higher altitudes ( 80 to $75 \mathrm{~km}$ ), with positive streamers propagating downwards, and with carrot sprites being more delayed and originating at lower altitudes $(\sim 65 \mathrm{~km})$, with both positive and negative streamers propagating 

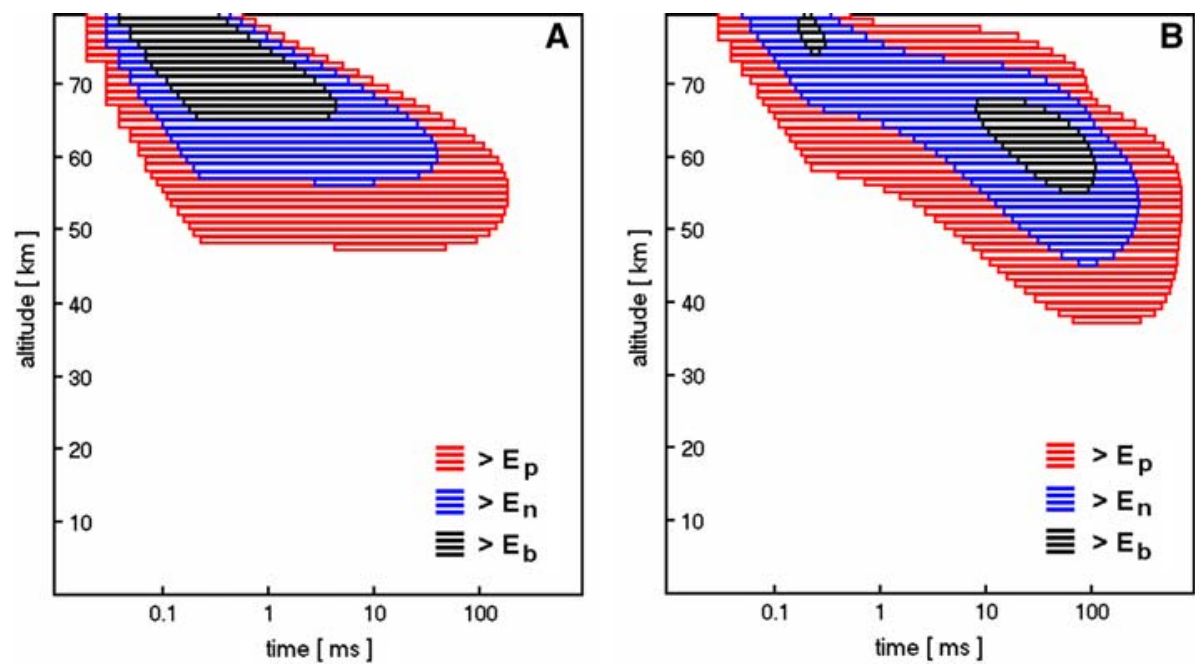

Fig. 17 Diagram showing the altitudes and times where and when three different breakdown threshold fields $\left(E_{b}, E_{n}\right.$ and $\left.E_{p}\right)$ are exceeded following + CG discharges $A$ (left) and $B$, with a continuing current (right). The electric field in both cases is always directed downwards. In the region where the threshold field $\mathrm{E}_{\mathrm{b}}$ is exceeded, streamers can be created and propagate. Positive streamers propagate downwards where the magnitude of the electric field is greater than $\mathrm{E}_{\mathrm{p}}$; negative streamers propagate upwards where the magnitude of the electric field is greater than En. During discharge $\mathrm{A}, \mathrm{E}_{\mathrm{b}}$ is exceeded $\sim 0.1 \mathrm{~ms}$ after the onset of the return stroke at the ionosphere, and down to $\sim 65 \mathrm{~km}$ after a few ms. During B, between 0.17 and $0.21 \mathrm{~ms}$ after the return stroke onset, this region is created at $\sim 78 \mathrm{~km}$ where a sprite halo may be produced. Then similar conditions are created $\sim 10 \mathrm{~ms}$ after the return stroke onset at $\sim 65 \mathrm{~km}$; a situation which lasts for several tens of ms at altitudes $>55 \mathrm{~km}$. Also at this time the threshold for the formation of positive and negative streamers is exceeded over a wide range of altitudes, so that the sprite can be produced by both downward and upward propagating streamers over a height range of $\sim 30 \mathrm{~km}$

downwards and upwards, respectively (Stanley et al. 1999; McHarg et al. 2007, and references therein).

The sprite is modelled as a region of significantly increased conductivity, $\sim 10^{-7} \mathrm{~S} / \mathrm{m}$, expanding downwards to $50 \mathrm{~km}$ altitude with a velocity of $10 \mathrm{~km} / \mathrm{ms}$, again using switches. Sprite A (column-like) starts with the closing of the first switch at $80 \mathrm{~km}$, each switch representing the volume above the thunderstorm of thickness $1 \mathrm{~km}, 0.1 \mathrm{~ms}$ after the $110 \mathrm{kA}$ return stroke. For the carrot-like sprite B, the switch at $65 \mathrm{~km}$ closes first, $10 \mathrm{~ms}$ after the $30 \mathrm{kA}$ return stroke and during the $2 \mathrm{kA}$ continuing current. In this case the upward propagation of a sprite was modelled by subsequently closing switches from 65 to $80 \mathrm{~km}$, starting at $10.5 \mathrm{~ms}$, thereby contributing to the spatial and temporal development of the sprite. One ms after sprite A starts it has developed down to $70 \mathrm{~km}$, and a further $1 \mathrm{~ms}$ later (at sprite time, $\mathrm{t}_{\mathrm{s}}=2 \mathrm{~ms}$ ) down to $60 \mathrm{~km}$. On the other hand, sprite B developed down to $65 \mathrm{~km}$ in $1 \mathrm{~ms}$, and a further $1 \mathrm{~ms}$ later (at sprite time ts $=2 \mathrm{~ms}$ ) down even to $45 \mathrm{~km}$ and up to $80 \mathrm{~km}$. These features are clearly seen in the middle four panels of Fig. 18. Breakdown occurs where and when the profile is shown in bold; large electric fields remain in this region for some tens of ms. Both sprites A and B reduce the ionospheric potential globally by only $\sim<2 \mathrm{~V}$. If there were to be two sprites in $20 \mathrm{~s}$, the potential of the ionosphere would be expected to change by $\sim<3 \mathrm{~V}$. Associated with the sharp vertical changes of electric field there are charge layers, as shown in the various panels of Fig. 18. These are especially marked at the top and bottom of the thundercloud and also at the top and bottom of the sprite. 
Fig. 18 Changes of the vertical electric field above a

thundercloud caused by a model +CG discharge and a subsequent sprite are shown: the left hand panels are for discharge $\mathrm{A}$ and sprite $\mathrm{A}$, whereas the right hand panels are for discharge $B$ (with a continuing current) and sprite B, at various times after the return stroke starts. The bold line shows where $E_{b}$ is exceeded. Sprite A, initiated at $80 \mathrm{~km}$ at $0.1 \mathrm{~ms}$ after the return stroke field reaches $80 \mathrm{~km}$, propagates downwards, reaching down to $45 \mathrm{~km}$ in $3.5 \mathrm{~ms}$. Sprite B is initiated at $65 \mathrm{~km}$, after $10 \mathrm{~ms}$, and propagates both downwards to $45 \mathrm{~km}$ and upwards to $80 \mathrm{~km}$, in $2 \mathrm{~ms}$. The occurrence of a sprite reduces the electric field above the thunderstorm at sprite altitudes. The situation depicted here is more complicated than that shown by Rycroft et al. (2007)

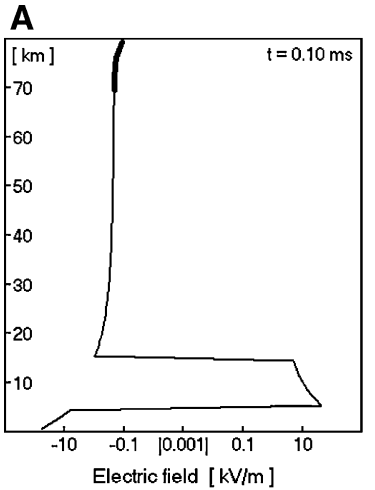

\section{B}
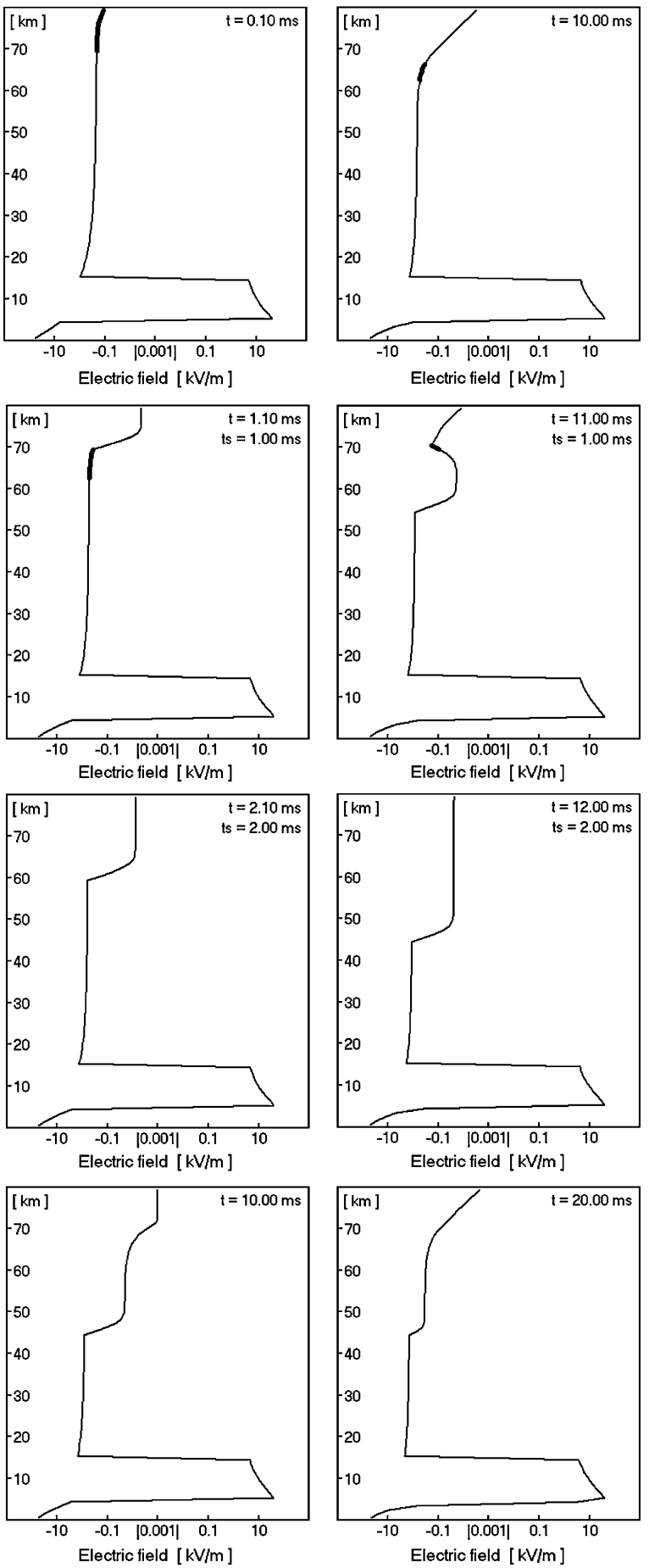
During the EuroSprite campaigns, events similar to sprite A were observed on 26 September 2005 at 01:49:15.291-332 UT (on one video frame having a duration of $41 \mathrm{~ms}$ ) and at 03:10:29.186-227 UT, and also on 17 August 2006 at 22:58:46.203-244 UT. Sprites similar to sprite B were recorded on 29 July 2005 at 01:32:51.249-333 UT, on 17 August 2006 at 23:38:07.736-789 UT and on 13 October 2006 at 22:17:00.597-634 UT.

These results indicate that, whilst there can be strong effects above a thundercloud following a +CG lightning discharge, these are not expected to have any effects which might be noted on the global scale. For example, the fair weather electric field would change by only $\sim 0.01 \%$ following one of these model $+\mathrm{CG}$ discharges, or by less than 1 part in $10^{\wedge} 5$ after two model sprites occurring in $20 \mathrm{~s}$.

\section{Particle Kinetic Simulations of the Sprite Discharge}

Electric discharges in gases can take a number of forms. The most well known discharge in the atmosphere is lightning between electrically charged regions of a cloud or from a cloud to the ground. Although lightning has been studied for many years, there are still new aspects of this natural phenomenon. While observations of X-and $\gamma$-rays associated with the charging of clouds dates back to the 1980s (Parks et al. 1981; McCarthy and Parks 1985; Eack et al. 1996), the discovery of $\mathrm{X}$ - and $\gamma$-rays in association with lightning is only a few years old (Moore et al. 2001). It is thought that X- and $\gamma$-rays are bremsstrahlung radiation from energetic electrons accelerated in the electric fields of clouds and lightning (Gurevich et al. 1992, 1999; Roussel-Dupré et al. 1994). The study of this phenomenon has gained momentum with the discovery from space of bursts of $\mathrm{X}$ - and $\gamma$-rays observed by satellite from regions of the atmosphere above thunderstorms (Fishman et al. 1994; Smith et al. 2005).

Laboratory studies of electric discharges date back to the late nineteenth century, and many of the fundamentals of the discharge process are now well established (Raizer 1997). The characteristics of laboratory discharges depend on the medium in which they occur and the boundary conditions such as electrode geometry, material, applied voltage, etc. At ground pressure in air, the electrical breakdown voltage is $\sim 3 \mathrm{MV} / \mathrm{m}$. The breakdown voltage is inversely proportional to the gas density $\mathrm{N}$ in which the breakdown occurs, and often the "reduced" electric field $\mathrm{E}_{\mathrm{r}}=\mathrm{E} / \mathrm{N}$ is used to characterise the electric field in a gas (The unit of this reduced electric field is the Townsend (Td), where $1 \mathrm{Td}=10^{-21} \mathrm{Vm}^{2}$ ).

Discharges may develop from a single electron which spawns additional electrons by collisionally ionizing the gas, creating an ionization avalanche. When the avalanche has grown in magnitude to the point where the space charge fields are significant relative to the background electric field, the avalanche can develop into a streamer. The streamer creates an ionization path through the gas that may allow additional charge to flow into the streamer path from the electrodes. The streamer then becomes a leader, with a high electron density and a small electric field within the highly conducting leader region. The development of this chain process may occur in steps; a streamer propagates a limited distance and stops until the streamer region is again filled with electrons, turning the region into a leader and bringing with it the electric potential, and then continues from the tip of this region to send forth a new streamer. This process is well known in lightning, and is termed stepped leader propagation (Rakov and Uman 2003).

A streamer may propagate from the anode towards the cathode, i.e. in the direction of the electric field, and one speaks of a positive streamer, or against the electric field, which 
is a negative streamer. It is generally thought that the downward propagating elements of sprites to low altitudes are positive streamers while upward propagating elements are negative streamers. The upward and downward propagation of streamers are seen in highspeed video recordings of sprites (Cummer et al. 2006a; McHarg et al. 2007). It is interesting to note the fundamental difference between negative and positive streamers. For negative streamers electrons are accelerated in the direction of the streamer propagation and thus create the additional avalanche ionization needed ahead of the streamer. For positive streamers, electrons are accelerated against the propagation direction and a second ionization process is needed. This is either ionization from background electrons if the gas is partially ionized or ionization from photons emitted from the high electric field region of the streamer head. In the atmosphere, the energy of photons emitted by the nitrogen molecule — when excited - is sufficient to ionize the oxygen molecule (Zheleznyak et al. 1982). This reaction path is a fundamental process of atmospheric electric discharges.

Computer simulations of discharges are difficult because very high spatial resolution is required in the regions around the streamer tips where the space charge fields vary strongly (Ebert et al. 2006). Likewise, it is a problem to resolve the electron kinetics because of the exponential growth of the number of electrons in a discharge. For these reasons, only limited aspects of the problem have been simulated. Often, simulations are carried out in one dimension (1D) and/or in a fluid description. However, advances in computer speed, memory size and numerical techniques have allowed increasingly sophisticated simulations (Arrayás et al. 2002; Liu and Pasko 2004; Montijn et al. 2006). Some recent particle simulations of streamer development at sprite altitudes are presented here.

\subsection{The Simulation Model}

A computer particle code has been developed to study particle kinetics of electric discharges in air. The code is in $2 \mathrm{D}$ axi-symmetrical coordinates, simulating the development of an electron avalanche, its transition into a streamer and the propagation of the streamer. The code includes photoionization processes that allow the development and propagation also of positive streamers. However, effects of pre-ionisation of the atmosphere or negative ions are not considered, although they may affect positive streamer propagation (Pancheshnyi 2005). The code uses a Particle-In-Cell (PIC) technique with Monte Carlo collisions, where the charged particles are followed in a Cartesian mesh, the electric field is updated at grid-points from the charged particle densities and Poisson's equation, and collisions with neutral air molecules are random according to cross section probabilities (Birdsall 1991). The code is used to study streamer generation and propagation under atmospheric conditions of sprite ignition in the mesosphere and the associated particle acceleration and optical emissions. A detailed description of the code is given in Chanrion and Neubert (2008).

\subsection{Optical Emissions from Streamers at Sprite Altitudes}

By colliding with air constituents, the electrons of a streamer discharge excite the air molecules. Returning to their ground state, the excited air molecules emit photons producing optical emissions from the streamer. The main optical emissions of sprite streamers in the visible range come mostly from the 1st positive, 2nd positive and 1st negative nitrogen bands. From the Monte Carlo part of the code, one can calculate the production rate of excited neutrals along streamer simulation from which the optical emission rates can be derived by solving the transition equations. 

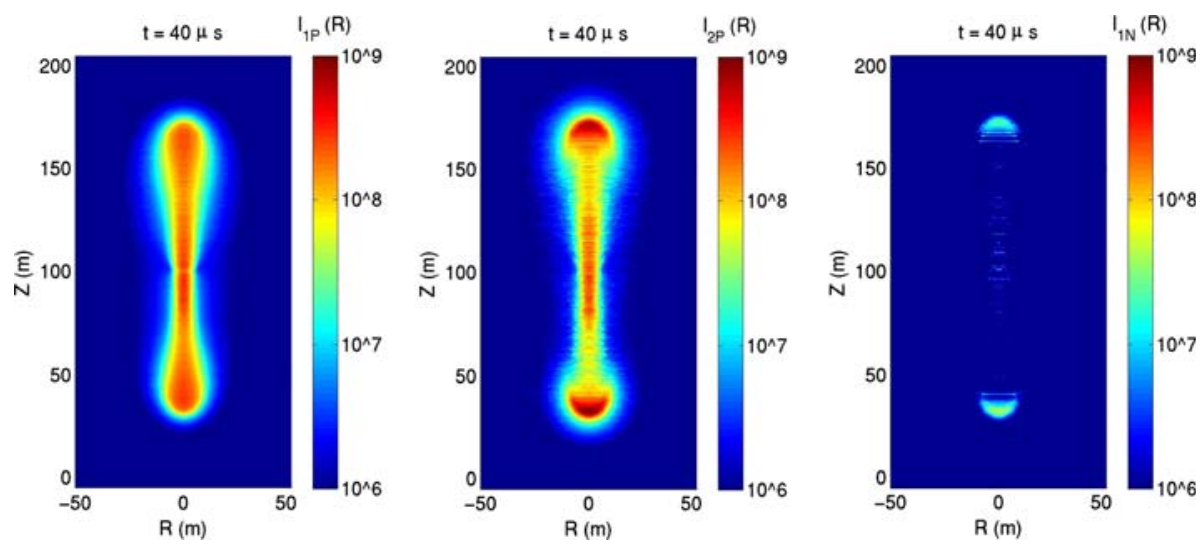

Fig. 19 Optical emission intensities for a streamer simulation at sprite altitude with the background field $E_{o}=1.5 E_{k}$. From left to right panel: nitrogen 1st positive (1P), 2nd positive (2P) and 1st negative $(1 \mathrm{~N})$

Results from a streamer simulation are presented in Fig. 19. Following Liu and Pasko (2004), the streamer is simulated in the mesosphere, at $70 \mathrm{~km}$ altitude in a background electric field of 1.5 times the electric field threshold for conventional breakdown and is initiated from a plasma cloud with peak density of $5 \times 10^{5} \mathrm{~cm}^{-3}$ and a Gaussian spatial distribution with a scale of $3 \mathrm{~m}$. The intensities of optical emissions in different spectral bands are shown at the time $\mathrm{t}=40 \mu \mathrm{s}$. The results are in good agreement with the fluid simulations of Liu and Pasko (2004). Estimates of streamer brightness from recent high speed imaging of sprite streamers give an average streamer head intensity ranging in the interval $9 \times 10^{8}-5 \times 10^{11} \mathrm{R}$ (Stenbeak-Nielsen et al. 2007). Our simulation gives an average intensity of $1.5 \times 10^{9} \mathrm{R}$, which is within the range of intensities derived from the observations.

\subsection{High Energy Electrons from Streamers}

By using a non isotropic scattering model for electron collisions with air molecules and a set of cross-sections that goes up to $10 \mathrm{keV}$ electron energy, the code can study the production of high energy electrons by sprite streamers or by streamer regions of lightning leaders as described by Moss et al. 2006. The most interesting point is to understand if the streamer's electric field can accelerate electrons to their runaway regime from which electrons can gain sufficient energy to produce $\mathrm{X}$ - and $\gamma$-ray emission by bremsstrahlung radiation. The runaway process can be understood by comparing the friction force $F_{D}$, an average force that represents the stopping power due to collisions, and the electric force $F_{E}$, from the electric field accelerating electrons to higher energy. The two forces are represented in Fig. 20 in air at sea level pressure as a function of the electron energy. The two forces are of equal magnitude for two energies $\varepsilon_{1}$ and $\varepsilon_{2}$ that represent, respectively, a stable and an unstable equilibrium. The runaway regime is defined by the energy $\varepsilon_{2}$ above which electrons keep gaining energy from the electric field.

The electron distribution functions corresponding with the simulation presented in Sect. 8.2 at the time $40 \mu \mathrm{s}$ are shown in Fig. 21. The distribution function for electrons in the body of the streamer are shown in blue (the background electric is partially screened), in the negative streamer head in green (the background field is enhanced) and in the region 


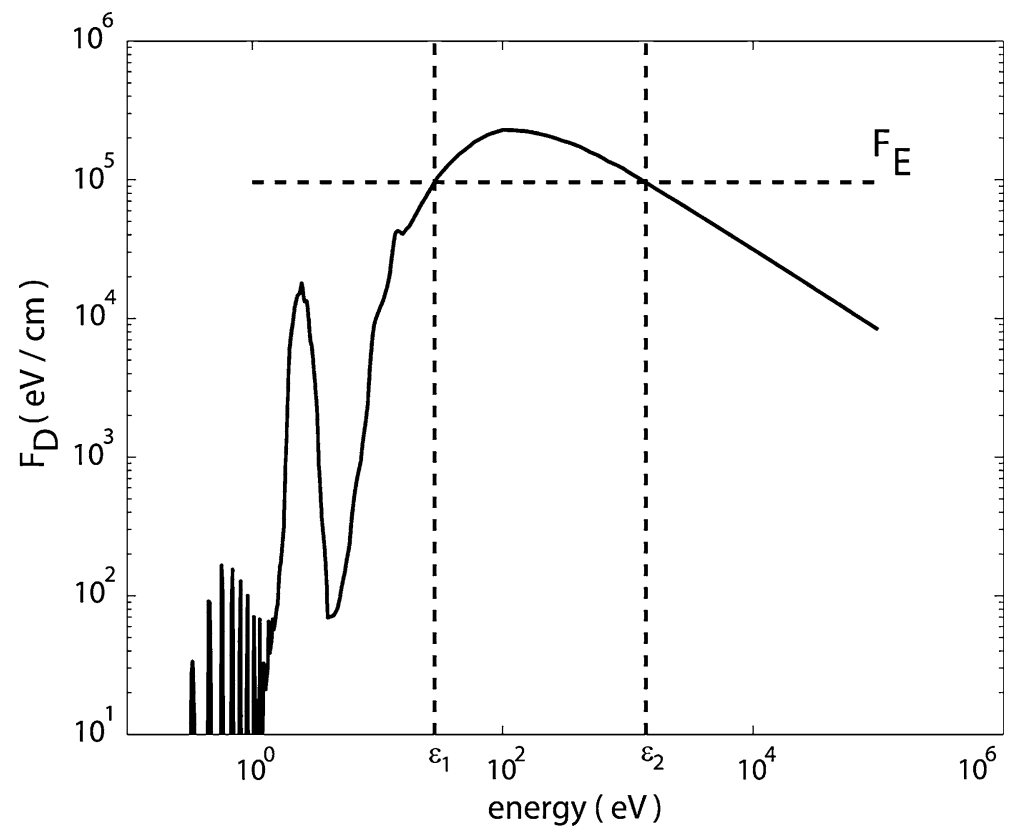

Fig. 20 The frictional force as a function of energy of free electrons in air composed of $80 \%$ nitrogen and $20 \%$ oxygen at atmospheric pressure at sea level. The horizontal dashed line shows the force on an electron exerted by a background electric field $50 \%$ greater than the breakdown threshold electric field. The intersections with the curve mark the electron energies at which the two forces balance. Point 1 is a stable equilibrium and point 2 unstable, allowing electrons to be accelerated to high energies (see text). At energies above $1 \mathrm{MeV}$ the force begins to increase again due to the increasing relativistic mass of the electron (Chanrion and Neubert 2008)

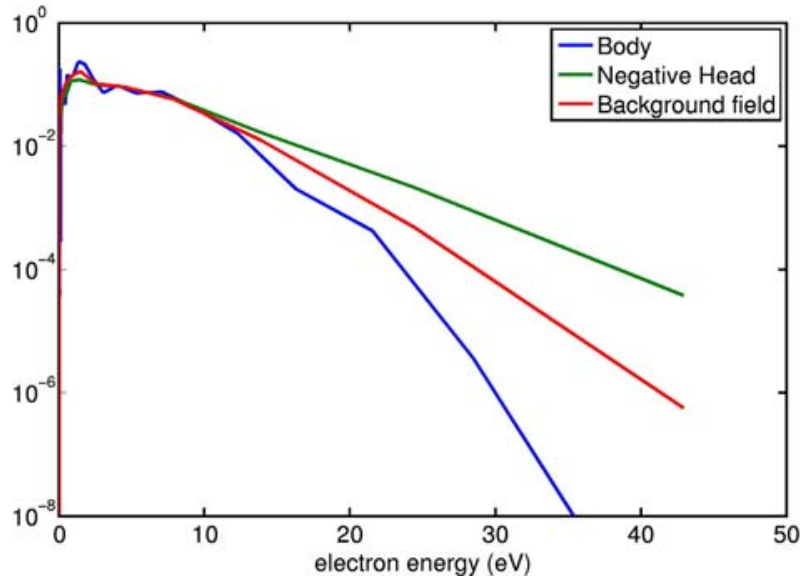

Fig. 21 The electron distribution function for the streamer simulation presented in Fig. 19. The distribution function is shown for electrons in the background gas dominated by the background electric field, in the streamer body, which is the region with the lowest electric field and in the streamer head where the field is a maximum 
surrounding the streamer in red (background electric field). The distribution functions show the effect of the streamer formation on the energy levels reachable by electrons. In the body of the streamer, the electric field is reduced and thus electrons are less energetic than if they were drifting in the background field. In the streamer tip the field is enhanced and the electrons are more energetic. Depending on the magnitude of the background electric field and on the altitude of the streamer, the enhancement of the field in the streamer tip can be high enough to accelerate electrons into the runaway regime. These runaway electrons created by streamers could generate a source of energetic electrons able to produce $\mathrm{X}$ - and $\gamma$-ray emission by bremsstrahlung radiation.

\section{Simulations of Perturbations to $\mathrm{NO}_{\mathrm{X}}$ and Ozone by Sprites}

Odd nitrogen ( $\mathrm{N}, \mathrm{NO}$ and $\mathrm{NO}_{2}$, together known as $\mathrm{NO}_{\mathrm{X}}$ ) and ozone are among the most important chemically active species in the middle and upper atmosphere. Ozone controls the dynamic balance of the atmosphere due to its absorption of solar radiation, and $\mathrm{NO}_{\mathrm{X}}$ affects the concentration of ozone. In the troposphere $\mathrm{NO}_{\mathrm{X}}$ creates ozone whereas in the stratosphere and mesosphere it destroys ozone. The concentration of $\mathrm{NO}_{\mathrm{X}}$ in the mesosphere is known to be enhanced by transient events such as auroras and solar proton events (SPEs) (Crutzen and Solomon 1980). Comparisons of $\mathrm{NO}_{\mathrm{X}}$ concentrations predicted by local models with satellite measurements show that the theoretical understanding of thermospheric $\mathrm{NO}_{\mathrm{X}}$ concentrations is not complete and that vertical transport by neutral winds must be important (Barth and Bailey 2004; Saetre et al. 2007). Mesospheric $\mathrm{NO}_{\mathrm{X}}$ is long-lived in the winter polar vortex and can subside into the stratosphere (Seppälä et al. 2007). The main stratospheric source of $\mathrm{NO}_{\mathrm{X}}$, however, is oxidation of $\mathrm{N}_{2} \mathrm{O}$ from the troposphere (Vitt and Jackman 1996).

Thunderstorms can contribute to $\mathrm{NO}_{\mathrm{X}}$ in the stratosphere and mesosphere in at least three ways. The first is strong convection in a thunderstorm cell that may carry tropospheric air into the lower stratosphere (Huntrieser et al. 2007). The second is by chemical effects of energetic electrons from the magnetosphere precipitated into the mesosphere and thermosphere from solar wind interactions with the magnetosphere or by whistler mode waves from lightning discharges (Rycroft 1973; Rodger et al. 2007). The third is local production of $\mathrm{NO}_{\mathrm{X}}$ by sprites. The processes in sprites are in many ways similar to those in the aurora, although on smaller spatial and temporal scales, and can therefore be assumed to have at least local effects on middle-atmospheric $\mathrm{NO}_{\mathrm{X}}$ chemistry. In the troposphere lightning is a significant source of $\mathrm{NO}_{\mathrm{X}}(7 \mathrm{Tg} /$ year), comparable to burning of biomass ( $8 \mathrm{Tg}$ /year) and fossil fuels (22 Tg/year) (Schumann and Huntrieser 2007). Here a significant production channel of $\mathrm{NO}_{\mathrm{X}}$ is through energetic neutral atom conversion where the heating of the atmosphere by the continuing current in the ion channel of the lightning stroke allows suprathermal oxygen atoms to react directly with $\mathrm{N}_{2}$ (Balakrishnan and Dalgarno 2003). There is as yet no evidence for significant continuing currents in sprites or heating of the atmosphere beyond a few degrees, so this channel is not considered relevant for sprites in the mesosphere.

The effects of sprite discharges on the chemistry of the middle atmosphere have been addressed by several recent theoretical studies, based on independent streamer propagation models from a particle code, with inputs from spectral observations of sprites taken aboard a satellite (Enell et al. 2008), from a fluid code of streamer propagation (Sentman et al. 2008), or by a plasma code with a Boltzmann solver (Gordillio-Vazquez 2008). Here some results of the model by Enell et al. (2008) are summarized. As there is no unambiguous 
evidence for a continuing current in sprites it is assumed that suprathermal atoms do not occur in sprites, although they may in the longer-lived blue jets and gigantic jets (Su et al. 2003). An additional point to be made here concerns experiments showing that sprite-like discharges (streamers) produce less $\mathrm{NO}_{\mathrm{X}}$ per event than lightning-like (arc) discharges (Peterson et al. 2005). This is, however, only because arcs are more energetic than streamers. The chemical production rates of oxygen radicals, ozone, etc., per unit of dissipated energy can be much higher in streamers, which is the reason for using streamer technology for many energy efficient gas processing purposes (Winands 2007).

\subsection{The Chemistry Code}

The assumption that the ions and neutrals of the sprite plasma are not heated more than a few degrees above the background neutral temperature suggests the use of the Sodankylä coupled Ion-neutral Chemistry (SIC) model for estimating the $\mathrm{NO}_{\mathrm{X}}$ production by sprites. SIC was originally developed for modelling of perturbations to the chemistry of the upper mesosphere and lower thermosphere induced by energetic charged particles precipitating from the magnetosphere, as inferred from observations by riometers, incoherent scatter radars, satellite-borne instruments and other measurements (Turunen et al. 1996). The present standard version of SIC6.x (Verronen 2005; Verronen (2006) is a time-dependent box model, where the coupled differential equations describing of the concentrations of the species are integrated for one altitude at a time. Almost 400 reactions of positive ions, negative ions and minor neutral species are taken into account. The reaction rate coefficients depend on neutral temperature and pressure but the reaction energetics are not treated explicitly. Ionization in SIC6.x is forced by sunlight (visible, UV and X rays), galactic cosmic rays, electrons and protons. Solar radiation and background density profiles are constant during one timestep of a complete altitude range update. Vertical transport, radiative transfer and background atmosphere altitude profiles are updated between the intervals. The profiles of the temperature and the neutral background species are taken from the MSISE-90 empirical model (Hedin 1991) and from tables given in Shimazaki 1984. Water vapour and $\mathrm{CO}_{2}$ are less well represented. For these we use fixed mixing ratios of 5 and 335 ppmv, respectively. The water mixing ratio affects $\mathrm{HO}_{\mathrm{X}}$ production which is also important for ozone chemistry (Verronen et al. 2006). This issue merits further future studies. To estimate the chemical changes during a transient event, the SIC model is first run for a repeated full diurnal cycle in order to reach a quasi-steady state, which provides the reference background concentrations with which the event scenario is compared.

An updated version (SIC7.x) has been written for modelling sprites in the mesosphere (Enell et al. 2008). SIC7 includes 465 reactions of 29 negative ions, 45 positive ions and 50 neutral species. The most important excited states of $\mathrm{N}_{2}, \mathrm{O}_{2}, \mathrm{~N}_{2}{ }^{+}, \mathrm{N}$ and $\mathrm{O}$ are now treated as separate species, and the reaction rate coefficients are functions of the electron temperature. An interface has been added to assimilate rates of excitation, ionization and dissociation of nitrogen and oxygen as obtained from other methods such as optical observations or discharge simulations.

In SIC7.x, production of nitric oxide in sprites occurs through three channels:

1. Dissociation of molecular oxygen and subsequent reactions of $\mathrm{O}(1 \mathrm{D})$ atoms such as $\mathrm{O}(1 \mathrm{D})+\mathrm{N}_{2} \mathrm{O} \rightarrow 2 \mathrm{NO}$.

2. Reactions of the long-lived excited state $\mathrm{N}_{2}\left(A^{3} \Sigma_{u}^{+}\right)$. Its transition to the ground state, called the Vegard-Kaplan band, is highly forbidden and therefore the main loss is through chemical quenching (Vallance Jones 1974). 
3. Ionization of $\mathrm{N}_{2}$ :

$$
\mathrm{N}_{2}^{+}+\mathrm{O} \rightarrow \mathrm{NO}^{+}+\mathrm{N}\left({ }^{2} \mathrm{D}\right)
$$

followed by reaction (2) and recombination of $\mathrm{NO}^{+}$with electrons.

Reaction (3) is of less importance since $\mathrm{N}_{2}{ }^{+}$is quickly lost by charge exchange with $\mathrm{O}_{2}$, and hence is not available to form either $\mathrm{O}^{+}$or $\mathrm{N}\left({ }^{2} \mathrm{D}\right)$ (Sentman et al. 2008).

\subsection{Model Results on $\mathrm{NO}_{\mathrm{X}}$ Production in Sprites}

Estimates of the enhancements of $\mathrm{NO}_{\mathrm{X}}$ by sprites predicted by SIC7.x have been presented by Enell et al. (2008). The input rates of dissociation, excitation and ionisation are estimated from optical measurements of sprites made by a photometer on the FORMOSAT-2 satellite (Adachi et al. 2006). Since the measurements are not directly applicable because of lack of spatial and temporal resolution, they are instead used indirectly to estimate the electric field in the sprite streamers assuming that the photons primarily come from this region. These fields are then used to derive needed input rates for dissociation, excitation and ionization of nitrogen and oxygen using the Siglo cross sections (www.siglokinema.com). Figure 22 shows the production of NO (left) and corresponding relative enhancement (right) for a background atmosphere at 00:30 UT during a northern-hemispheric summer night (August 1-2). The estimated total production of $\mathrm{NO}_{\mathrm{X}}$ in this scenario is around 5 times the background in the streamers. In comparison the model of GordillioVazquez (2008) predicts $\mathrm{NO}$ and $\mathrm{NO}_{2}$ enhancements of a factor ten, which is in fairly good agreement given that these models present early efforts to study the phenomenon.
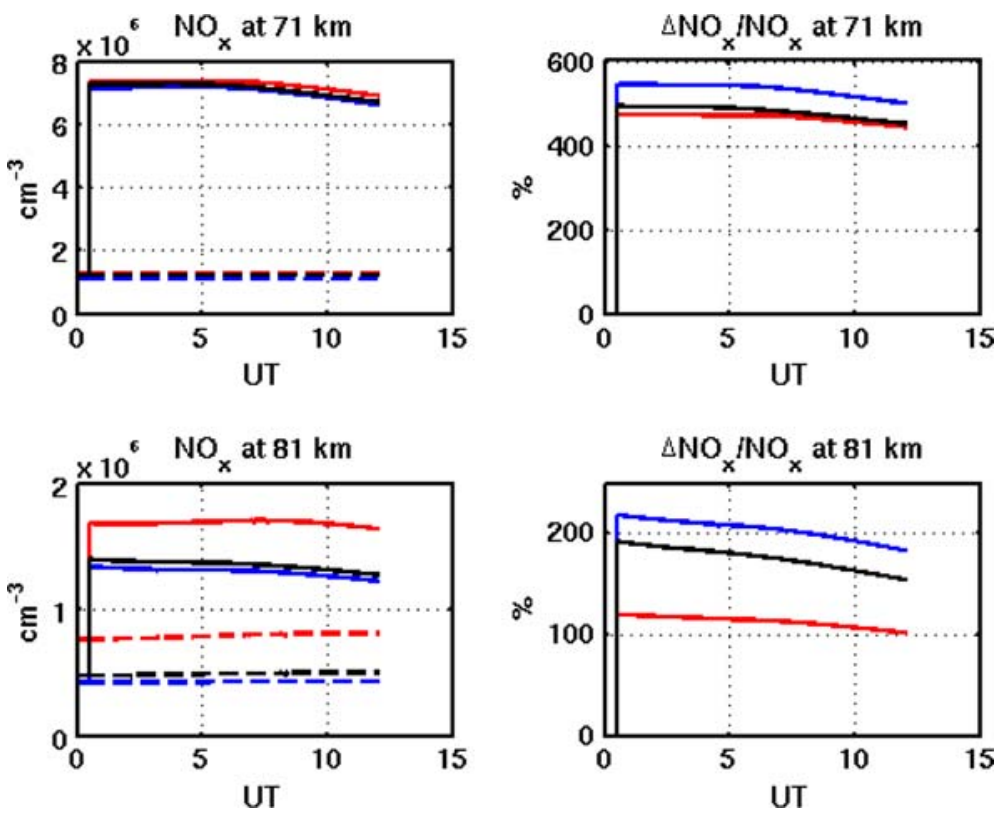

Fig. 22 Left column: $\mathrm{NO}_{\mathrm{X}}$ production by sprites. A sprite burst is imposed at a latitude of $60^{\circ} \mathrm{N}$ (black solid line), at $40^{\circ} \mathrm{N}$ (blue solid line) and at the equator (red solid line). Dashed lines show the unperturbed atmosphere. Right column: The relative increase above the control run concentrations (Enell et al. 2008) 
Assuming a streamer reaching from $50-80 \mathrm{~km}$ altitude, the average NO production in a streamer is $\sim 5 \times 10^{12} \mathrm{~m}^{-3}$. For a streamer of $10 \mathrm{~m}$ by $10 \mathrm{~m}$ cross section the volume of a streamer is $\sim 3 \times 10^{6} \mathrm{~m}^{-3}$ and the total number of NO molecules produced in a streamer is $\sim 1.5 \times 10^{19}$, with an estimated average total production on the order of $10^{23}-10^{25}$ molecules per event, based on the dimensions of a typical sprite event (Gerken et al. 2000). By comparison, Sentman et al. (2008) estimated a production on the order of $5 \times 10^{19}$ molecules per streamer, which is consistent with the above result.

Since $\mathrm{NO}_{\mathrm{X}}$ is long-lived in the mesosphere with conversions between $\mathrm{NO}$ and $\mathrm{NO}_{2}$ taking place through photochemistry, the chemical significance to the atmosphere of spriteproduced $\mathrm{NO}_{\mathrm{X}}$ is determined by transport out of the active region. The local effective buildup may be limited to a few hours, thus allowing large thunderstorm systems to accumulate up to 5 times the background concentration locally over a sprite-active cell of a storm. The global impact of sprites can be estimated from the global sprite occurrence rates of $\sim 3 / \mathrm{min}$ (Ignaccolo et al. 2006) discussed in Sect. 6. This rate implies a global production of the order of $10^{31}$ molecules/year, which is of the same magnitude as the minimum total $\mathrm{NO}_{\mathrm{Y}}$ (i.e. $\mathrm{NO}_{\mathrm{X}}$ plus stratospheric "reservoir species" such as $\mathrm{N}_{2} \mathrm{O}, \mathrm{N}_{2} \mathrm{O}_{5}$ and $\mathrm{HNO}_{3}$ ) produced by solar proton events during a quiet year, and two orders of magnitude below its production by cosmic rays (Vitt and Jackman 1996). The stratospheric production by oxidation of $\mathrm{N}_{2} \mathrm{O}$ is on the order of $10^{34}$ molecules/year (Vitt and Jackman 1996). From these considerations it follows that only over very intense thunderstorms can sprites lead to a significant impact upon the local density of $\mathrm{NO}_{\mathrm{X}}$. However, the global impact of sprites is diluted by their rarity; thus the preliminary studies presented here suggest that sprite-related processes are unlikely to play a significant role in the total $\mathrm{NO}_{\mathrm{X}}$ budget of the stratosphere and mesosphere, although further studies are needed to consolidate our understanding of sprite chemistry.

\subsection{Effects of Sprites on Ozone}

Ozone is affected by $\mathrm{NO}_{\mathrm{X}}$ through catalytic cycles. The maximum sensitivity of ozone to $\mathrm{NO}_{\mathrm{X}}$ is in the stratosphere below $50 \mathrm{~km}$ at altitudes, which is a region only marginally affected by sprite streamers. On the other hand, dynamical time scales are longer at $50 \mathrm{~km}$, thus allowing a longer accumulation time. Above about $60 \mathrm{~km} \mathrm{HO}_{\mathrm{X}}$ dominates the ozone catalytic cycles. The perturbations to ozone from $\mathrm{HO}_{\mathrm{X}}$ reactions were found in the SIC model to be below the precision of the model. However, the impact of the sprite-produced NO on ozone was estimated to decrease the ozone concentration by a few percent in the 50-60 km altitude range for NO enhancements of 2-10 (Enell et al. 2008). Significant ozone perturbations from sprites are then unlikely, except for particularly sprite-active storms.

\subsection{Comparisons with Observations}

The chemical impact of sprites is further studied using the nighttime measurements of $\mathrm{NO}_{2}$ concentrations in the middle atmosphere given by Arnone et al. 2008a The measurements are by the Michelson Interferometer for Passive Atmospheric Sounding (MIPAS) instrument (Fischer et al. 2007) on board the European Space Agency (ESA) ENVIronmental SATellite (ENVISAT). The measurements were retrieved with the new two-dimensional Geofit Multi-Target Retrieval algorithm (Niro et al. 2007) which enhances the detectability of small signals. The retrieved $\mathrm{NO}_{2}$ was correlated with intense active thunderstorms detected by the World Wide Lightning Location Network (WWLLN) (Jacobson et al. 2006). 
The study found enhancements of $\mathrm{NO}_{2}$ above active thunderstorms, suggesting spriteinduced $\mathrm{NO}_{\mathrm{X}}$ perturbations. The local enhancement increases with altitude from a few percent at $47 \mathrm{~km}$ to tens of percent at $60 \mathrm{~km}$, thus being roughly consistent with SIC model estimates. Enhancements were not found on larger regional scales, as confirmed by studies based on data from the GOMOS instrument on ENVISAT (Rodger et al. 2008).

\section{Perturbations to Atmospheric Dynamics}

The possible occurrence of sprite-induced ozone changes raises the question of their role in the large scale atmospheric system. To what extent could sprites significantly affect climate and contribute to its variability? As seen in Sect. 9, the effect on the amounts of ozone from sprites seems to be low, even though they could have some effect for the more intense thunderstorms. The transport of $\mathrm{NO}_{\mathrm{X}}$ produced by the sprites in the middle atmosphere is effective, and the chemicals are dispersed in both the meridional and the zonal directions within some hours to days, depending on the location of the storm. In this section we study the effect of different magnitudes of ozone perturbations to the middle atmosphere to assess a possible effect due to sprites in a climatological mean.

The extent to which even the small ozone perturbations estimated in the previous section could impact climate resides in the non-linear behaviour of the atmosphere. The circulation of the middle atmosphere is fundamentally determined by the temperature gradient between the tropics and the poles, and by the dispersion of planetary waves propagating upwards from the troposphere. The temperature gradient between the tropics and the poles and the Coriolis force give rise to zonal winds, which are easterly in the winter hemisphere and westerly in the summer hemisphere. In the meridional plane, the circulation consists of stratospheric air rising from the tropics and sinking at mid-latitudes, and a mesosphere summer hemisphere to winter pole flow accompanied by air rising in the summer pole and sinking into the troposphere in the winter pole (termed the residual circulation). This circulation is driven by upward propagating planetary waves in the winter hemisphere which break in the stratosphere, release their westerly momentum and thus reduce the easterly zonal winds (Christiansen 2001). Since the propagation of the planetary waves is affected by the local strength of the zonal winds, it may be affected by localized ozone perturbations in the stratosphere. The waves cannot propagate in a westerly zonal wind and they may therefore not penetrate through the zero wind line which extends vertically at the equator from the tropopause throughout the middle atmosphere. The position of this zero wind line has a proven effect on the pattern of the planetary wave propagation (e.g., Gray 2003). The dynamics also control the downward propagation of stratospheric temperature anomalies into the troposphere (Christiansen 2001), which imply a possible impact of stratospheric ozone changes onto the tropospheric climate.

Depending on the magnitude of the ozone perturbation produced by sprites, the propagation of planetary waves and the Brewer-Dobson circulation could be affected. Several model experiments were performed to assess the strength of the ozone perturbation needed to produce a significant change in the stratospheric dynamics and the extent to which this change propagates down to the troposphere.

\subsection{The Methodology}

The study was performed on two atmospheric models. The stratospheric impact of different magnitudes of ozone perturbations was assessed using the Stratosphere-Mesosphere Model 
(SMM) from the UK Met Office (Austin and Butchart 1992; Berg et al. 2007). The model has a vertical resolution of $0.125 \mathrm{hPa}$, or about $2 \mathrm{~km}$, ranging from $314 \mathrm{hPa}$ to $0.03 \mathrm{hPa}$, i.e. from the upper troposphere to the lower mesosphere. The horizontal resolution is $5^{\circ} \times 5^{\circ}$ on a global grid. To simulate the troposphere we introduced transient daily geopotential heights from the NCEP/NCAR reanalysis data at the lower boundary (Berg et al. 2007). This solution provides a realistic and naturally variable planetary wave forcing to the model.

The SMM simulations were then coupled to an atmospheric global circulation model (AGCM) to assess a possible tropospheric response. The AGCM used is cycle 14 of the ARPEGE model from MeteoFrance (Déqué et al. 1994; Christiansen et al. 1997). The ARPEGE model has 41 vertical levels with a high resolution of 1-2 km in the low stratosphere but only few levels in the high stratosphere to low mesosphere. The horizontal resolution is the same as for the SMM, i.e. $5^{\circ} \times 5^{\circ}$. The oceans are in a prescribed climatological state which prevents long delays in the response to the perturbations compared to having a coupled ocean in the model. Neither of the models has active chemistry. While the SMM was run with a full seasonal cycle, the AGCM was run in perpetual January mode to save computing time, therefore focusing on the Northern hemisphere winter season. In fact, in this season the coupling between the stratosphere and the troposphere is the largest, through the propagation of the planetary waves.

Since sprites have typical scales of tens of km, they are subgrid phenomena and cannot be modelled individually into standard global circulation models. As a first approximation, a climatological mean approach was thus adopted and sprites were assumed to be concentrated over the tropics and the midlatitudes where most thunderstorms occur. The experiments were then performed downscaling from very large magnitudes $(50 \%)$ to lower ones, to find how large an ozone perturbation must be to produce a significant response in the model stratosphere and troposphere.

The SMM stratosphere was perturbed at the tropics $\left(-30^{\circ}\right.$ to $+30^{\circ}$ latitude $)$ and at the mid-latitudes $\left(+/-30\right.$ to $70^{\circ}$ latitude) with zonally uniform ozone reductions of 5,10 , and $20 \%$ centred on the stratopause $(10-0.1 \mathrm{hPa}$, i.e. about $30-80 \mathrm{~km})$. Each experiment extended over 20 years with a full seasonal cycle, thus allowing statistical analyses to be performed. The perturbations centred at the stratopause were then repeated with the ARPEGE AGCM for ozone reductions of 10, 20 and 50\%. The ARPEGE AGCM experiments were run in perpetual winter and extended over 600 days, which is roughly equivalent to 20 years assuming a decorrelation time of about 1 month.

In Sect. 9, the largest chemical impact of sprites was found to be associated with very intense sprite-producing thunderstorms which have timescales of several hours. An additional study of the sensitivity of the SMM stratosphere to repeated impulsive perturbations was thus carried out, introducing a time-dependency to the tropical stratopause perturbation experiment. In this case, the perturbation was introduced only for 1 day every 2 days, one every 4 days, every 8 days and every 16 days.

\subsection{Results}

Figure 23 shows the results of the stratopause experiments (10-0.1 hPa, i.e. about $30-80 \mathrm{~km}$ ) performed on the SMM at the tropics and at midlatitudes. In this figure, and in the following figures, the statistical significance levels of 90 and $95 \%$ are shaded. The testing was performed using the Student's t-test of means for mean values over each winter for the SMM, and for 30 day periods for the ARPEGE AGCM. Induced by the perturbations, both the mid-latitudinal and tropical regions show the largest negative response of the temperature 

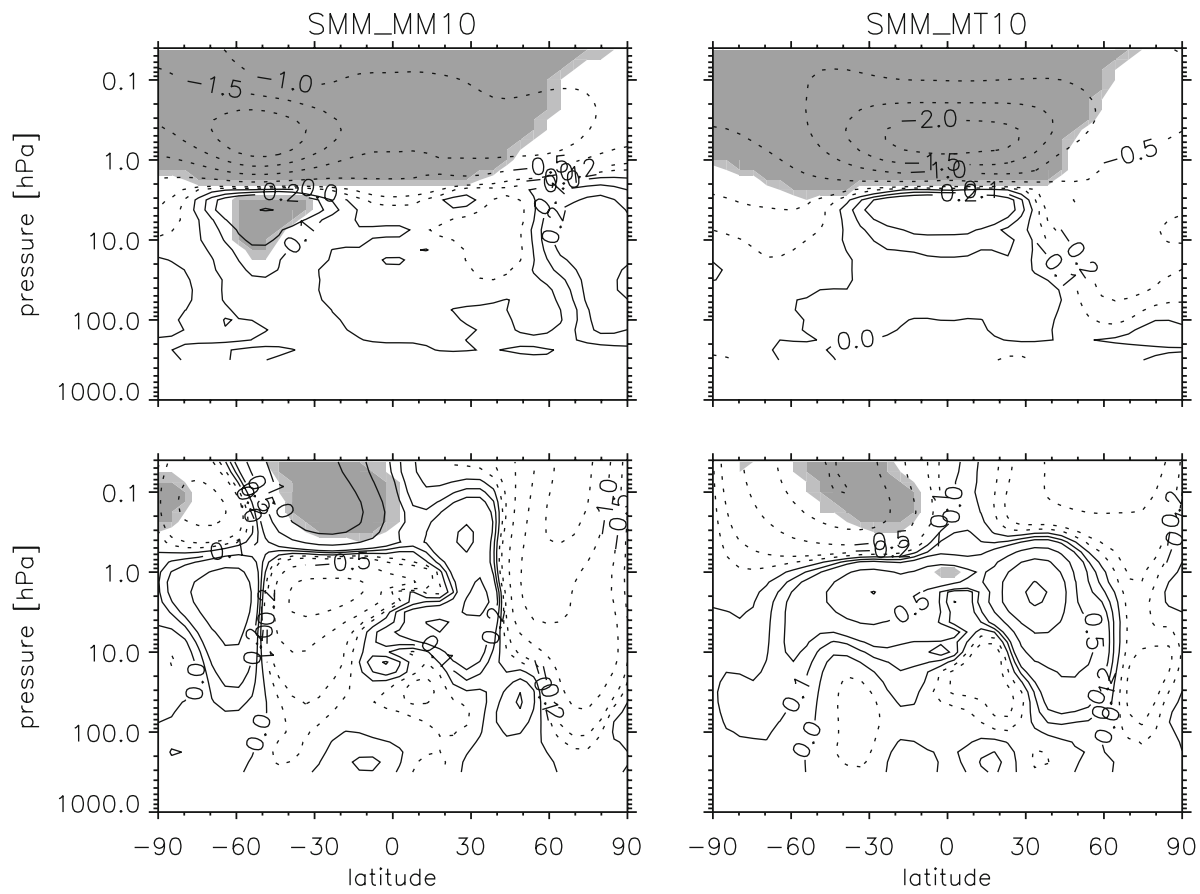

Fig. 23 The SMM response in temperature (top) and zonal winds (bottom) to the stratopause 10\% ozone reduction experiments at the midlatitudes (left) and tropics (right). The figure shows the difference between the perturbed and the control experiments. Responses at the $90 \%$ and $95 \%$ significance levels are shaded in grey

field within the perturbed region (top panels). Directly below the perturbed region there is a significant warming: this warming is due to absorption of the increased UV radiation that was not absorbed by the upper layers because of the ozone reduction. A $10 \%$ ozone decrease causes a temperature change which is significant for most of the latitudinal region at and above the stratopause, thus extending beyond the perturbed region through a dynamical response. The resulting change in the zonal wind (bottom panels) is weak and only significant in the lower mesosphere and around the stratopause. The changes follow the thermal wind approximation, i.e. that they are a direct result of the change in the temperature gradient. Inspection of the net heating rates (not shown) confirms a dynamical response (dynamical heating - see, e.g., Christiansen et al. 1997), with descending air confined in the perturbed regions. At both sides of these regions of dynamical heating are regions of dynamical cooling, i.e. the air is ascending. The statistical significance of the changes in the dynamical heating rates shows that not all of the changes are of a radiative nature. The patterns of the changes are consistent for all perturbation magnitudes, but the regions of significant change shrink with lower magnitudes. Downscaling from large (20\%) to weak (5\%) perturbations leads to a very confined local response.

The ARPEGE AGCM responds in a very similar way to the SMM in the middle atmosphere. Figure 24 shows the zonal wind response of the ARPEGE perturbation experiments performed at the tropical stratopause and with 10, 20 and 50\% ozone reduction. Small regions of significant change appear in the tropospheric wind response which is roughly consistent for different perturbation magnitudes. Zonal winds show a significant shift toward the equator of the southern subtropical jet stream, which is 

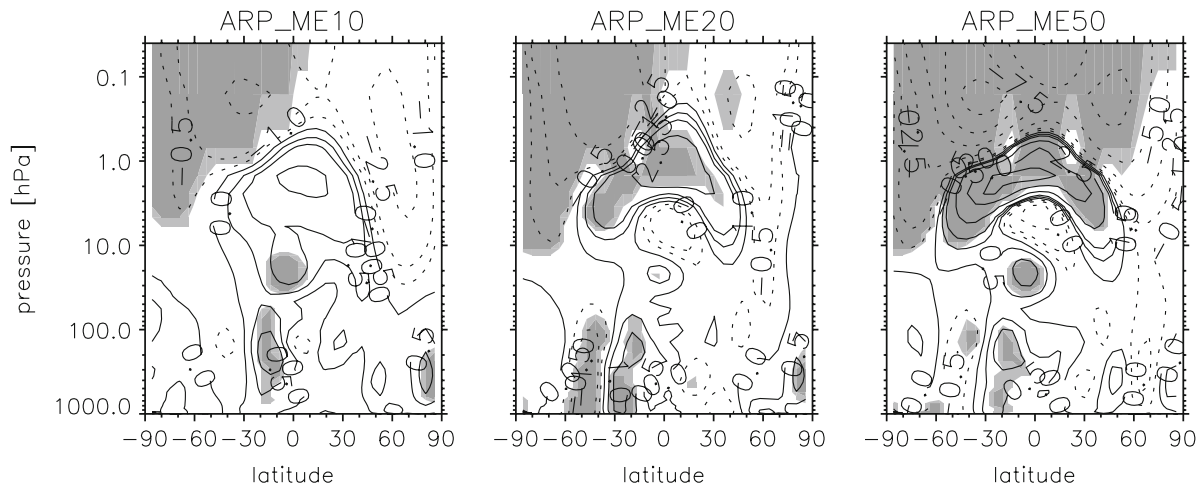

Fig. 24 The ARPEGE response in zonal winds to the tropical stratopause ozone perturbation of magnitude $10 \%, 20 \%$ and $50 \%$ (left to right). The figure shows the difference between the perturbed and the control experiments. Responses at the $90 \%$ and $95 \%$ significance levels are shaded in grey

consistent also for the tropical case (not shown), even though the strength of the shift varies somewhat. Interestingly, the largest regions of statistical significant response are found in the $20 \%$ magnitude and are almost lost in the $50 \%$ case, showing a non-linearity in the propagation of the atmospheric response into the troposphere.

The clustering of sprite activity above intense thunderstorms was mimicked through the impulsive perturbation experiments. Figure 25 shows the temperature response for the tropical stratopause experiments with $10 \%$ ozone reductions applied for 1 day every 2 days, every 4 and every 8 days (top to bottom panels). The magnitude of the statistically significant response scales almost linearly with the average magnitude of the perturbation, disappearing below the experiment sensitivity with 1 day of $10 \%$ ozone reduction every 8 days. Below this limit, the response fades away, indicating that the magnitude of the perturbation is too small to induce a statistically significant response.

\subsection{Discussion}

A general result for both the middle atmosphere model and the GCM is that, in the stratosphere, the local changes in both temperature and zonal wind scale linearly with the magnitude of the perturbation in sunlit regions, for the perturbation magnitudes of a few to tens of percent decrease in ozone. The tropospheric response is not as predictable, with the $20 \%$ magnitude experiment leading to larger tropospheric responses than the $50 \%$ case.
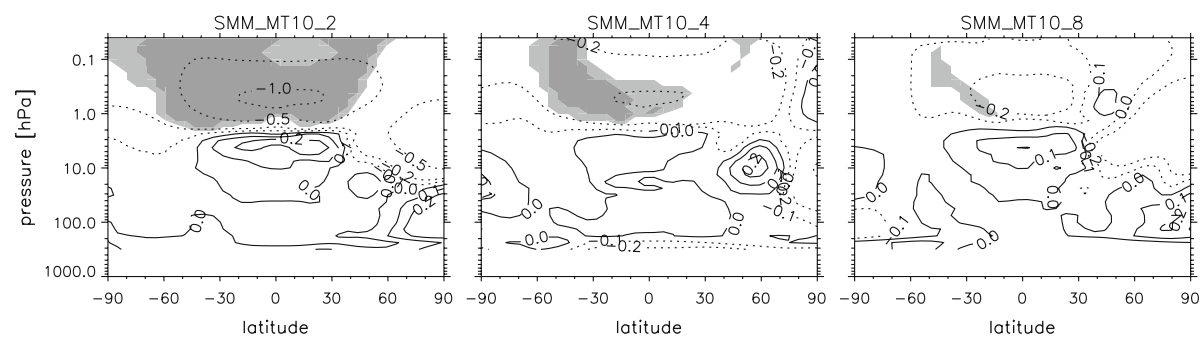

Fig. 25 The SMM temperature response to the 10\% tropical stratopause ozone perturbation (as in Fig. 23 top-right) applied impulsively for 1 day every 2 days, one every 4 and one every 8 days (left to right). Notice that only the response at the $95 \%$ significance level is shown 
This suggests a competing action of different radiative and dynamical processes, with the radiative drive taking over once the magnitude of the perturbation increases above a certain level. Dynamical processes are also at play in the winter hemisphere: especially near the Northern pole, the strongly disturbed temperature field makes it difficult for most perturbations to lead to a coherent statistically significant response. However, impulsive perturbations were found to be able more easily to alter the triggering of sudden stratospheric warming, leading to large impulsive temperature changes and possible propagation down to the troposphere.

Even accounting for these non-linear responses, the smallest perturbation needed by the model for any significant response (a zonally uniform stratopause $10 \%$ ozone reduction applied to the whole tropics for 1 day every 8 days) is far larger than the upper limit estimates deduced in the previous section (i.e. a sporadic $1 \%$ ozone reduction above very intense sprite-producing thunderstorms over a $300 \mathrm{~km} \times 300 \mathrm{~km}$ region). These weak perturbations of the ozone concentrations are not likely to affect the tropospheric climate in any significant way through a radiative/dynamical pathway as shown by the model experiments. However, intense sprite activity is likely to cause a weak local temperature change and possibly lead to a transient perturbation of the local dynamics which cannot be resolved by the adopted global models.

\section{Discussion}

The past few years have seen a leap forward in our understanding of electric discharges in the mesosphere, both from activities of European research groups primarily reported on here and from the wider international community. However, while some areas of sprite physics are better understood, there are also significant questions raised that deserve attention in the years to come.

One question concerns the perturbation to the atmosphere by sprites. This issue is raised by the observation of infrasound waves from sprites, observed at up to $1000 \mathrm{~km}$ distance. The significance of the observation is its relation to the energy input to the atmosphere. Estimates in the past have been based on observations of the optical intensity of sprites in various spectral bands. They have varied by several orders of magnitude, with up to $\sim 1 \mathrm{GJ}$ for large events (Heavner 2000) and later the reduced estimates of 1-10 MJ (Sentman and São Sabbas 2002). The infrasound observations suggest large energy inputs, of the order of 0.4-40 GJ (Farges et al. 2005).

The question of energy input is related the level of ionization in sprites and the electric currents which they carry. Are sprites formed primarily a result of the excitation of atmospheric constituents by a modest density of electrons, perhaps released from negative ions, or is there significant ionization in sprites? Two regions of electric activity are involved in sprite generation; one is the region of sprites in the mesosphere and the other is the causative lightning discharge in the thunderstorm in the troposphere. Studies of the mesosphere are by necessity made by remote means and most commonly by observations of electromagnetic or optical signatures. The optical observations can distinguish between the two regions but electromagnetic detection techniques cannot. Thus there remains an ambiguity in electromagnetic studies concerning the source of observed signatures. Optical observations from the ground, on the other hand, are hampered by the absorption of emission lines associated with ionization that makes it difficult to estimate ionization rates in sprites. The observations obtained in the EuroSprite campaign of VLF transmitter signal perturbations suggest that sprites themselves create significant sources of enhanced 
ionization at and below the lower boundary of the ionosphere. The conclusion is supported by studies of VLF radiation from lightning and sprites where efforts are made to distinguish between the two sources. Here the data suggest that sprites are sources of VLF radiation, which require electric currents to flow. This is further supported by the studies of others which combine optical data and electromagnetic measurements in the ELF range (Cummer et al. 2006b). In addition, imaging observations of interactions between branches of sprites clearly show the electric nature of these (Cummer et al. 2006a) and high-speed imaging show streamer tips, just as in laboratory discharges (McHarg et al. 2007).

We conclude, therefore, that sprites are electric discharges in the mesosphere with significant currents and significant perturbations to the atmosphere, as regards their detectability by conventional means. The quantitative estimation of all the perturbations, however, remains unsolved, in particular concerning heating of the neutral atmosphere, the plasma density of streamers and the electric currents which they carry.

A second aspect raised by the observations concerns the electric field established in the mesosphere following a lightning discharge. Although this field is perhaps the most important single entity to observe and understand in relation to sprite generation, our knowledge is rudimentary. It can only be estimated by a combination of modelling and observations of charge moment changes from ELF radio observations. In general, discussions on sprite generation consider the quasi-electrostatic field (ignoring the displacement current) from the discharge of a vertical dipole, simulating the cloud-to-ground discharge. However, observations of VLF radiation relating to sprite morphology clearly show the very complex nature of the problem, including a complex electric field source in the thunderstorms primarily due to horizontal intra-cloud and inter-cloud discharges. It is clear that we need to understand the complete electric fields produced by cloud-to-ground and intra/intercloud discharges. Very few attempts to model these latter fields have been made in the past (Valdivia et al. 1998; Cho and Rycroft 2001), but the advances made also in observations of the intra/inter-cloud component should allow further progress to be made in this area.

A third and final point relates to perturbations of the chemistry of the mesosphere. Here, models are available that can simulate a multitude of reaction paths and the challenge is to identify those which are the most important. This can only be done to the extent that the physics of the discharges is known. The simulations presented here have made assumptions about the sprite discharge, e.g., that there is no heating of the ambient atmosphere. While it is generally thought that little heating is associated with sprites, our infrasound observations indicate that this may not be true. At this point in our understanding we do not know how the neutral atmosphere is heated in sprite streamers or in the more diffuse region of the upper parts of carrot sprites. With this assumption, the studies of chemical perturbations to the concentrations of $\mathrm{NO}_{\mathrm{X}}$ and ozone and the associated perturbations to atmospheric dynamics have shown that sprites have a definite local effect, perhaps regional effects, but insignificant global effects. The conclusions on the global effects are likely to remain unchanged in future, because of the limited rate of sprite events. However, more realistic models should be developed, and these may show unexpected effects.

Situated at 50-85 km altitude, the mesosphere is inaccessible to satellites, balloons and aircraft, and is difficult to probe by remote methods because of its tenuous character. As a result, detailed knowledge of the mesosphere is still lacking. Electric discharges in the mesosphere represent a spectacular, impulsive illumination of the region. With an in-depth understanding of the discharge process it will be possible to gain new insights into the composition and dynamics of this layer of the atmosphere, lying at the edge of space, at the boundary between the Earth's environment and the hostile space environment. 
Acknowledgements The work presented here was conducted as part of the Research Training Network "Coupling of Atmospheric Layers", CAL, sponsored by the EU 5. Framework Programme under contract no.: HPRN-CT-2002-00216. We thank Stéphane Pédeboy of the Météorage Company for providing nearreal time data on lightning activity and Jean-Yves Lojou of the Vaisala group for the SAFIR data. Support for the establishment of the Crete VLF station was provided in part by the STAR Laboratory, Stanford University, the European Office of Aerospace Research and Development (EOARD), and the Air Force Research Laboratory, under contract FA8655-03-1-3028. We thank Troy Wood of STAR Laboratory for his excellent work in installing the Crete VLF system.

Open Access This article is distributed under the terms of the Creative Commons Attribution Noncommercial License which permits any noncommercial use, distribution, and reproduction in any medium, provided the original author(s) and source are credited.

\section{Appendix}

Appendix 1 Optical sprite observations over Europe during 2003 from Observatoire Midi Pyrénées

\begin{tabular}{|c|c|c|c|c|c|c|c|c|c|}
\hline TLE\# & TLE time & & M & $\begin{array}{l}\text { Flash } \\
\text { time }\end{array}$ & & $\begin{array}{l}\text { Lat } \\
\text { (North) }\end{array}$ & $\begin{array}{l}\text { Long } \\
\text { (East) }\end{array}$ & $\begin{array}{l}\text { Peak I } \\
\text { (A) }\end{array}$ & $\begin{array}{l}\text { Distance } \\
(\mathrm{km})\end{array}$ \\
\hline \multicolumn{10}{|c|}{ Storm1 } \\
\hline \multirow[t]{2}{*}{01.01} & 20030721 & 020514.630 & 1 & $02: 05: 14$ & 7828741 & 45.705 & 3.075 & -49.3 & 387.9 \\
\hline & & & 1 & $02: 05: 14$ & 8527730 & 45.916 & 2.700 & 23.1 & 389.0 \\
\hline \multirow[t]{3}{*}{01.02} & 20030721 & 020759.870 & 1 & 02:07:59 & 5380839 & 45.788 & 2.820 & 31.3 & 382.9 \\
\hline & & & 2 & 02:07:59 & 7167443 & 45.796 & 2.755 & 32.3 & 380.6 \\
\hline & & & 1 & 02:07:59 & 9124903 & 45.830 & 2.290 & 56.5 & 363.8 \\
\hline \multirow[t]{3}{*}{01.03} & 20030721 & 020920.000 & 1 & 02:09:20 & 153040 & 45.732 & 3.276 & 46.0 & 400.5 \\
\hline & & & 2 & 02:09:20 & 641258 & 45.729 & 3.237 & 44.1 & 398.3 \\
\hline & & & 1 & 02:09:20 & 1990054 & 45.887 & 2.940 & 32.6 & 397.2 \\
\hline 01.04 & 20030721 & 021151.750 & 1 & $02: 11: 51$ & 7182770 & 45.593 & 2.444 & 57.6 & 348.1 \\
\hline \multirow[t]{2}{*}{01.05} & 20030721 & 021700.830 & 1 & 02:17:00 & 8183461 & 45.739 & 3.135 & 45.8 & 393.9 \\
\hline & & & 1 & 02:17:00 & 8808437 & 45.980 & 2.502 & 111.3 & 386.6 \\
\hline 01.06 & 20030721 & 021946.230 & 1 & $02: 19: 46$ & 2516176 & 46.837 & 3.680 & 185.8 & 516.2 \\
\hline 01.07 & 20030721 & 021955.430 & 1 & 02:19:55 & 3601061 & 45.872 & 3.381 & 38.8 & 417.5 \\
\hline 01.08 & 20030721 & 022259.390 & 1 & $02: 22: 59$ & 4304597 & 46.097 & 3.758 & 28.5 & 455.6 \\
\hline \multirow[t]{2}{*}{01.09} & 20030721 & 022334.430 & 1 & $02: 23: 34$ & 6286526 & 45.866 & 2.428 & 44.6 & 372.8 \\
\hline & & & 1 & $02: 23: 34$ & 6407980 & 45.959 & 2.421 & 16.5 & 381.4 \\
\hline \multirow[t]{4}{*}{01.10} & 20030721 & 022634.230 & 1 & $02: 26: 34$ & 1805136 & 46.248 & 3.786 & 20.2 & 469.7 \\
\hline & & & 2 & $02: 26: 34$ & 1810964 & 46.239 & 3.694 & 22.4 & 464.3 \\
\hline & & & 1 & $02: 26: 34$ & 2855231 & 46.168 & 3.696 & 51.9 & 458.3 \\
\hline & & & 1 & $02: 26: 34$ & 4970698 & 46.266 & 3.318 & 39.7 & 448.5 \\
\hline 01.11 & 20030721 & 022814.270 & 1 & $02: 28: 14$ & 1960128 & 45.700 & 3.105 & 57.6 & 389.1 \\
\hline 01.12 & 20030721 & 022814.310 & 1 & $02: 28: 14$ & 1960128 & 45.700 & 3.105 & 57.6 & 389.1 \\
\hline 01.13 & 20030721 & 023152.030 & 1 & $02: 31: 52$ & 250349 & 45.554 & 2.841 & 36.7 & 363.4 \\
\hline 01.14 & 20030721 & 023321.870 & 1 & $02: 33: 21$ & 8277416 & 46.066 & 3.661 & 35.9 & 448.1 \\
\hline 01.15 & 20030721 & 023347.270 & 1 & $02: 33: 47$ & 3051369 & 45.730 & 3.314 & 24.6 & 402.3 \\
\hline \multirow[t]{2}{*}{01.16} & 20030721 & 023499.950 & 1 & 02:34:59 & 9947208 & 45.829 & 3.074 & 24.9 & 398.6 \\
\hline & & & 1 & $02: 35: 00$ & 1568612 & 45.902 & 2.588 & 49.3 & 382.9 \\
\hline 01.17 & 20030721 & 023840.590 & 1 & 02:38:40 & 6642509 & 46.383 & 3.220 & 161.2 & 454.6 \\
\hline
\end{tabular}


Appendix 1 continued

\begin{tabular}{|c|c|c|c|c|c|c|c|c|c|}
\hline TLE\# & TLE time & & M & $\begin{array}{l}\text { Flash } \\
\text { time }\end{array}$ & & $\begin{array}{l}\text { Lat } \\
\text { (North) }\end{array}$ & $\begin{array}{l}\text { Long } \\
\text { (East) }\end{array}$ & $\begin{array}{l}\text { Peak I } \\
\text { (A) }\end{array}$ & $\begin{array}{l}\text { Distance } \\
(\mathrm{km})\end{array}$ \\
\hline & & & 1 & 02:38:40 & 8186266 & 46.301 & 2.911 & 99.8 & 433.7 \\
\hline & & & 1 & 02:38:40 & 8477866 & 46.190 & 3.019 & 40.2 & 428.1 \\
\hline 01.18 & 20030721 & 024206.870 & 1 & $02: 42: 06$ & 9145316 & 45.992 & 2.770 & 103.2 & 399.1 \\
\hline 01.19 & 20030721 & 024332.470 & 1 & $02: 43: 32$ & 3923382 & 46.475 & 4.387 & 42.8 & 519.4 \\
\hline \multirow[t]{2}{*}{01.20} & 20030721 & 024639.030 & 1 & $02: 46: 39$ & 476445 & 45.482 & 3.364 & 46.6 & 385.0 \\
\hline & & & 1 & 02:46:39 & 788618 & 45.394 & 3.570 & 33.7 & 390.1 \\
\hline 01.21 & 20030721 & 025012.190 & 1 & 02:50:12 & 2396788 & 46.864 & 4.148 & 39.6 & 540.0 \\
\hline 01.22 & 20030721 & 025038.790 & 1 & $02: 50: 38$ & 7225762 & 45.604 & 3.342 & 25.9 & 393.5 \\
\hline 01.23 & 20030721 & 025108.270 & 1 & 02:51:08 & 3103047 & 46.194 & 3.422 & 59.6 & 447.1 \\
\hline 01.24 & 20030721 & 025703.630 & 1 & 02:57:03 & 4838543 & 45.741 & 3.456 & 17.5 & 410.7 \\
\hline \multirow[t]{2}{*}{01.25} & 20030721 & 025703.590 & 1 & 02:57:03 & 6687528 & 45.832 & 3.294 & 20.0 & 409.8 \\
\hline & & & 1 & 02:57:03 & 9635451 & 46.242 & 3.215 & 18.0 & 441.6 \\
\hline \multirow[t]{2}{*}{01.26} & 20030721 & 030328.510 & 1 & $03: 03: 28$ & 5468795 & 46.489 & 3.268 & 52.0 & 466.4 \\
\hline & & & 1 & 03:03:28 & 6842424 & 46.166 & 3.102 & 40.1 & 429.6 \\
\hline \multirow[t]{2}{*}{01.27} & 20030721 & 030634.030 & 1 & 03:06:33 & 9252952 & 45.912 & 3.549 & 91.1 & 429.6 \\
\hline & & & 1 & 03:06:34 & 850786 & 45.528 & 3.407 & 72.5 & 391.0 \\
\hline 01.28 & 20030721 & 030925.550 & 1 & 03:09:25 & 1895247 & 45.500 & 3.862 & 17.2 & 415.0 \\
\hline \multicolumn{2}{|c|}{ Large delay } & & 1 & 03:09:25 & 6027777 & 45.657 & 3.262 & 39.5 & 393.6 \\
\hline \multirow[t]{2}{*}{01.29} & 20030721 & 031334.230 & 1 & $03: 13: 34$ & 581061 & 45.824 & 3.812 & 30.7 & 436.6 \\
\hline & & & 1 & $03: 13: 34$ & 2758955 & 45.824 & 3.393 & 50.9 & 414.1 \\
\hline \multicolumn{10}{|c|}{ Storm 2} \\
\hline 02.01 & 20030722 & 215105.028 & 1 & 21:51:04 & 6203053 & 46.749 & 9.546 & 119.0 & 860.1 \\
\hline 02.02 & 20030722 & 215430.294 & 1 & $21: 54: 30$ & 3017605 & 45.064 & 5.604 & 102.7 & 503.8 \\
\hline 02.03 & 20030722 & 215705.459 & 1 & 21:57:05 & 4447978 & 45.054 & 5.605 & 63.4 & 503.3 \\
\hline \multicolumn{10}{|c|}{ Storm3 } \\
\hline 03.01 & 20030723 & 211132.326 & 1 & $21: 11: 32$ & 2977297 & 44.598 & 3.866 & 60.4 & 357.9 \\
\hline 03.02 & 20030723 & 213458.150 & & & & & & & \\
\hline 03.03 & 20030723 & 215211.204 & 1 & 21:52:11 & 776952 & 44.990 & 5.039 & 33.6 & 460.2 \\
\hline \multirow[t]{2}{*}{03.04} & 20030723 & 215628.452 & 1 & $21: 56: 28$ & 1965217 & 44.956 & 5.107 & 63.9 & 463.3 \\
\hline & & & 2 & $21: 56: 28$ & 2587845 & 44.976 & 5.053 & 27.3 & 460.5 \\
\hline 03.05 & 20030723 & 215903.476 & 1 & 21:59:03 & 3271532 & 45.010 & 5.080 & 44.4 & 464.1 \\
\hline 03.06 & 20030723 & 215903.496 & 1 & 21:59:03 & 3271532 & 45.010 & 5.080 & 44.4 & 464.1 \\
\hline 03.07 & 20030723 & 220535.710 & 1 & $22: 05: 35$ & 6789675 & 45.038 & 5.191 & 53.3 & 473.3 \\
\hline 03.08 & 20030723 & 220906.796 & 1 & 22:09:06 & 6832650 & 45.047 & 5.127 & 25.4 & 469.2 \\
\hline 03.09 & 20030723 & 220906.816 & 1 & 22:09:06 & 9047731 & 44.876 & 4.647 & 30.5 & 427.0 \\
\hline \multirow[t]{2}{*}{03.10} & 20030723 & 225102.258 & 1 & $22: 51: 02$ & 992804 & 43.951 & 5.926 & 42.5 & 490.1 \\
\hline & & & 1 & $22: 51: 02$ & 2217239 & 44.106 & 5.728 & 75.5 & 478.1 \\
\hline \multirow[t]{3}{*}{03.11} & 20030723 & 231234.800 & 1 & $23: 12: 34$ & 4376970 & 44.593 & 5.096 & 23.5 & 446.1 \\
\hline & & & 1 & $23: 12: 34$ & 8127213 & 44.367 & 5.452 & 54.8 & 464.4 \\
\hline & & & 1 & $23: 12: 35$ & 538850 & 44.223 & 5.762 & 46.7 & 483.9 \\
\hline 03.12 & 20030723 & 232141.117 & 1 & $23: 21: 41$ & 1091627 & 44.665 & 5.096 & 147.5 & 449.1 \\
\hline \multirow[t]{2}{*}{03.13} & 20030723 & 232141.257 & 1 & $23: 21: 41$ & 1091627 & 44.665 & 5.096 & 147.5 & 449.1 \\
\hline & & & 1 & $23: 21: 41$ & 2725542 & 44.610 & 5.283 & 22.5 & 460.6 \\
\hline
\end{tabular}


Appendix 1 continued

\begin{tabular}{|c|c|c|c|c|c|c|c|c|c|}
\hline TLE\# & TLE time & & M & $\begin{array}{l}\text { Flash } \\
\text { time }\end{array}$ & & $\begin{array}{l}\text { Lat } \\
\text { (North) }\end{array}$ & $\begin{array}{l}\text { Long } \\
\text { (East) }\end{array}$ & $\begin{array}{l}\text { Peak I } \\
\text { (A) }\end{array}$ & $\begin{array}{l}\text { Distance } \\
(\mathrm{km})\end{array}$ \\
\hline & & & 1 & $23: 21: 41$ & 4188476 & 44.463 & 5.592 & 23.5 & 478.3 \\
\hline 03.14 & 20030724 & 002328.337 & 1 & $00: 23: 28$ & 3197169 & 44.573 & 6.656 & 70.4 & 562.6 \\
\hline 03.15 & 20030724 & 002827.485 & 1 & $00: 28: 27$ & 4826391 & 44.686 & 6.711 & 59.5 & 570.4 \\
\hline 03.16 & 20030724 & 003301.555 & 1 & 00:33:01 & 5385529 & 44.641 & 6.749 & 45.1 & 571.8 \\
\hline \multicolumn{10}{|c|}{ Storm4 } \\
\hline \multirow[t]{2}{*}{04.01} & 20030727 & 204619.521 & 1 & $20: 46: 19$ & 3447626 & 46.514 & 9.783 & 17.2 & 865.8 \\
\hline & & & 1 & $20: 46: 19$ & 8040170 & 47.020 & 9.559 & 35.6 & 874.4 \\
\hline \multirow[t]{3}{*}{04.02} & 20030727 & 211355.814 & 1 & $21: 13: 55$ & 6270131 & 47.488 & 9.913 & 49.2 & 922.6 \\
\hline & & & 1 & $21: 13: 55$ & 7977263 & 47.341 & 9.782 & 76.1 & 906.1 \\
\hline & & & 1 & $21: 13: 55$ & 9361352 & 47.073 & 9.527 & 42.7 & 875.0 \\
\hline \multicolumn{10}{|l|}{ Storm5 } \\
\hline 05.01 & 20030820 & 201937.903 & 1 & $20: 19: 37$ & 5350414 & 45.106 & 6.865 & -14.5 & 596.9 \\
\hline \multicolumn{10}{|c|}{ Storm6 } \\
\hline 06.01 & 20030822 & 212829.394 & 1 & $21: 28: 29$ & 2436928 & 39.961 & -0.761 & 25.3 & 344.2 \\
\hline 06.02 & 20030822 & 212829.514 & 1 & $21: 28: 29$ & 2436928 & 39.961 & -0.761 & 25.3 & 344.2 \\
\hline \multirow[t]{2}{*}{06.03} & 20030822 & 213108.481 & 1 & 21:31:08 & 4962900 & 39.704 & -1.095 & 55.4 & 378.2 \\
\hline & & & 1 & $21: 31: 08$ & 6075565 & 39.753 & -1.268 & 68.9 & 376.6 \\
\hline 06.04 & 20030822 & 213405.766 & 1 & 21:34:05 & 7828360 & 39.665 & -0.787 & 56.6 & 377.0 \\
\hline 06.05 & 20030822 & 213405.786 & 1 & $21: 34: 05$ & 7828360 & 39.665 & -0.787 & 56.6 & 377.0 \\
\hline 06.06 & 20030822 & 213643.191 & 1 & $21: 36: 43$ & 1933773 & 39.734 & -1.073 & 113.8 & 374.4 \\
\hline 06.07 & 20030822 & 214252.243 & 1 & $21: 42: 52$ & 2564001 & 39.740 & -0.735 & 99.6 & 368.0 \\
\hline \multicolumn{10}{|c|}{ Storm7 } \\
\hline 07.01 & 20030824 & 211741.901 & 1 & $21: 17: 41$ & 6923074 & 43.503 & 2.399 & 41.8 & 202.4 \\
\hline \multirow[t]{2}{*}{07.02} & 20030824 & 213742.359 & 1 & $21: 37: 42$ & 2763870 & 43.443 & 2.543 & 129.9 & 212.1 \\
\hline & & & 1 & $21: 37: 42$ & 3696938 & 43.446 & 2.564 & 54.1 & 213.8 \\
\hline \multicolumn{10}{|l|}{ Storm8 } \\
\hline \multirow[t]{2}{*}{08.01} & 20030825 & 195647.448 & 1 & $19: 56: 46$ & 8297394 & 42.538 & 11.219 & 26.5 & 917.5 \\
\hline & & & 1 & $19: 56: 47$ & 4590832 & 42.790 & 10.863 & 62.6 & 885.6 \\
\hline 08.02 & 20030825 & 203037.810 & 1 & $20: 30: 37$ & 8299507 & 42.477 & 11.120 & 144.8 & 910.3 \\
\hline 08.03 & 20030825 & 203235.014 & 1 & $20: 32: 35$ & 265978 & 42.381 & 11.266 & 71.5 & 923.6 \\
\hline 08.04 & 20030825 & 205612.599 & 1 & $20: 56: 12$ & 6021825 & 43.078 & 10.067 & 85.1 & 818.6 \\
\hline \multirow[t]{2}{*}{08.05} & 20030825 & 205955.386 & 1 & $20: 59: 55$ & 3887244 & 42.775 & 9.884 & 88.9 & 806.1 \\
\hline & & & 1 & $20: 59: 55$ & 5520819 & 43.033 & 10.002 & 42.8 & 813.6 \\
\hline 08.06 & 20030825 & 210830.763 & 1 & $21: 08: 30$ & 7575068 & 43.064 & 9.407 & 62.5 & 765.1 \\
\hline 08.07 & 20030825 & 211456.337 & 1 & $21: 14: 56$ & 3165277 & 42.922 & 9.963 & 150.6 & 811.2 \\
\hline \multirow[t]{2}{*}{08.08} & 20030825 & 213517.357 & 1 & $21: 35: 16$ & 9525907 & 42.445 & 9.682 & 25.2 & 793.7 \\
\hline & & & 1 & $21: 35: 17$ & 3605032 & 42.820 & 9.762 & 134.8 & 795.7 \\
\hline 08.09 & 20030825 & 213517.397 & 1 & $21: 35: 17$ & 3605032 & 42.820 & 9.762 & 134.8 & 795.7 \\
\hline \multirow[t]{2}{*}{08.10} & 20030825 & 213517.417 & 1 & $21: 35: 17$ & 3605032 & 42.820 & 9.762 & 134.8 & 795.7 \\
\hline & & & 1 & $21: 35: 17$ & 4947733 & 43.233 & 9.763 & 47.1 & 793.3 \\
\hline \multirow[t]{2}{*}{08.11} & 20030825 & 213721.481 & 1 & $21: 37: 21$ & 4824718 & 42.847 & 9.336 & 76.3 & 760.8 \\
\hline & & & 1 & $21: 37: 21$ & 5813983 & 43.028 & 9.659 & 34.2 & 785.8 \\
\hline
\end{tabular}


Appendix 1 continued

\begin{tabular}{|c|c|c|c|c|c|c|c|c|c|}
\hline \multirow{2}{*}{$\begin{array}{l}\text { TLE\# } \\
\text { Storm9 }\end{array}$} & \multicolumn{2}{|l|}{ TLE time } & \multirow[t]{2}{*}{ M } & \multicolumn{2}{|l|}{$\begin{array}{l}\text { Flash } \\
\text { time }\end{array}$} & \multirow[t]{2}{*}{$\begin{array}{l}\text { Lat } \\
\text { (North) }\end{array}$} & \multirow[t]{2}{*}{$\begin{array}{l}\text { Long } \\
\text { (East) }\end{array}$} & \multirow[t]{2}{*}{$\begin{array}{l}\text { Peak I } \\
\text { (A) }\end{array}$} & \multirow[t]{2}{*}{$\begin{array}{l}\text { Distance } \\
(\mathrm{km})\end{array}$} \\
\hline & & & & & & & & & \\
\hline \multirow[t]{2}{*}{09.01} & 20030828 & 201800.815 & 1 & 20:18:00 & 8216922 & 46.316 & 4.309 & 84.4 & 502.5 \\
\hline & & & 1 & $20: 18: 00$ & 9656683 & 46.389 & 3.955 & 45.5 & 490.0 \\
\hline \multirow[t]{3}{*}{09.02} & 20030828 & 225706.221 & 1 & $22: 57: 06$ & 1293877 & 45.798 & 5.795 & 69.2 & 556.0 \\
\hline & & & 1 & $22: 57: 06$ & 3947627 & 46.047 & 6.091 & 55.1 & 590.3 \\
\hline & & & 1 & $22: 57: 06$ & 4725884 & 45.738 & 6.455 & 31.8 & 597.0 \\
\hline 09.03 & 20030828 & 230324.974 & 1 & $23: 03: 24$ & 9936912 & 45.348 & 5.509 & 110.6 & 511.5 \\
\hline 09.04 & 20030828 & 231110.569 & & & & & & & \\
\hline 09.05 & 20030828 & 231110.689 & & & & & & & \\
\hline \multirow[t]{3}{*}{09.06} & 20030828 & 231110.829 & 1 & $23: 11: 10$ & 8468338 & 45.745 & 5.628 & 57.9 & 541.9 \\
\hline & & & 1 & $23: 11: 11$ & 2703137 & 45.984 & 6.063 & 24.5 & 584.7 \\
\hline & & & 1 & $23: 11: 11$ & 4065650 & 46.140 & 5.884 & 15.1 & 582.8 \\
\hline 09.07 & 20030828 & 231355.134 & 1 & $23: 13: 55$ & 1571086 & 45.450 & 5.592 & 124.2 & 522.6 \\
\hline \multirow[t]{2}{*}{09.08} & 20030828 & 231355.194 & 2 & $23: 13: 55$ & 1938103 & 45.444 & 5.584 & 22.4 & 521.8 \\
\hline & & & 1 & $23: 13: 55$ & 5448105 & 45.744 & 5.698 & 18.1 & 546.4 \\
\hline 09.09 & 20030828 & 231441.175 & 1 & $23: 14: 41$ & 1379871 & 47.295 & 7.837 & 45.7 & 778.6 \\
\hline 09.10 & 20030828 & 231655.799 & 1 & $23: 16: 55$ & 5048005 & 45.492 & 5.652 & 117.6 & 529.0 \\
\hline 09.11 & 20030828 & 231655.839 & 1 & $23: 16: 55$ & 8033441 & 45.982 & 5.965 & 106.8 & 578.1 \\
\hline 09.12 & 20030828 & 231655.859 & 1 & $23: 16: 55$ & 8158742 & 45.466 & 6.049 & 41.0 & 554.9 \\
\hline \multirow[t]{2}{*}{09.13} & 20030828 & 231655.899 & 1 & $23: 16: 55$ & 9034059 & 45.931 & 6.254 & 72.2 & 594.1 \\
\hline & & & 1 & $23: 16: 55$ & 9261566 & 46.060 & 6.052 & 36.1 & 588.5 \\
\hline \multirow[t]{2}{*}{09.14} & 20030828 & 231842.362 & 1 & $23: 18: 42$ & 2239738 & 45.471 & 5.646 & 18.2 & 527.5 \\
\hline & & & 2 & $23: 18: 42$ & 3518902 & 45.487 & 5.704 & 68.0 & 532.3 \\
\hline 09.15 & 20030828 & 231946.584 & 1 & $23: 19: 46$ & 5570899 & 45.548 & 5.726 & 113.6 & 537.1 \\
\hline 09.16 & 20030828 & 231946.984 & 1 & $23: 19: 46$ & 9867420 & 45.710 & 6.345 & 112.9 & 588.0 \\
\hline 09.17 & 20030828 & 231947.184 & 1 & $23: 19: 47$ & 1936325 & 45.441 & 6.536 & 72.7 & 587.7 \\
\hline 09.18 & 20030828 & 232154.569 & 1 & $23: 21: 54$ & 5142768 & 45.579 & 5.765 & 83.7 & 541.5 \\
\hline 09.19 & 20030828 & 232154.589 & 1 & $23: 21: 54$ & 5142768 & 45.579 & 5.765 & 83.7 & 541.5 \\
\hline 09.20 & 20030828 & 232154.789 & 1 & $23: 21: 54$ & 7771318 & 45.832 & 5.866 & 20.0 & 562.8 \\
\hline 09.21 & 20030828 & 232442.474 & 1 & $23: 24: 42$ & 4254060 & 45.582 & 5.772 & 72.3 & 542.1 \\
\hline 09.22 & 20030828 & 232920.382 & 1 & $23: 29: 20$ & 2764177 & 45.298 & 5.882 & 71.1 & 534.7 \\
\hline 09.23 & 20030828 & 232920.422 & 1 & $23: 29: 20$ & 2764177 & 45.298 & 5.882 & 71.1 & 534.7 \\
\hline 09.24 & 20030828 & 232920.662 & 1 & $23: 29: 20$ & 6606870 & 45.735 & 6.295 & 60.0 & 585.9 \\
\hline 09.25 & 20030828 & 232920.702 & 1 & $23: 29: 20$ & 6606870 & 45.735 & 6.295 & 60.0 & 585.9 \\
\hline 09.26 & 20030828 & 232920.782 & 1 & $23: 29: 20$ & 6606870 & 45.735 & 6.295 & 60.0 & 585.9 \\
\hline 09.27 & 20030828 & 233140.708 & & & & & & & \\
\hline \multirow[t]{2}{*}{09.28} & 20030828 & 233424.592 & 1 & $23: 34: 24$ & 4886795 & 45.412 & 5.733 & 32.2 & 530.2 \\
\hline & & & 1 & $23: 34: 24$ & 7554713 & 45.684 & 5.887 & 30.9 & 555.6 \\
\hline \multirow[t]{2}{*}{09.29} & 20030829 & 000442.550 & 1 & 00:04:42 & 5532696 & 45.786 & 6.368 & 74.5 & 593.7 \\
\hline & & & 1 & $00: 04: 42$ & 7874671 & 45.657 & 6.650 & 56.0 & 606.3 \\
\hline 09.30 & 20030829 & 004024.043 & 1 & $00: 40: 24$ & 275916 & 45.530 & 5.821 & 46.0 & 542.6 \\
\hline 09.31 & 20030829 & 004454.285 & 1 & $00: 44: 54$ & 2034265 & 45.562 & 5.889 & 56.2 & 549.0 \\
\hline 09.32 & 20030829 & 014111.170 & 1 & $01: 41: 11$ & 973522 & 46.573 & 9.460 & 111.7 & 845.8 \\
\hline
\end{tabular}


Appendix 1 continued

\begin{tabular}{|c|c|c|c|c|c|c|c|c|c|}
\hline TLE\# & TLE time & & M & $\begin{array}{l}\text { Flash } \\
\text { time }\end{array}$ & & $\begin{array}{l}\text { Lat } \\
\text { (North) }\end{array}$ & $\begin{array}{l}\text { Long } \\
\text { (East) }\end{array}$ & $\begin{array}{l}\text { Peak I } \\
\text { (A) }\end{array}$ & $\begin{array}{l}\text { Distance } \\
(\mathrm{km})\end{array}$ \\
\hline 09.33 & 20030829 & 021601.574 & 1 & 02:16:01 & 5827200 & 45.964 & 6.051 & 129.7 & 582.7 \\
\hline 09.34 & 20030829 & 021643.235 & & & & & & & \\
\hline 09.35 & 20030829 & 023414.607 & 1 & $02: 34: 14$ & 6231497 & 45.844 & 5.836 & 106.3 & 561.4 \\
\hline \multirow[t]{2}{*}{09.36} & 20030829 & 023414.747 & 1 & $02: 34: 14$ & 7637664 & 46.006 & 6.027 & 112.0 & 583.6 \\
\hline & & & 1 & $02: 34: 14$ & 8716812 & 46.080 & 6.405 & 93.9 & 612.7 \\
\hline \multirow[t]{2}{*}{09.37} & 20030829 & 023519.989 & 1 & $02: 35: 19$ & 9960544 & 46.643 & 9.691 & 45.6 & 865.2 \\
\hline & & & 1 & $02: 35: 20$ & 970295 & 46.783 & 9.897 & 25.9 & 885.9 \\
\hline 08.12 & 20030825 & 214129.390 & 1 & $21: 41: 29$ & 4038027 & 42.802 & 9.061 & 42.5 & 738.8 \\
\hline 08.13 & 20030825 & 214129.450 & 1 & $21: 41: 29$ & 5111275 & 42.968 & 9.497 & 52.6 & 773.0 \\
\hline \multirow[t]{2}{*}{08.14} & 20030825 & 214129.490 & 1 & $21: 41: 29$ & 6144416 & 42.823 & 9.812 & 69.4 & 799.7 \\
\hline & & & 1 & $21: 41: 29$ & 6227234 & 43.301 & 9.555 & 39.1 & 776.3 \\
\hline 08.15 & 20030825 & 214454.916 & 1 & $21: 44: 55$ & 1214298 & 43.292 & 9.614 & 31.8 & 781.1 \\
\hline 08.16 & 20030825 & 214454.936 & 1 & $21: 44: 55$ & 1396312 & 43.058 & 9.324 & 32.8 & 758.4 \\
\hline \multirow[t]{3}{*}{08.17} & 20030825 & 215022.015 & 2 & 21:50:21 & 9421691 & 43.104 & 8.818 & 59.5 & 717.1 \\
\hline & & & 1 & $21: 50: 22$ & 252537 & 43.132 & 9.032 & 63.2 & 734.3 \\
\hline & & & 1 & $21: 50: 22$ & 1589191 & 42.941 & 9.666 & 34.8 & 786.9 \\
\hline 08.18 & 20030825 & 215659.620 & 1 & $21: 56: 59$ & 6192954 & 43.123 & 8.723 & 53.9 & 709.3 \\
\hline 08.19 & 20030825 & 215659.720 & 1 & 21:56:59 & 7213260 & 43.152 & 9.256 & 47.7 & 752.4 \\
\hline 08.20 & 20030825 & 220634.519 & 1 & $22: 06: 34$ & 4835368 & 43.121 & 8.742 & 45.7 & 710.8 \\
\hline 09.38 & 20030829 & 023826.394 & & & & & & & \\
\hline 09.39 & 20030829 & 023922.816 & & & & & & & \\
\hline 09.40 & 20030829 & 024110.641 & 1 & $02: 41: 10$ & 6582007 & 46.061 & 6.073 & 76.2 & 590.0 \\
\hline 09.41 & 20030829 & 025332.523 & 1 & $02: 53: 32$ & 4942708 & 46.560 & 9.748 & 41.1 & 865.3 \\
\hline 09.42 & 20030829 & 025636.888 & 1 & $02: 56: 36$ & 8960817 & 46.299 & 6.291 & 68.2 & 618.6 \\
\hline 09.43 & 20030829 & 025753.230 & 1 & $02: 57: 53$ & 2270698 & 46.827 & 10.342 & 98.4 & 918.8 \\
\hline 09.44 & 20030829 & 030525.885 & 1 & $03: 05: 25$ & 8787280 & 46.508 & 9.954 & 41.8 & 877.5 \\
\hline 09.45 & 20030829 & 031340.460 & 1 & $03: 13: 40$ & 3181245 & 46.072 & 6.096 & 38.1 & 592.1 \\
\hline \multirow[t]{2}{*}{09.46} & 20030829 & 031946.970 & 1 & $03: 19: 46$ & 9768514 & 46.823 & 10.229 & 19.6 & 910.8 \\
\hline & & & 1 & 03:19:47 & 1633218 & 46.992 & 10.407 & 30.7 & 930.9 \\
\hline 09.47 & 20030829 & 033552.860 & & & & & & & \\
\hline 09.48 & 20030829 & 033552.900 & & & & & & & \\
\hline 09.49 & 20030829 & 034419.996 & 1 & $03: 44: 20$ & 214724 & 45.184 & 5.101 & -141.5 & 474.7 \\
\hline 09.50 & 20030829 & 034543.638 & 1 & $03: 45: 43$ & 6640816 & 46.402 & 6.503 & 268.7 & 638.5 \\
\hline 09.51 & 20030829 & 034543.678 & 1 & $03: 45: 43$ & 6640816 & 46.402 & 6.503 & 268.7 & 638.5 \\
\hline 09.52 & 20030829 & 034707.201 & & & & & & & \\
\hline 09.53 & 20030829 & 034707.221 & & & & & & & \\
\hline
\end{tabular}

The times (UT) of sprite events are shown with the corresponding geographic location (in degrees and thousandths of a degree), peak current I and multiplicity of the associated +CG lightning

Also shown is the distance from the cameras to the events. Transient Luminous Event (TLE) time is given in the following format: YYYYMMDD (column 2) HHMMSS.SSS (column 3). Flash time is in the format: HH:MM:SS (column 6) and tenths of microseconds (column 7). M is the multiplicity of the lightning flash 


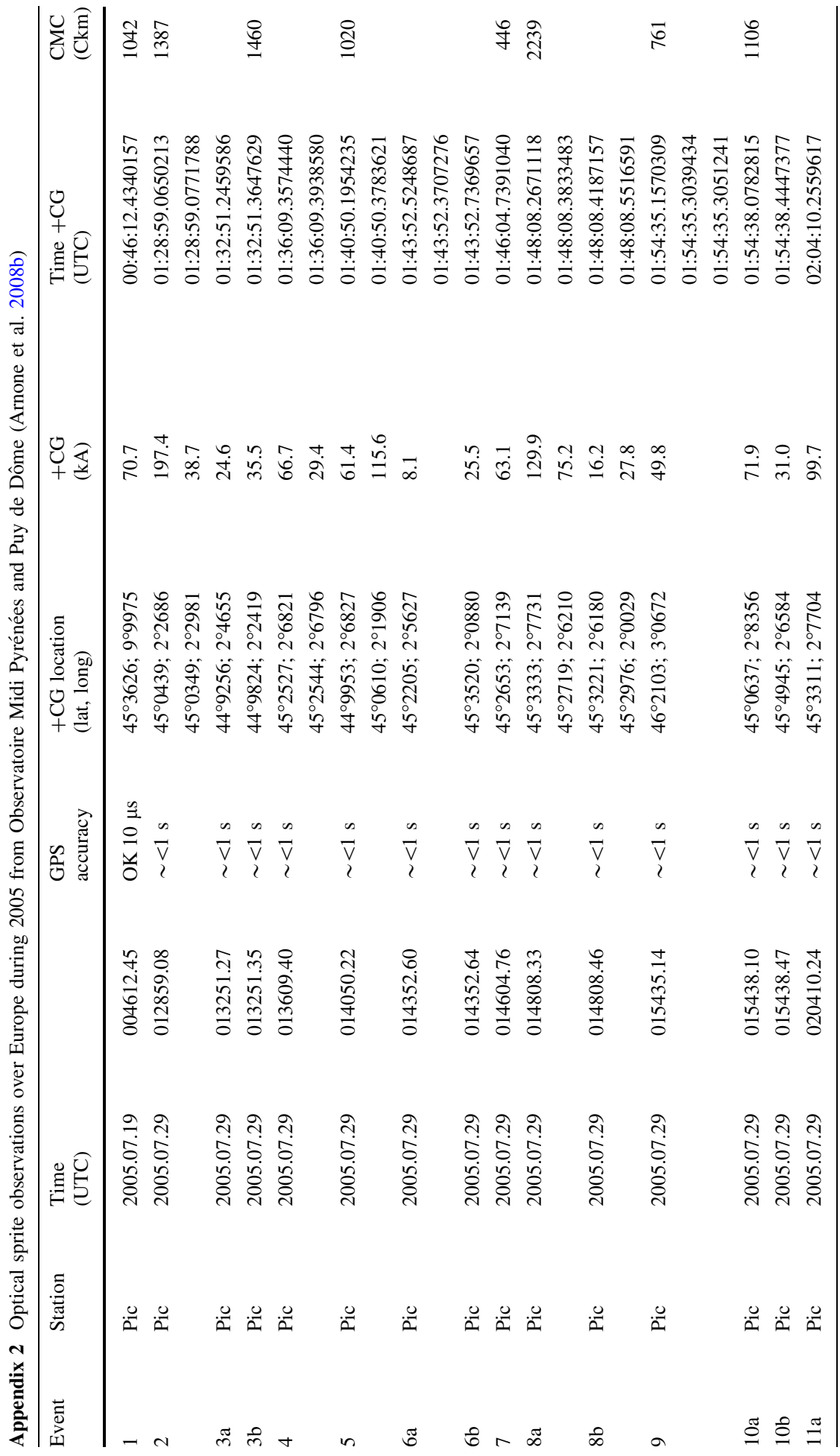




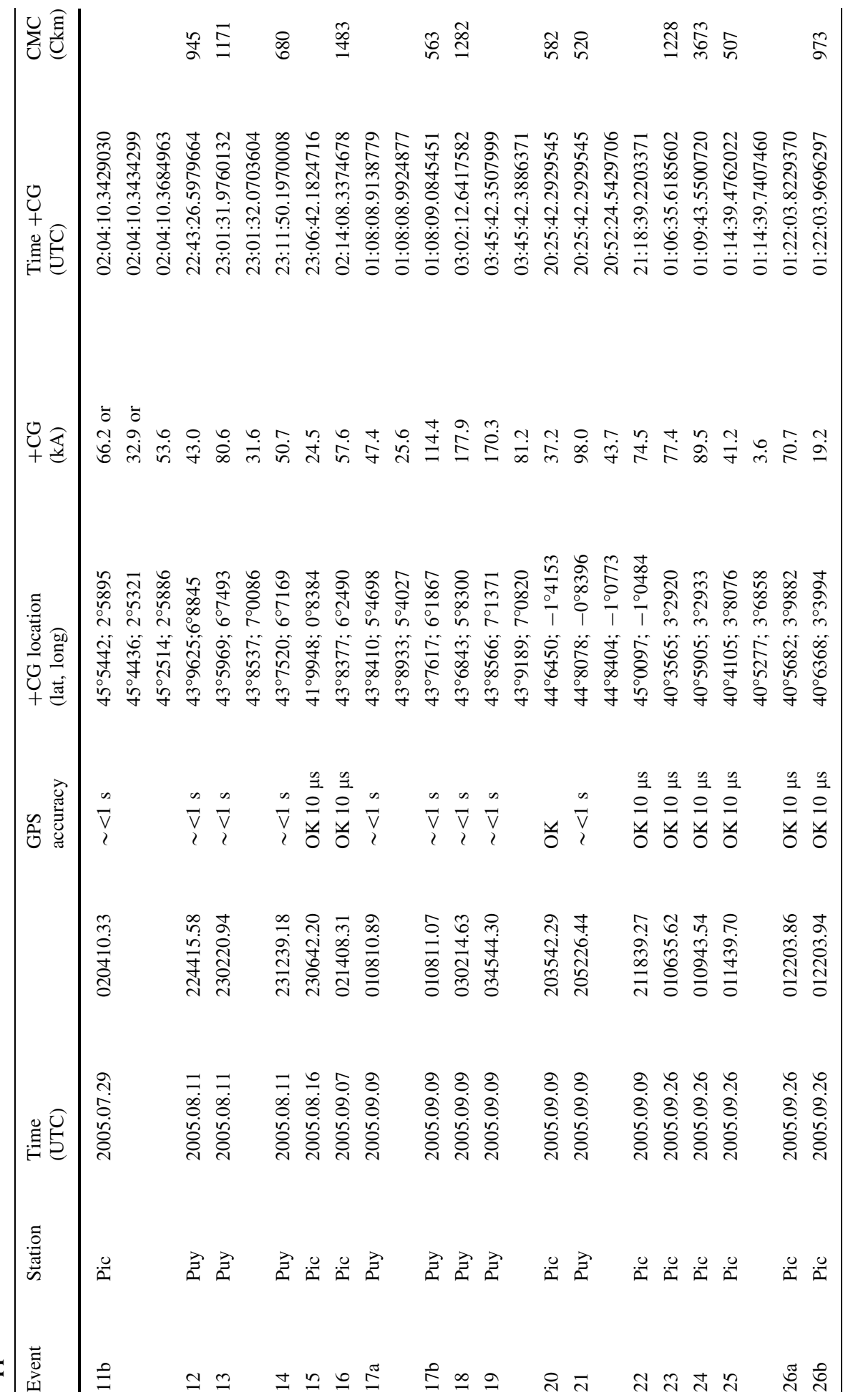




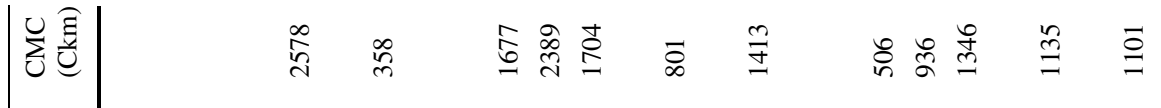

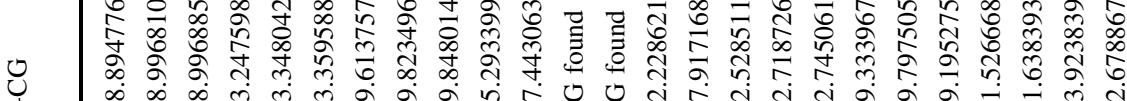

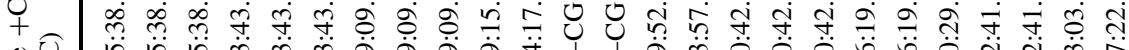

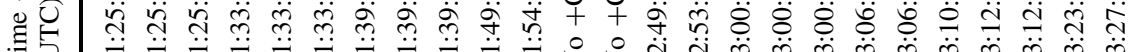

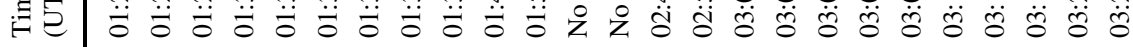

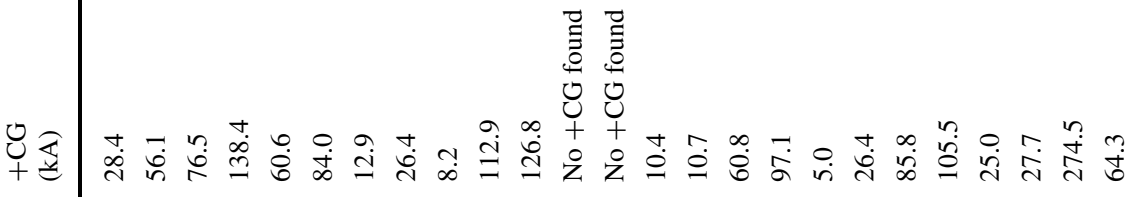

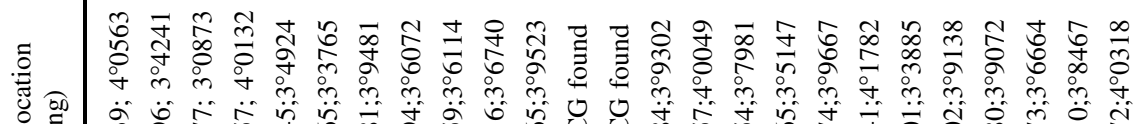

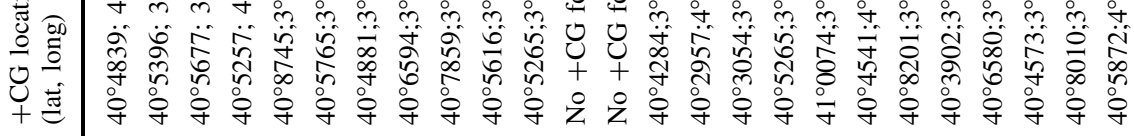

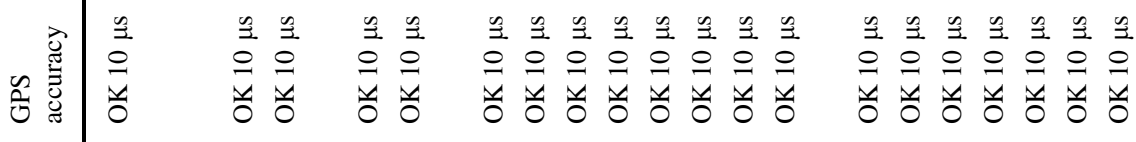

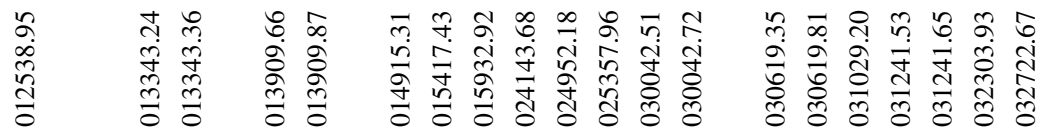

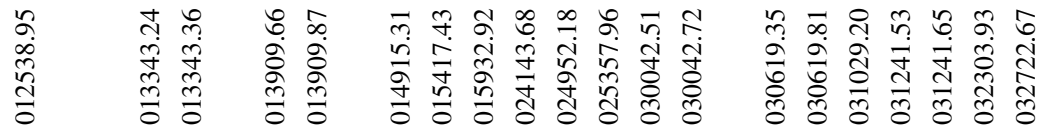

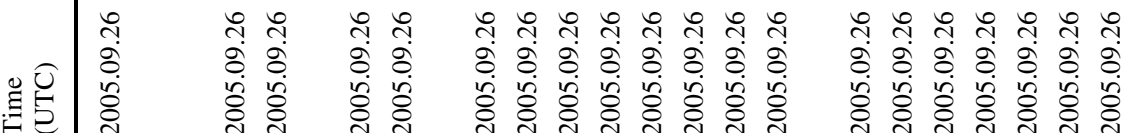

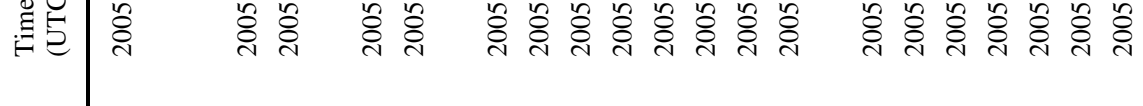

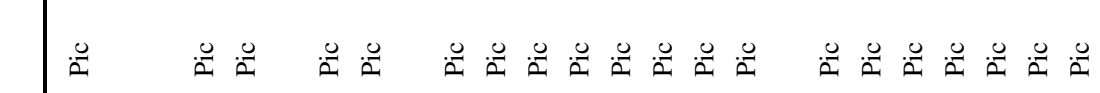

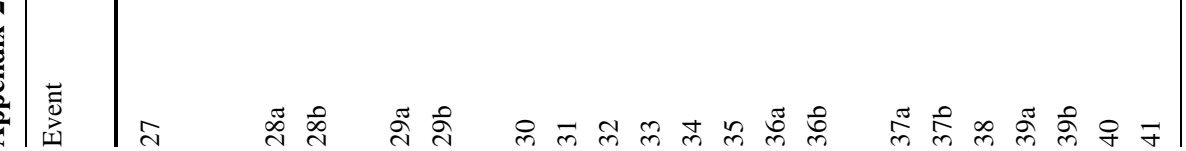




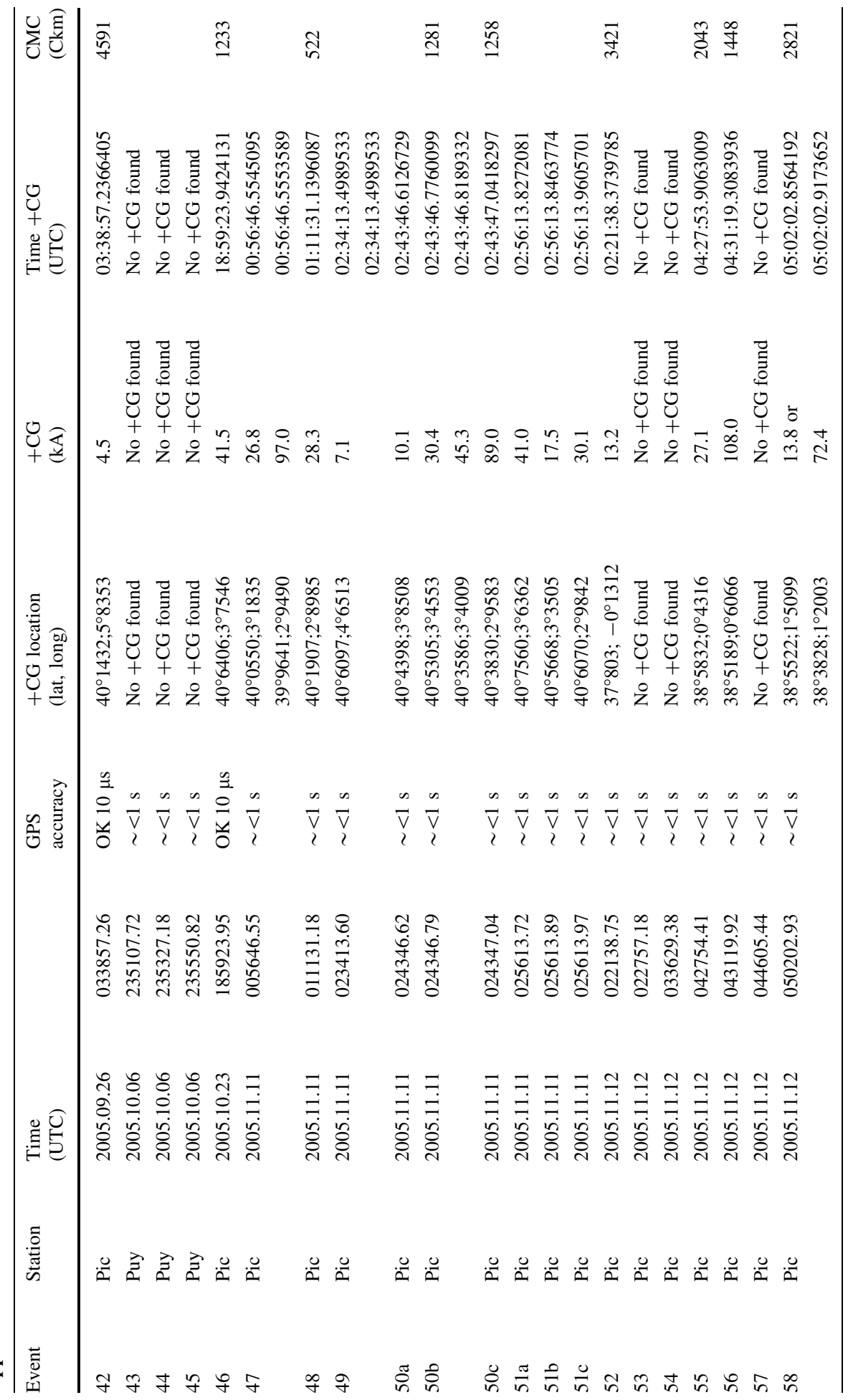




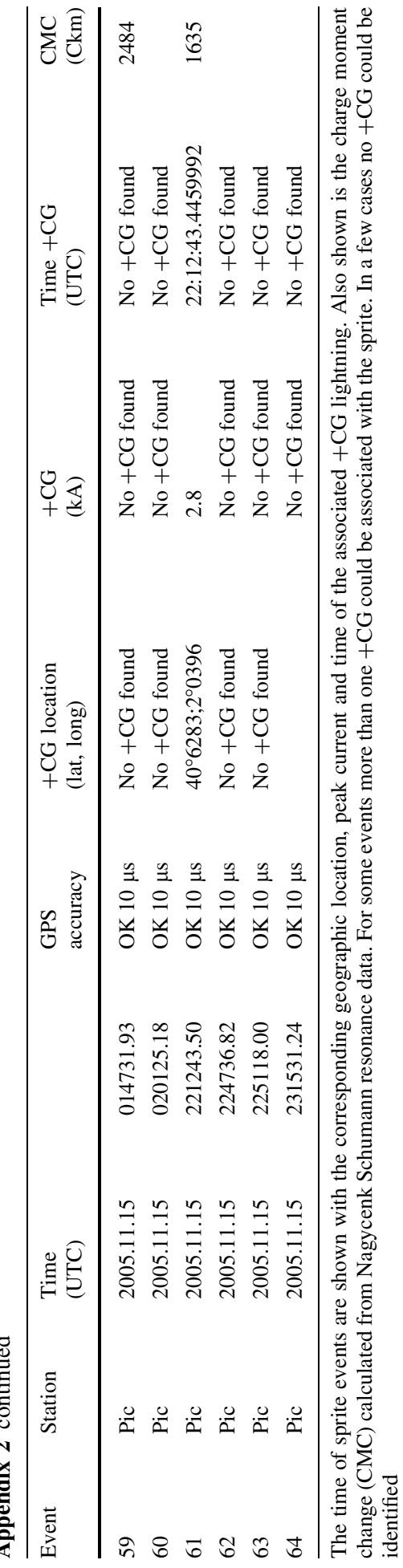


Appendix 3 Optical sprite observations over Europe during 2006 from Observatoire Midi Pyrénées

\begin{tabular}{|c|c|c|c|c|c|c|}
\hline Event & Time & (UTC) & Accuracy GPS & $\begin{array}{l}\text { Time }+C G \\
\text { (UTC) }\end{array}$ & $\begin{array}{l}\text { +CG location } \\
\text { (lat, long) }\end{array}$ & $\begin{array}{l}\mathrm{I}+\mathrm{CG} \\
(\mathrm{kA})\end{array}$ \\
\hline 1 & 2006.07 .03 & 022723.298 & $\sim 20 \mathrm{~ms}$ & $\mathrm{No}+\mathrm{CG}$ & No $+\mathrm{CG}$ found & \\
\hline 2 & 2006.07 .03 & 023456.918 & $\sim 20 \mathrm{~ms}$ & 023456.877 & $44.308700 ;-0.574400$ & 25.6 \\
\hline \multirow[t]{2}{*}{3} & 2006.07 .03 & 023723.748 & $\sim 20 \mathrm{~ms}$ & 023723.754 & $44.976900 ;-1.360700$ & 40.7 \\
\hline & & & & 023727.831 & $45.605400 ;-2.529100$ & 8.9 \\
\hline \multirow[t]{2}{*}{4} & 2006.07 .03 & 024255.164 & $\sim 20 \mathrm{~ms}$ & 024255.068 & $45.069900 ;-0.818000$ & 31.0 \\
\hline & & & & 024255.288 & $44.910000 ;-1.184400$ & 32.9 \\
\hline 5 & 2006.07 .03 & 024608.421 & $\sim 20 \mathrm{~ms}$ & 024608.389 & $45.629300 ;-2.016500$ & 7.8 \\
\hline 6 & 2006.07 .03 & 025238.185 & $\sim 20 \mathrm{~ms}$ & 025238.176 & $45.299500 ;-1.073700$ & 22.6 \\
\hline 7 & 2006.07 .04 & 204606.591 & $\sim 20 \mathrm{~ms}$ & 204606.598 & $44.350600 ;-0.808200$ & 81.8 \\
\hline 8 & 2006.07 .04 & 223651.838 & $\mathrm{OK} 10 \mu \mathrm{s}$ & 223651.733 & $47.247000 ;-0.139000$ & 55.6 \\
\hline 9 & 2006.07 .04 & 225153.730 & OK $10 \mu \mathrm{s}$ & 225153.733 & $46.937100 ;-0.848000$ & 52.8 \\
\hline \multirow[t]{2}{*}{10} & 2006.07.05 & 000436.446 & $\mathrm{OK} 10 \mu \mathrm{s}$ & 000436.299 & $45.228400 ;-1.917100$ & 19.1 \\
\hline & & & & 000436.446 & $45.269400 ;-1.966500$ & 38.2 \\
\hline 11 & 2006.07 .05 & 001642.461 & OK $10 \mu \mathrm{s}$ & 001642.422 & $45.578900 ; 2.084900$ & 76.5 \\
\hline \multirow[t]{3}{*}{12} & 2006.07 .05 & 003843.416 & OK $10 \mu \mathrm{s}$ & 003843.522 & $45.572500 ; 2.103000$ & 39.3 \\
\hline & & & & 003843.524 & $45.459600 ; 2.139000$ & 48.8 \\
\hline & & & & 003843.596 & $45.243000 ; 2.242500$ & 29.6 \\
\hline 13 & 2006.07 .05 & 030531.032 & $\sim 500 \mu \mathrm{s}$ & 030531.017 & $45.138300 ; 2.603800$ & 85.3 \\
\hline 14 & 2006.07 .05 & 224233.711 & OK $10 \mu \mathrm{s}$ & $\mathrm{No}+\mathrm{CG}$ & No + CG found & \\
\hline 15 & 2006.07 .21 & 220615.805 & $\mathrm{OK} 10 \mu \mathrm{s}$ & 220615.521 & $43.473600 ; 0.743600$ & 33.5 \\
\hline 16 & 2006.07 .22 & 014657.000 & $\sim 10 \mathrm{~ms}$ & 014657.004 & $44.731200 ; 0.999900$ & 45.2 \\
\hline 17 & 2006.07 .22 & 020132.056 & $\sim 10 \mathrm{~ms}$ & 020132.056 & $44.871800 ; 1.169100$ & 61.8 \\
\hline 18 & 2006.07 .27 & 011317.209 & $\mathrm{OK} 40 \mu \mathrm{s}$ & 011317.168 & $45.957100 ; 1.076500$ & 51.0 \\
\hline 19 & 2006.07 .27 & 013657.253 & $\sim 15 \mathrm{~ms}$ & 013657.202 & $46.145900 ; 1.519200$ & 138.4 \\
\hline \multirow[t]{3}{*}{20} & 2006.07 .27 & 022418.582 & $\sim 4 \mathrm{~ms}$ & 022418.533 & $47.612600 ; 2.061200$ & 25.5 \\
\hline & & & & 022418.570 & $47.622400 ; 1.970000$ & 99.3 \\
\hline & & & & 022418.880 & $47.954800 ; 1.745600$ & 56.1 \\
\hline \multirow[t]{8}{*}{21} & 2006.07 .27 & 023317.129 & $\mathrm{OK} 10 \mu \mathrm{s}$ & 023317.109 & $47.381900 ; 1.038200$ & 82.0 \\
\hline & & & & 023317.235 & $47.618900 ; 1.182800$ & 87.9 \\
\hline & & & & 023317.454 & $47.716200 ; 1.177600$ & 33.4 \\
\hline & & & & 023317.604 & $47.713200 ; 1.730000$ & 36.8 \\
\hline & & & & 023317.928 & $47.868200 ; 1.746600$ & 36.8 \\
\hline & & & & 023318.096 & $48.070100 ; 1.949700$ & 56.9 \\
\hline & & & & 023318.167 & $47.557800 ; 1.804800$ & 32.3 \\
\hline & & & & 023318.551 & $47.867900 ; 1.594000$ & 63.4 \\
\hline \multirow[t]{4}{*}{22} & 2006.07 .27 & 023650.569 & $\mathrm{OK} 10 \mu \mathrm{s}$ & 023650.522 & $47.461200 ; 1.125200$ & 136.0 \\
\hline & & & & 023650.633 & $47.634300 ; 1.209400$ & 104.2 \\
\hline & & & & 023650.740 & $47.542700 ; 1.207200$ & 29.5 \\
\hline & & & & 023650.807 & $47.698500 ; 1.726700$ & 31.6 \\
\hline \multirow[t]{3}{*}{23} & 2006.08 .17 & 222944.167 & $\sim 20 \mathrm{~ms}$ & 222944.159 & $44.778700 ; 4.351300$ & 55.2 \\
\hline & & & & 222944.729 & $49.522400 ; 8.051100$ & 7.2 \\
\hline & & & & 222944.855 & $48.673700 ; 6.562400$ & 25.8 \\
\hline
\end{tabular}


Appendix 3 continued

\begin{tabular}{|c|c|c|c|c|c|c|}
\hline Event & Time & (UTC) & Accuracy GPS & $\begin{array}{l}\text { Time }+C G \\
\text { (UTC) }\end{array}$ & $\begin{array}{l}\text { +CG location } \\
\text { (lat, long) }\end{array}$ & $\begin{array}{l}\mathrm{I}+\mathrm{CG} \\
(\mathrm{kA})\end{array}$ \\
\hline 24 & 2006.08 .17 & 223400.272 & OK $20 \mu \mathrm{s}$ & 223400.221 & $44.907700 ; 4.339200$ & 57.2 \\
\hline \multirow[t]{2}{*}{25} & \multirow[t]{2}{*}{2006.08 .17} & \multirow[t]{2}{*}{225058.941} & \multirow[t]{2}{*}{$\sim 40 \mathrm{~ms}$} & 225058.535 & $48.368800 ; 7.249700$ & 24.0 \\
\hline & & & & 225058.918 & $45.196300 ; 4.842500$ & 100.0 \\
\hline \multirow[t]{2}{*}{26} & \multirow[t]{2}{*}{2006.08 .17} & \multirow[t]{2}{*}{225333.480} & \multirow[t]{2}{*}{$\sim 40 \mathrm{~ms}$} & 225333.431 & $45.134000 ; 4.766600$ & 44.2 \\
\hline & & & & 225333.540 & $45.070400 ; 4.482800$ & 19.1 \\
\hline \multirow[t]{2}{*}{27} & \multirow[t]{2}{*}{2006.08 .17} & \multirow[t]{2}{*}{225846.222} & \multirow[t]{2}{*}{$\sim 1 \mathrm{~ms}$} & 225846.219 & $45.136200 ; 4.421300$ & 115.3 \\
\hline & & & & 225846.648 & $44.968800 ; 4.819300$ & 27.0 \\
\hline 28 & 2006.08 .17 & 230049.125 & $\sim 1 \mathrm{~ms}$ & 230049.141 & $45.377700 ; 4.888600$ & 141.4 \\
\hline \multirow[t]{2}{*}{29} & \multirow[t]{2}{*}{2006.08 .17} & \multirow[t]{2}{*}{233807.755} & \multirow[t]{2}{*}{$\sim 1 \mathrm{~ms}$} & 233807.719 & $44.716400 ; 5.177600$ & 29.5 \\
\hline & & & & 233808.102 & $45.325800 ; 5.255600$ & 68.9 \\
\hline \multirow[t]{5}{*}{30} & \multirow[t]{5}{*}{2006.08 .17} & \multirow[t]{5}{*}{234732.476} & \multirow[t]{5}{*}{$\sim 6 \mathrm{~ms}$} & 234732.373 & $44.741200 ; 5.268800$ & 45.0 \\
\hline & & & & 234732.603 & $45.164800 ; 5.211800$ & 73.8 \\
\hline & & & & 234732.677 & $45.166300 ; 5.044000$ & 12.3 \\
\hline & & & & 234732.728 & $45.587000 ; 4.846200$ & 34.8 \\
\hline & & & & 234732.933 & $45.990600 ; 4.972000$ & 25.1 \\
\hline \multirow[t]{4}{*}{31} & \multirow[t]{4}{*}{2006.08 .17} & \multirow[t]{4}{*}{235316.611} & \multirow[t]{4}{*}{ OK $20 \mu \mathrm{s}$} & 235316.610 & $44.842200 ; 5.379800$ & 62.2 \\
\hline & & & & 235316.746 & $45.387000 ; 5.085800$ & 35.1 \\
\hline & & & & 235316.802 & $45.495000 ; 5.129200$ & 16.1 \\
\hline & & & & 235316.922 & $45.856600 ; 4.977100$ & 47.3 \\
\hline \multirow[t]{3}{*}{32} & \multirow[t]{3}{*}{2006.08 .17} & \multirow[t]{3}{*}{235715.386} & \multirow[t]{3}{*}{ OK $50 \mu \mathrm{s}$} & 235715.262 & $44.692000 ; 5.449400$ & 40.7 \\
\hline & & & & 235715.489 & $45.283000 ; 5.325400$ & 139.6 \\
\hline & & & & 235715.545 & $45.468800 ; 5.189200$ & 107.4 \\
\hline \multirow[t]{4}{*}{33} & \multirow[t]{4}{*}{2006.08 .18} & \multirow[t]{4}{*}{001427.977} & \multirow[t]{4}{*}{ OK $1 \mathrm{~ms}$} & 001427.837 & $44.735300 ; 5.695900$ & 31.9 \\
\hline & & & & 001427.522 & $44.516800 ; 5.605700$ & 27.8 \\
\hline & & & & 001427.912 & $44.961800 ; 5.841300$ & 40.4 \\
\hline & & & & 001428.020 & $45.387300 ; 5.545800$ & 118.9 \\
\hline
\end{tabular}

The time of sprite events are shown with the corresponding geographic location, peak current and time of the associated + CG lightning. For some events more than one +CG could be associated with the sprite. In a few cases no $+\mathrm{CG}$ could be identified

\section{References}

Adachi T, Fukunishi H, Takahashi Y, Hiraki Y, Hsu R-R, Su H-T et al (2006) Electric field transition between the diffuse and streamer regions of sprites estimated from ISUAL/array photometer measurements. Geophys Res Lett 33:17803. doi:10.1029/2006GL026495

Allegrini P, Grigolini P, Hamilton P, Palatella L, Raffaelli G, Virgilio M (2002) Facing non-stationary conditions with a new indicator of entropy increase: the CASSANDRA algorithm. In: Nova MM (ed) Emergent nature. World Scientific, Singapore

Allegrini P, Benci V, Grigolini P, Hamilton P, Ignaccolo M, Menconi G et al (2003) Compression and diffusion: a joint approach to detect complexity. Chaos Solitons Fractals 15:517. doi:10.1016/ S0960-0779(02)00136-4

Armstrong RA, Shorter JA, Taylor MJ, Suszcynsky DM, Lyons WA, Jeong LS (1998) Photometric measurements in the SPRITES '95 and '96 campaigns: nitrogen second positive $(399.8 \mathrm{~nm})$ and the first negative (427.8 nm) emission. J Atmos Terr Phys 60:787. doi:10.1016/S1364-6826(98)00026-1

Arnold N, Neubert T (2002) The electric earth: cosmic influences on the atmosphere. Astron Geophys 43:6.9-6.12 
Arnone E, Kero A, Dinelli BM, Enell C-F, Arnold NF, Papandrea E et al (2008a) Seeking sprite-induced signatures in remotely sensed middle atmosphere $\mathrm{NO}_{2}$. Geophys Res Lett 35:L05807. doi:10.1029/ 2007GL031791

Arnone E, Berg P, Boberg F, Bór J, Chanrion O, Enell C-F et al (2008b) The Eurosprite 2005 campaign. In: Proc. 33rd atmospheric studies by optical methods (33AM), IRF Sci. Rep. no. 292. Swedish Institute of Space Physics, Kiruna

Arrayás M, Ebert U, Hundsdorfer W (2002) Spontaneous branching of anode-directed streamers between planar electrodes. Phys Rev Lett 88:174502. doi:10.1103/PhysRevLett.88.174502

Austin J, Butchart N (1992) A three-dimensional modeling study of the influence of planetary wave dynamics on polar ozone photochemistry. J Geophys Res 97(D9):10165-10186

Balakrishnan N, Dalgarno A (2003) Nitric oxide production in collisions of hot $\mathrm{O}(3 \mathrm{P})$ atoms with $\mathrm{N}_{2}$. J Geophys Res 108(A2). doi:10.1029/2002JA009566

Barth CA, Bailey SM (2004) Comparison of a thermospheric model with Student Nitric Oxide Explorer (SNOE) observations of nitric oxide. J Geophys Res 109(A3). doi:10.1029/2003JA010227

Berg P, Christiansen B, Thejll P, Arnold N (2007) The dynamical response of the middle atmosphere to the tropospheric solar signal. J Geophys Res 112:D20122. doi:10.1029/2006JD008237

Birdsall CK (1991) Particle in cell charged particle simulations, plus Monte Carlo collisions with neutral atoms. IEEE Trans Plasma Sci 19(2):65-85. doi:10.1109/27.106800

Blanc E (1985) Observations in the upper atmosphere of infrasonic waves from natural and artificial sources: A summary. Ann Geophys 3:6673-6688

Blanc E, Farges T, Roche R, Brebion D, Hua T, Labarthe A et al (2004) Nadir observations of sprites from the International Space Station. J Geophys Res 109:A02306. doi:10.1029/2003JA009972

Boccippio DJ, Williams ER, Heckman SJ, Lyons WA, Baker IT, Boldi R (1995) sprites, ELF transients, and positive ground strokes. Science 269:1088. doi:10.1126/science.269.5227.1088

Boeck WL, Vaughan OH Jr, Blakeslee RJ, Vonnegut B, Brook M, McKune J (1995) Observations of lighting in the stratosphere. J Geophys Res 100:1465. doi:10.1029/94JD02432

Boeck WL, Vaughan OH Jr, Blakeslee RJ, Vonnegut B, Brook M (1998) The role of the space shuttle videotapes in the discovery of sprites, jets and elves. J Atmos Terr Phys 60:669. doi:10.1016/ S1364-6826(98)00025-X

Bösinger T, Mika A, Shalimov SL, Haldoupis C, Neubert T (2006) Is there a unique signature in the ULFresponse to sprite-associated lightning flashes? J Geophys Res 111:A10310. doi:10.1029/2006JA 011887

Brunetti M, Cecchini S, Galli M, Giovannini G, Pagliarin A (2000) Gamma-ray bursts of atmospheric origin in the MeV energy range. Geophys Res Lett 27(11):1599-1602. doi:10.1029/2000GL003750

Carey LD, Murphey MJ, McCormick TL, Demetriades NWS (2005) Lightning location relative to storm structure in a leading-line, trailing-stratiform mesoscale convective system. J Geophys Res 110:D03105. doi:10.1029/2003JD004371

Chaboureau J-P, Cammas J-P, Duron J, Mascart PJ, Sitnikov NM, Voessing H-J (2007) A Numerical study of tropical cross-tropopause transport by convective overshoots. Atmos Chem Phys 7:1731-1740

Chanrion O, Neubert T (2008) A PIC-MCC code for simulations of long streamer propagation at sprite altitude. J Comput Phys 227:7222-7245. doi:10.1016/j.jcp.2008.04.016

Chern JL, Hsu RR, Su HT, Mende SB, Fukunishi H, Takahashi Y et al (2003) Global survey of upper atmospheric transient luminous events on the ROCSAT-2 satellite. J Atmos Sol Terr Phys 65:647-659. doi:10.1016/S1364-6826(02)00317-6

Cho M, Rycroft MJ (1998) Computer simulation of the electric field structure and optical emission from cloud-top to the ionosphere. J Atmos Sol Terr Phys 60:871-888. doi:10.1016/S1364-6826(98)00017-0

Cho M, Rycroft MJ (2001) Non-uniform ionisation of the upper atmosphere due to the electromagnetic pulse from a horizontal lightning discharge. J Atmos Sol Terr Phys 63:559-580. doi:10.1016/ S1364-6826(00)00235-2

Christian HJ, Blakeslee RJ, Boccippio DJ, Boeck WL, Buechler DE, Driscoll KT, Goodman SJ, Hall JM, Koshak WJ, Mach DM, Stewart MF (2003) Global frequency and distribution of lightning as observed from space by the Optical Transient Detector. J Geophys Res 108(D1):4005. doi:10.1029/2002 JD002347

Christiansen B (2001) Downward propagation of zonal mean zonal wind anomalies from the stratosphere to the troposphere: Model and reanalysis. J Geophys Res 106(D21):27307-27322. doi:10.1029/2000JD 000214

Christiansen B, Guldberg A, Hansen AW, Riishøjgaard LP (1997) On the response of a three-dimensional general circulation model to imposed changes in the ozone distribution. J Geophys Res 102(D11): 13051-13077. doi:10.1029/97JD00529 
Crutzen PJ, Solomon S (1980) Response of mesospheric ozone to particle precipitation. Planet Space Sci 28:1147-1153. doi:10.1016/0032-0633(80)90073-2

Cummer SA (2003) Current moment in sprite-producing lightning. J Atmos Sol Terr Phys 65:499. doi: 10.1016/S1364-6826(02)00318-8

Cummer SA, Inan US (1997) Measurement of charge transfer in sprite producing lightning using ELF radio atmospherics. Geophys Res Lett 24(14):1731-1734. doi:10.1029/97GL51791

Cummer SA, Inan US, Bell TF, Barrington-Leigh CP (1998) ELF radiation produced by electrical currents in sprites. Geophys Res Lett 25(8):1281-1284. doi:10.1029/98GL50937

Cummer SA, Jaugey N, Li J, Lyons WA, Nelson TE, Gerken EA (2006a) Submillisecond imaging of sprite development and structure. Geophys Res Lett 33:L04104. doi:10.1029/2005GL024969

Cummer SA, Frey HU, Mende SB, Hsu R-R, Su H-T, Chen AB et al (2006b) Simultanous radio and satellite optical measurements for high-altitude sprite current and lightning continuing current. J Geophys Res 111:A10315. doi:10.1029/2006JA011809

Cummins KL, Murphy MJ, Bardo EA, Hiscox WL, Pyle RB, Pifer AE (1998) A combined TOA/MDF technology upgrade of the U.S. National Lightning Detection Network. J Geophys Res 103:9035-9044. doi:10.1029/98JD00153

Déqué M, Dreveton C, Braun A, Cariolle D (1994) The ARPEGE/IFS atmosphere model: A contribution to the French community climate modelling. Clim Dyn 10:249-266. doi:10.1007/BF00208992

Dewan EM, Picard RH, O’Neil RR, Gardiner HA, Gibson J, Mill JD et al (1998) MSX satellite observations of thunderstorm-generated gravity-waves in mid-wave infrared images of the upper stratosphere. Geophys Res Lett 25:939-942. doi:10.1029/98GL00640

Dowden RL, Brundell JB, Lyons WA, Nelson T (1996) Detection and location of red sprites by VLF scattering of subionospheric transmissions. Geophys Res Lett 23:1737-1740. doi:10.1029/96GL01697

Drüe C, Hauf T, Finke U, Keyn S, Kreyer O (2007) Comparison of a SAFIR lightning detection network in northern Germany to the operational BLIDS network. J Geophys Res 112:D18114. doi: 10.1029/2006JD007680

Dwyer JR, Rassoul HK, Al-Dayeh M, Caraway L, Wright B, Chrest A et al (2004a) Measurements of x-ray emission from rocket-triggered lightning. Geophys Res Lett 31:L05118. doi:10.1029/2003GL018770

Dwyer JR, Rassoul HK, Al-Dayeh M, Caraway L, Wright B, Chrest A et al (2004b) A ground level gammaray burst observed in association with rocket-triggered lightning. Geophys Res Lett 31:L05119. doi: 10.1029/2003GL018771

Dwyer JR, Rassoul HK, Saleh Z, Uman MA, Jerauld J, Plumer JA (2005) X-ray bursts produced by laboratory sparks in air. Geophys Res Lett 32:L20809. doi:10.1029/2005GL024027

Eack KB, Beasley WH, Rust WD, Marshall TC, Stoltenberg M (1996) X-ray pulses observed above a mesoscale convective system. Geophys Res Lett 23:2915. doi:10.1029/96GL02570

Ebert U, Montijn C, Briels TMP, Hundsdorfer W, Meulenbroek B, Rocco A et al (2006) The multiscale nature of streamers. Plasma Sources Sci Technol 15:118-129. doi:10.1088/0963-0252/15/2/S14

Enell C-F, Arnone E, Chanrion O, Adachi T, Verronen PT, Seppälä A et al (2008) Parameterisation of the chemical effect of sprites in the middle atmosphere. Ann Geophys 26:13-27

Farges T, Blanc E, Le Pichon A, Neubert T, Allin TH (2005) Identification of infrasound produced by sprites during the Sprite2003 campaign. Geophys Res Lett 32:L01813. doi:10.1029/2004GL021212

Farges T, Blanc E, Tanguy M (2007) Experimental evidence of D region heating by lightning-induced electromagnetic pulses on MF radio links. J Geophys Res 112:A10302. doi:10.1029/2007JA012285

Fischer H, Birk M, Blom C, Carli B, Carlotti M, von Clarmann T et al (2007) M. L'opez-Puertas, P. Mosner, H. Nett, H. Oelhaf, G. Perron, J. Remedios, M. Ridolfi, G. Stiller, and R. Zander, MIPAS: an instrument for atmospheric and climate research. Atmos Chem Phys Discuss 7:8795-8893

Fishman GJ, Baht PN, Mallozzi R, Horack JM, Koshut T, Kouveliotou C et al (1994) Discovery of intense gamma-ray flashes of atmospheric origin. Science 164:1313. doi:10.1126/science.264.5163.1313

Franz RC, Nemzek RJ, Winckler JR (1990) Television image of a large upward electrical discharge above a thunderstorm system. Science 249:48. doi:10.1126/science.249.4964.48

Frey HU, Mende SB, Cummer SA, Chen AB, Hsu R-R, Su HT et al (2005) Beta-type stepped leader of elveproducing ligtning. Geophys Res Lett 32:L13824. doi:10.1029/2005GL023080

Fukunishi HY, Takahashi Y, Kubota M, Sakanoi K, Inan US, Lyons WA (1996) Elves: lightning-induced transient luminous events in the lower ionosphere. Geophys Res Lett 23:2157. doi:10.1029/ 96GL01979

Fukunishi H, Takahashi Y, Sato M, Shono A, Fujito M, Watanabe Y (1997) Ground- based observations of ULF transients excited by strong lightning discharges producing elves and sprites. Geophys Res Lett 24(23):2973. doi:10.1029/97GL03022

Füllekrug M (2006) Elementary model of sprite igniting electric fields. Am J Phys 74(9):804-805. doi: $10.1119 / 1.2206573$ 
Füllekrug M, Constable S (2000) Global triangulation of intense lightning discharges. Geophys Res Lett 27(3):333-336. doi:10.1029/1999GL003684

Füllekrug M, Reising S (1998) Excitation of Earth-Ionosphere Cavity Resonances by Sprite-Associated Lightning Flashes. Geophys Res Lett 25:4145-4148. doi:10.1029/1998GL900133

Füllekrug M, Moudry DR, Dawes G, Sentman DD (2001) Mesospheric sprite current triangulation. J Geophys Res 106(17):20189-20194. doi:10.1029/2001JD900075

Füllekrug M, Mareev EA, Rycroft MJ (eds) (2006a) Sprites, elves and intense lightning discharges Springer, Dordrecht, p 398

Füllekrug M, Ignaccolo M, Kuvshinov A (2006b) Stratospheric Joule heating by lightning continuing current inferred from radio remote sensing. Radio Sci 41. doi:10.1029/2006RS003472

Gerken E, Inan U, Barrington-Leigh C (2000) Telescopic imaging of sprites. Geophys Res Lett 27:26372640. doi:10.1029/2000GL000035

Gordillio-Vazquez FJ (2008) Air plasma kinetics under the influence of sprites. J Phys D Appl Phys 41:xxx. doi:10.1088/0022-3727/41/17/175303

Gray LJ (2003) The influence of the equatorial upper stratosphere on stratospheric sudden warmings. Geophys Res Lett 30:4. doi:10.1029/2002GL016430

Gurevich AV, Zybin KP (2004) High energy cosmic ray particles and the most powerful discharges in thunderstorm atmosphere. Phys Lett A 329:341-347. doi:10.1016/j.physleta.2004.06.094

Gurevich AV, Milikh GM, Roussell-Dupré RA (1992) Runaway electron mechanism of air breakdown and preconditioning during a thunderstorm. Phys Lett A 165:463. doi:10.1016/0375-9601(92)90348-P

Gurevich AV, Zybin KP, Roussel-Dupré RA (1999) Lightning initiation by simultaneous effect of runaway breakdown and cosmic ray showers. Phys Res Lett 254(1-2):79-87

Haldoupis C, Neubert T, Inan U, Mika A, Allin TH, Marshall RA (2004) Sub-ionospheric early VLF signal perturbations observed in one-to-one association with sprites. J Geophys Res 109(A10):A10303. doi: 1029/2004JA010651

Haldoupis C, Steiner RJ, Mika Á, Shalimov S, Marshall RA, Inan US et al (2006) "Early/slow" events: a new category of VLF perturbations observed in relation with sprites. J Geophys Res 111:A11321. doi: 10.1029/2006JA011960

Heavner MJ (2000) Optical spectroscopic observations of sprites, blue jets, and elves: inferred microphysical processes and their macrophysical implications. Thesis, University of Alaska, Fairbanks

Hedin AE (1991) Extension of the MSIS thermospheric model into the middle and lower atmosphere. J Geophys Res 96(A2):1159-1172. doi:10.1029/90JA02125

Huntrieser H, Schlager H, Roiger A, Lichtenstern M, Schumann U, Kurz C et al (2007) X over Brazil during TROCCINOX: Airborne measurements in tropical and subtropical thunderstorms and the importance of mesoscale convective systems. Atmos Chem Phys 7:2987-3013

Ignaccolo M, T Farges A Mika, TH Allin, O Chanrion, E Blanc, T Neubert, AC Fraser-Smith, M. Füllekrug (2006) The planetary rate of sprite events. Geophys Res Lett 33(11):L11808, 1-4

Ignaccolo M, Farges T, Blanc E, Füllekrug M (2008) Automated chirp detection with diffusion entropy: Application to infrasound from sprites. Chaos Solitons Fractals 38:1039-1050. doi:10.1016/j.chaos. 2007.02.011

Inan US, Lehtinen NG (2005) Production of terrestrial gamma-ray flashes by an electromagnetic pulse from a lightning return stroke. Geophys Res Lett 32:L19818. doi:10.1029/2005GL023702

Inan US, Bell TF, Pasko VP, Sentman DD, Wescott EM, Lyons WA (1995) VLF signatures of ionospheric disturbances associated with sprites. Geophys Res Lett 22:3461-3464. doi:10.1029/95GL03507

Inan US, Sampson WA, Taranenko YN (1996) Space-time structure of optical flashes and ionization changes produced by lightning-EMP. Geophys Res Lett 23:133. doi:10.1029/95GL03816

Inan US, Piddyachiy D, Peter WB, Sauvaud JA, Parrot M (2007) DEMETER satellite observations of lightning-induced electron precipitation. Geophys Res Lett 34:L07103. doi:10.1029/2006GL029238

Jacobson RA, Holzworth R, Harlin J, Dowden R, Lay E (2006) Performance assessment of the World Wide Lightning Location Network (WWLLN), using the Los Alamos Sferic Array (LASA) as ground truth. J Atmos Ocean Technol 23:1082. doi:10.1175/JTECH1902.1

Leblanc F, Aplin KL, Yair Y, Harrison RG, Lebreton JP, Blanc M (eds) (2008) Planetary atmospheric electricity. Space Sci Ser ISSI 30:532

Lehtinen NG, Walt M, Inan US, Bell TF, Pasko VP (1996) Gamma-ray emission produced by a relativistic beam of runaway electrons accelerated by quasi-electrostatic thundercloud fields. Geophys Res Lett 23:2645. doi:10.1029/96GL02573

Lehtinen NG, Bell TF, Pasko VP, Inan US (1997) A two-dimensional model of runaway electron beams driven by quasi-electrostatic thundercloud fields. Geophys Res Lett 23:2635 
Le Pichon A, Garcés MA, Blanc E, Barthelemy M, Drob DP (2002) Acoustic propagation and atmosphere characteristics derived from infrasonic waves generated by the Concorde. J Acoust Soc Am 111:629641. doi:10.1121/1.1404434

Liszka L (2004) On the possible infrasound generation by sprites. J Low Frequency Noise Vib Active Contr 23:85-93. doi:10.1260/0263092042869838

Liszka L, Hobara Y (2006) Sprite-attributed infrasonic chirps-their detection, occurrence and properties between 1994 and 2004. J Atmos Sol Terr Phys 68:1179-1188. doi:10.1016/j.jastp.2006.02.016

Liu N, V P Pasko (2004) Effects of photoionization on propagation and branching of positive and negative streamers in sprites. J Geophys Res 109, A04301, 1-17. doi:10.1029/2003JA010064

Lyons WA (1994) Characteristics of luminous structures in the stratosphere above thunderstorms as imaged by low-light video. Geophys Res Lett 21:875-878. doi:10.1029/94GL00560

Lyons WA (1996) Sprite observations above the US High Plains in relation to their parent thunderstorm systems. J Geophys Res 101:29641-29652. doi:10.1029/96JD01866

Lyons WA, Nelson TE, Williams ER, Cummer SA, Stanley MA (2003) Characteristics of sprite-producing positive cloud-to-ground lightning during the 10 July STEPS mesoscale convective system. Mon Weather Rev 131:2417. doi :10.1175/1520-0493(2003)131<2417:COSPCL >2.0.CO;2

Lyons WA, Andersen LM, Nelson TE, Huffines GR (2006) Characteristics of sprite-producing electrical storms in the STEPS2000 domain. In: Second conf. on meteorological applications of lightning data, Amercan Meteorological Society, Atlanta

Marshall JS, Palmer WM (1948) The distribution of raindrops with size. J Meteorol 5:165-166

Marshall RA, Inan US, Lyons WA (2007) Very low frequency sferic bursts, sprites and their association with lightning activity. J Geophys Res 112:D22105. doi:1029/2007JD008857

Mazur V, Williams E, Boldi R, Maier L, Proctor DE (1997) Initial comparison of lightning mapping with operational time-of-arrival and interferometric systems. J Geophys Res 102(D10):11071-11086. doi: 10.1029/97JD00174

Mazur V, Shao X-M, Krehbiel PR (1998) “Spider” lightning in intracloud and positive cloud-to-ground flashes. J Geophys Res 103(D16):19811-19822. doi:10.1029/98JD02003

McCarthy MP, Parks GK (1985) Further observations of X-rays inside thunderstorm systems. Geophys Res Lett 12:393. doi:10.1029/GL012i006p00393

McHarg MG, Stenbaek-Nielsen HC, Kammae T (2007) Observation of streamer formation in sprites. Geophys Res Lett 34:L06804. doi:10.1029/2006GL027854

Mende SB, Frey HU, Rairden RL, Su H-T, Hsu R-R, Hsu R-R, Hsu R-R, Hsu R-R, Hsu R-R, Hsu R-R, Allin $\mathrm{TH}$ et al (2002) Fine structure of sprites and proposed global observations, Cospar Colloquia Series. In: Liu LH (ed) Space Weather Study using Multipoint Techniques, vol 12. Pergamon Elsevier Science, pp 275-282

Mende SB, Frey HU, Hsu R-R, Su HT, Chen AB, Lee LC, Sentman DD, Takahashi Y, Fukunishi H (2005) $\mathrm{D}$ region ionisation by lightning-induced electromagnetic pulses. J Geophys Res 110:A11312. doi: 10.1029/2005JA011064

Mika Á (2007) Very Low Frequency EM Wave Studies of Transient Luminous Events in the Lower Ionosphere. PhD thesis, University of Crete, May

Mika Á, Haldoupis C, Marshall RA, Neubert T, Inan US (2005) Subionospheric VLF signatures and their association with sprites observed during EuroSprite-2003. J Atmos Sol Terr Phys 67:1580-1597. doi: 10.1016/j.jastp.2005.08.011

Mika Á, Haldoupis C, Neubert T, Hsu HT, Hsu RR, Steiner RJ et al (2006) Early VLF perturbations observed in association with elves. Ann Geo 24:2179-2189

Miyasato R, Fukunishi H, Takahashi Y, Taylor MJ (2003) Energy estimation of electrons producing sprite halos using array photometer data. J Atmos Sol Terr Phys 65:573-581. doi:10.1016/S13646826(02)00322-X

Montijn C, Hundsdorfer W, Ebert U (2006) An adaptive grid refinement strategy for the simulation of negative streamers. J Comput Phys 219:801-835. doi:10.1016/j.jcp.2006.04.017

Moore CB, Eack KB, Aulich GD, Rison W (2001) Energetic radiation associated with lightning steppedleaders. Geophys Res Lett 28(11):2141

Morrill J, Bucsela E, Siefring C, Heavner M, Berg S, Moudry D, et al (2002) Electron energy and electric field estimates in sprites derived from ionised and neutral N2 emissions. Geophys Res Lett 29. doi: 10.1029/2001GL014018

Moss GD, Pasko VP, Liu N, Veronis G (2006) Monte Carlo model for analysis of thermal runaway electrons in streamer tips in transient luminous events and streamer zones of lightning leaders. J Geophys Res 111:A02307. doi:10.1029/2005JA011350

Moudry D, Stenbaek-Nielsen H, Sentman D, Wescott E (2003) Imaging of elves, halos and sprite initiation at $1 \mathrm{~ms}$ time resolution. J Atmos Sol Terr Phys 65:509-518. doi:10.1016/S1364-6826(02)00323-1 
Nemiroff RJ, Bonnell JT, Norris JP (1997) Temporal and spectral characteristics of terrestrial gamma flashes. J Geophys Res 102:9659. doi:10.1029/96JA03107

Neubert T (2003) On sprites and their exotic kin. Science 300:747

Neubert T, Allin TH, Stenbaek-Nielsen H, Blanc E (2001) Sprites over Europe. Geophys Res Lett 28:3585. doi:10.1029/2001GL013427

Neubert T, Allin TH, Blanc E, Farges T, Haldoupis C, Mika A et al (2005) Co-ordinated observations of transient luminous events during the Eurosprite2003 campaign. J Atmos Sol Terr Phys 67:807-820. doi:10.1016/j.jastp.2005.02.004

Niro F, Brizzi G, Carlotti M, Papandrea E, Ridolfi M (2007) Precision improvements in the geo-fit retrieval of pressure and temperature from MIPAS limb observations by modeling $\mathrm{CO}_{2}$ line-mixing. J Quant Spectrosc Radiat Transf 103:14-26

Ogawa T, Tanaka Y, Fraser-Smith AC, Gendrin R (1967) Worldwide simultaneity of occurrence of a Q-type ELF burst in the Schumann resonance frequency range. J Geomag Geoelectr 19:377-385

Ohkubo A, Fukunishi H, Takahashi Y, Adachi T (2005) VLF/ELF sferic evidence for in-cloud discharge activity producing sprites. Geophys Res Lett 32:L04812. doi:10.1029/2004GL021943

Østgaaard N, Gjesteland T, Stadsnes J, Connell PH, Carlson B (2008) Production altitude and time delays of terrestrial gamma flashes: Revisiting the Burst and Transient Source Experiment spectra. J Geophys Res 113:A02307. doi:10.1029/2007JA012618

Pancheshnyi S (2005) Role of electronegative gas admixtures in streamer start, formation and branching phenomena. Plasma Sources Sci Technol 14:645-653. doi:10.1088/0963-0252/14/4/002

Parks GK, Mauk BH, Spiger R, Chin J (1981) X-ray enhancements detected during thunderstorm and lightning activities. Geophys Res Lett 8:1176. doi:10.1029/GL008i011p01176

Pasko VP (2006) Theoretical modeling of sprites and jets. In: Füllekrug M, Mareev EA, Rycroft MJ (eds) Sprites, elves and intense lightning discharges. Springer, Dordrecht, pp 253-311

Pasko V P, J B Snively (2007) Mechanism of infrasound radiation from sprites. Eos Trans AGU 88(52), Fall Meet. Suppl., Abstract AE23A-0899, San Francisco, CA, 10-14 December . OUT OF ORDER: IT SHOULD BE BEFORE Peterson

Pasko VP, Inan US, Taranenko YN, Bell TF (1995) Heating, ionization and upward discharges in the mesosphere due to intense quasi-electrostatic thundercloud fields. Geophys Res Lett 22:365. doi: 10.1029/95GL00008

Pasko VP, Inan US, Bell TF (1996) Sprites as luminous columns of ionization produced by quasi-electrostatic thundercloud fields. Geophys Res Lett 23:649. doi:10.1029/96GL00473

Pasko VP, Inan US, Bell TF, Taranenko YN (1997) Sprites produced by quasi-electrostatic heating and ionization in the lower ionosphere. J Geophys Res 102:4529. doi:10.1029/96JA03528

Pasko VP, Inan US, Bell TF (1998) Spatial structure of sprites. Geophys Res Lett 25:2123-2126. doi: 10.1029/98GL01242

Pasko VP, Stanley MA, Mathews JD, Inan US, Wood TG (2002) Electrical discharge from a thundercloud top to the lower ionosphere. Nature 416:152-154. doi:10.1038/416152a

Peterson H, Bailey M, Hallett J, Beasley W (2005) $\mathrm{NO}_{\mathrm{X}}$ production in simulated blue jets, sprites, and TLE discharges, In: AGU fall meeting abstracts, p A990+, December

Raizer YP (1997) Gas discharge physics. Springer, Netherland, p 125

Rakov VA, Uman MA (2003) Lightning: Physics and Effects. University Press, Cambridge, p 687

Reising SC, Inan US, Bell TF, Lyons WA (1996) Evidence for continuing currents in sprite-producing lightning flashes. Geophys Res Lett 23(24):3639-3742. doi:10.1029/96GL03480

Rodger C (1999) Red Sprites, Upward Lightning, and VLF Perturbations. Rev Geophys 37(3):317-336. doi: 10.1029/1999RG900006

Rodger CJ, McCormick RJ, Clilverd MA (2004) Testing the importance of precipitation loss mechanisms in the inner radiation belt. Geophys Res Lett 31:L10803. doi:10.1029/2004GL019501

Rodger CJ, Enell C-F, Turunen E, Clilverd MA, Thomson NR (2007) Significance of lightning driven inner radiation belt energy deposition into the atmosphere: Implications for ionisation-levels and neutral chemistry. Ann Geophys 25:1745-1757

Rodger CJ, Seppälä A, Clilverd MA (2008) Significance of transient luminous events to neutral chemistry: Experimental measurements. Geophys Res Lett 35:L07803. doi:10.1029/2008GL033221

Roussel-Dupré RA (1997) HF echoes from ionization potentially produced by high-altitude discharges. J Geophys Res 102:4613. doi:10.1029/96JA02354

Roussel-Dupré RA (2005) Current Modeling of High-Altitude Discharges at Los Alamos. In: CAL-Crete meeting

Roussel-Dupré RA, Gurevich AV (1996) On runaway break-down and upward propagating discharges. J Geophys Res 101:2297. doi:10.1029/95JA03278 
Roussel-Dupré RA, Gurevich AV, Tunnell T, Milikh GM (1994) Kinetic theory of runaway air breakdown. Phys Rev E Stat Phys Plasmas Fluids Relat Interdiscip Topics 49:2257. doi:10.1103/PhysRevE. 49.2257

Roussel Dupré RA, Symbalisty EMD, Tierney HE, Tripplett L (2002) New fully electromagnetic simulations of sprites initiated by runaway air breakdown. In: URSI proceedings, Maastricht, NL

Rowland HL (1998) Theories and simulations of elves, sprites and blue jets. J Atmos Sol Terr Phys 60:831844. doi:10.1016/S1364-6826(98)00034-0

Rycroft MJ (1973) Enhanced energetic electron intensities at $100 \mathrm{~km}$ altitude and a whistler propagating through the plasmasphere. Planet Space Sci 21(2):239-251. doi:10.1016/0032-0633(73)90009-3

Rycroft MJ, Odzimek A, Arnold NF et al (2007) New model simulations of the global atmospheric electric circuit driven by thunderstorms and electrified shower clouds: The roles of lightning and sprites. J Atmos Sol Terr Phys 69. doi:10.1016/j.jastp.2007.09.004

Saetre C, Barth CA, Stadsnes J, Østgaard N, Bailey SM, Baker DN et al (2007) Thermospheric nitric oxide at higher latitudes: Model calculations with auroral energy input. J Geophys Res 112:A08306. doi: 10.1029/2006JA012203

São Sabbas FT, Sentman DD (2003) Dynamical relationship of infrared cloudtop temperatures with occurrence rates of cloud-to-ground lightning and sprites. Geophys Res Lett 30:1236. doi: 10.1029/2002GL015382

Sato M, H Fukunishi (2003) Global sprite occurrence locations and rates derived from triangulation of transient Schumann resonance events. Geophys Res Lett 30(16):1859. doi:10.1029/2003GL017291

Schumann U, Huntrieser H (2007) The global lightning-induced nitrogen oxides source. Atmos Chem Phys Discuss 7:2623-2818

Sentman DD, São Sabbas FT (2002) Energy deposition of sprites in the middle-upper atmosphere. In: Third Brazilian workshop on atmospheric electricity, November 4-7, Rio de Janeiro, Brazil

Sentman DD, Wescott EM, Osborne DL, Hampton DL, Heavner MJ (1995) Preliminary results from the Sprites94 aircraft campaign: 1 Red sprites. Geophys Res Lett 22:1205. doi:10.1029/95GL00583

Sentman DD, Wescott EM, Picard RH, Winick JR, Stenbaek-Nielsen HC, Dewan EM et al (2003) Simultaneous observations of mesospheric gravity waves and sprites generated by a Midwestern thunderstorm. J Atmos Sol Terr Phys 65:537-550. doi:10.1016/S1364-6826(02)00328-0

Sentman DD, Stenbaek-Nielsen HC, McHarg MG, Morill JC (2008) Plasma chemistry of sprite streamers. J Geophys Res 113:D11112. doi:10.1029/2007JD008941

Seppälä A, Verronen PT, Clilverd MA, Randall CE, Tamminen J, Sofieva V et al (2007) Arctic and Antarctic polar winter NOx and energetic particle precipitation in 2002-2006. Geophys Res Lett 34:12810. doi:10.1029/2007GL029733

Shalimov SL, Bösinger T (2006) An alternative explanation for the ultra-slow tail of sprite-associated flashes of lightning. J Atmos Sol Terr Phys 68(7):814-820. doi:10.1016/j.jastp.2005.12.001

Shalimov SL, Bösinger T (2008) On distant excitation of the ionospheric Alfvén resonator by positive cloud-to-ground lightning discharges. J Geophys Res 113:A02303. doi:10.1029/2007JA012614

Shimazaki T (1984) Minor constituents in the middle atmosphere. In: Developments in earth and planetary physics, vol 6. D. Reidel Publishing Company, Dordrecht

Smith DM, Lopez LI, Lin RP, Barrington-Leigh CP (2005) Terrestrial gamma-ray flashes observed up to $20 \mathrm{MeV}$. Science 307:1085. doi:10.1126/science.1107466

Soula S, van der Velde O, Montanyà J, Neubert T, Ganot M (2008) Analysis of thunderstorm and lightning activity associated with sprites observed during the Eurosprite campaigns: two case studies. Atmos Res (in press)

Stanley M, Krehbiel P, Max Brook, Charles More, Rison W, Abrahams B (1999) High speed video of initial sprite development. Geophys Res Lett 26:3201. doi:10.1029/1999GL010673

Stanley M, Brook M, Krehbiel P (2000) Detection of daytime sprites via a unique sprite ELF signature. Geophys Res Lett 27:871-874. doi:10.1029/1999GL010769

Stenbaek-Nielsen DR, Moudry, Wescott EM, Sentman DD, Sâo FT (2000) Sprites and possible mesospheric effects. J Geophys Res 27:3829

Stenbaek-Nielsen MG, McHarg, Kammae T, Sentman DD (2007) Observed emission rates in sprite streamer heads. Geophys Res Lett 34(11):L11105. doi:10.1029/2007GL029881

Stolzenburg M, Marshall TC, Rust WD, Bruning E, MacGorman DR, Hamlin T (2007) Electric fields observed near lightning flash initiations. Geophys Res Lett 34:L04804. doi:10.1029/2006GL028777

Su HT, Hsu RR, Chen AB, Wang YC, Hsiao WS, Lai WC, Lee LC, Sato M, Fukunishi H (2003) Gigantic jets between a thundercloud and the ionosphere. Nature 423:974 26

Suszcynsky DM, Strabley R, Roussel-Dupre R et al (1999) Video and photometric observations of a sprite in coincidence with a meteor-triggered jet event. J Geophys Res 104(D24):31361-31367. doi: 10.1029/1999JD900962 
Svensmark H, Pedersen JOP, Marsh ND, Enghoff MB, Uggerhøj UI (2007) Experimental evidence for the role of ions in particle nucleation under atmospheric conditions. Proc R Soc A 463:385-396. doi: 10.1098/rspa.2006.1773

Symbalisty EMD, Roussel-Dupre RA, ReVelle DO, Suszcynsky DM, Yukhimuk VA, Taylor MJ (2000) Meteor trails and columniform sprites. Icarus 148(1):65-79. doi:10.1006/icar.2000.6517

Swenson GR, Rairden R (1998) What is the source of sprite seed electrons? In: AGU fall meeting, A41C-14, San Francisco

Tararenko YN, Inan US, Bell TF (1993) Interaction with the lower ionosphere of electromagnetic pulses from lightning: heating, attachment, and ionization. Geophys Res Lett 20:1539-1542. doi: 10.1029/93GL01696

Taranenko Y, Roussel-Dupré R (1996) High altitude discharges and gamma-ray flashes: a manifestation of runaway air breakdown. Geophys Res Lett 23:571. doi:10.1029/95GL03502

Taylor MJ, Bailey MA, Pautet PD, Cummer SA, Jaugey N, Thomas JN et al (2008) Rare measurements of a sprite with halo event driven by a negative lightning discharge over Argentina. Geophys Res Lett 35:L14812. doi:10.1029/2008GL033984

Tinsley BA, Rohrbaugh RP, Hei M, Beard KV (2000) Effects of image charges on the scavenging of aerosol particles by cloud droplets, and on droplet charging and possible ice nucleation processes. J Atmos Sci 57:2118. doi :10.1175/1520-0469(2000)057<2118:EOICOT>2.0.CO;2

Tinsley BA, Rohrbaugh RP, Hei M (2001) Electroscavenging in clouds with broad droplet size distributions and weak electrification. Atmos Res 115:59-60. doi:10.1016/S0169-8095(01)00112-0

Turunen E, Matveinen H, Tolvanen J, Ranta HD (1996) Region ion chemistry model. In: Schunk RW (ed) STEP Handbook of Ionospheric Models. Scientific Committee on Solar-Terrestrial Physics (SCOSTEP) Secretariat, Boulder, Colorado, USA, pp 1-25

Valdivia JA, Milikh GM, Papadopoulos K (1998) Model of red sprites due to Intracloud Fractal Lightning Discharges. Radio Sci 33:1655. doi:10.1029/98RS02201

Vallance Jones A (1974) Aurora Geophysics and Astrophysics monographs, vol 9. D. Reidel Publishing Company, Dordrecht

van der Velde OA, Mika Á, Soula S, Haldoupis C, Neubert T, Inan US (2006) Observations of the relationship between sprite morphology and in-cloud lightning processes. J Geophys Res 111:D15203. doi:10.1029/2005JD006879

Vaughan OH Jr, Vonnegut B (1989) Recent observations of lightning discharges from the top of a thundercloud into the air above. J Geophys Res 94:13179. doi:10.1029/JD094iD11p13179

Verronen PT (2006) Ionosphere-atmosphere interaction during solar proton events. PhD thesis, Finnish Meteorological Institute, Helsinki, Finland, ISBN: 951-697-650-6

Verronen PT, A Seppälä, MA Clilverd, CJ Rodger, E Kyrölä, C-F Enell, T Ulich, E Turunen, (2005) Diurnal variation of ozone depletion during the October-November 2003 solar proton event. J Geophys Res 110(A09S32). doi:10.1029/2004JA010932

Verronen PT, Seppälä A, Kyrölä E, Tamminen J, Pickett HM, Turunen E (2006) Production of Odd Hydrogen in the Mesosphere During the January 2005 Solar Proton Event. Geophys Res Lett 33:L24811. doi:10.1029/2006GL028115

Vitt FM, Jackman CH (1996) A comparison of sources of odd nitrogen production from 1974 through 1993 in the Earth's middle atmosphere as calculated using a two-dimensional model. J Geophys Res 101(D3):6729-6739. doi:10.1029/95JD03386

Wescott EM, Sentman D, Osborne D, Hampton D, Heavner M (1995) Preliminary results from the Sprites 94 aircraft campaign: 2. blue jets. Geophys Res Lett 22:1209. doi:10.1029/95GL00582

Wescott EM, Sentman D, Heavner M, Hampton D, Lyons WA, Nelson T (1998) Observations of 'Columniform' sprites. J Atmos Terr Phys 60:733. doi:10.1016/S1364-6826(98)00029-7

Williams ER (2002) Global electric circuit. In: Holton JR, Pyle JA, Curry JA (eds) Encyclopedia of atmospheric sciences. Academic Press, New York, pp 733-743

Wilson CTR (1925) The electric field of a thunderstorm and some of its effects. Proc R Soc Lond 37:32D

Winands GJJ (2007) Efficient streamer plasma generation. Ph.D. thesis, Eindhoven Univ. Techn., The Netherlands, available on http://alexandria.tue.nl/extra2/200710708.pdf

Winckler JR, Lyons WA, Nelson TE, Nemzek RJ (1996) New high-resolution ground-based studies of sprites. J Geophys Res 101:6997. doi:10.1029/95JD03443

Yair Y, Israelevich P, Devir AD, Moalem M, Price C, Joseph JH et al (2004) New observations of sprites from the space shuttle. J Geophys Res 109:D15201. doi:10.1029/2003JD004497

Zheleznyak MB, Mnatsakayan AK, Sizykh SV (1982) Photoionisation of nitrogen and oxygen mixtures by radiation from a gas discharge. High Temp 20:357-362 